No.1744

Revised April 2023

(Replaced January 2021 version)

\title{
The impact of regulation on innovation
}

Philippe Aghion

Antonin Bergeaud

John Van Reenen 


\begin{abstract}
We present a framework that can be used to assess the equilibrium impact of regulation on endogenous innovation with heterogeneous firms. We implement this model using French firm-level panel data where there is a sharp increase in the burden of labor regulations on companies with 50 or more employees. Consistent with the model's qualitative predictions, we find a sharp fall in the fraction of innovating firms just to the left of the regulatory threshold. Furthermore, we find a sharp reduction in the positive innovation response of firms to exogenous demand shocks just below the regulatory threshold. Using the structure of our model we quantitatively estimate parameters and find that the regulation reduces aggregate equilibrium innovation (and growth) by $5.8 \%$ which translates into a consumption equivalent welfare loss of at least $2.3 \%$, approximately doubling the static losses in the existing literature.
\end{abstract}

Key words: innovation, regulation, patents, firm size

JEL codes: O31; L11; L51; J8; L25

This paper was produced as part of the Centre's Growth Programme. The Centre for Economic Performance is financed by the Economic and Social Research Council.

This project began with a collaboration with Costas Meghir who was instrumental in our thinking over the paper and gave tremendous inspiration and help with framing the theory and empirical approach. Matthieu Lequien generously allowed us to use his data matching and cleaning patents, which was a huge multi-year project. Heidi Williams inspired us to push the work substantially further from an earlier draft. This is an extensively revised version of our working paper Aghion et al. (2021). We would like to thank the editor Mikhail Golosov and three anonymous referees. Great comments have also come from Daron Acemoglu, Ufuk Akcigit, Hunt Allcott, Sharon Belenzon, David Card, David Demming, Bernhard Ganglmair, Gordon Hansen, Claire Lelarge, Gianmarco Ottaviano, Cyril Verluise, Mike Webb and participants in seminars in AEA, Bath, Berkeley, Boston College, CEPR Globalization and Labor workshop, EFF Milan, Harvard, IMT, IWH, Kent, LBS, LSE, Mannheim, Microsoft Research Group, MIT, NBER, Peking HSBC, San Diego, Texas A\&M and UCL. Financial support from the ESRC/UKRI through POID, Sloan Foundation, SRF and Schmidt Sciences is gratefully acknowledged. This work is supported by a public grant overseen by the French National Research Agency (ANR) as part of the "Investissements d'Avenir" program (reference: ANR-10-EQPX-17 - Centre d'accès securisé aux données - CASD).

Philippe Aghion, College de France, INSEAD and London School of Economics and Centre for Economic Performance, London School of Economics. Antonin Bergeaud, HEC, CEPR and Centre for Economic Performance, London School of Economics. John Van Reenen, London School of Economics, MIT and Centre for Economic Performance, London School of Economics.

Published by

Centre for Economic Performance

London School of Economics and Political Science

Houghton Street

London WC2A 2AE

All rights reserved. No part of this publication may be reproduced, stored in a retrieval system or transmitted in any form or by any means without the prior permission in writing of the publisher nor be issued to the public or circulated in any form other than that in which it is published.

Requests for permission to reproduce any article or part of the Working Paper should be sent to the editor at the above address.

(c) P. Aghion, A. Bergeaud and J. Van Reenen, revised 2023. 


\section{Introduction}

There is considerable literature on the economic impacts of regulations, but relatively few studies on their impact on technological innovation. Most analyses focus on the static costs (and benefits) of regulation rather than on its dynamic effects. Yet these potential growth effects are likely to be much more important in the long run. Harberger triangles may be small, but rectangles can be very large. Many scholars have been concerned that slower growth in countries with heavy labor regulation, could be due to firms being reluctant to innovate due to the burden of red tape. For example, the slower growth of Southern European countries and parts of Latin America have often been blamed on onerous labor laws. ${ }^{1}$

Identifying the innovation effects of labor regulation is challenging. The OECD, World Bank, IMF and other agencies have developed various indices of the importance of these regulations, based on examination of laws and surveys of managers. These indices are then often included in econometric models and are sometimes found to be significant. Unfortunately, these macro indices of labor law are correlated with many other unobservable factors that are hard to convincingly control for. ${ }^{2}$ To address this issue, we exploit the fact that many regulations are size contingent and only apply when a firm gets sufficiently large. In particular, the burden of French labor legislation substantially increases when firms employ 50 or more workers. For example, such firms must create a works council with a minimum budget of $0.3 \%$ of total payroll, establish a health and safety committee, appoint a union representative and so on (see Appendix A for more institutional details). Several authors have found that these regulations have an important effect on the size of firms. Indeed, unlike the US firm size distribution, for example, in France, there is a clear bulge in the number of firms that are just below this regulatory threshold. ${ }^{3}$

Existing models that seek to rationalize these patterns have not usually considered how this regulation could affect innovation, as technology has been assumed exogenous. But when firms are choosing whether or not to invest in innovation, regulations are also likely to matter. Intuitively, firms may invest less in $R \& D$ as there is a very high cost of growing if the firm

\footnotetext{
${ }^{1}$ See for example, Gust and Marquez (2004); Bentolila and Bertola (1990), Bassanini et al. (2009), Schivardi and Schmitz (2020).

${ }^{2}$ Furthermore, it may be that the more innovative countries are less likely to adopt such regulations (e.g. Saint-Paul, 2002).

${ }^{3}$ See Garicano et al. (2016); Gourio and Roys (2014); Ceci-Renaud and Chevalier (2011); and Smagghue (2020). Often, it is hard to see such discontinuities in the size distribution at regulation thresholds (e.g. Hsieh and Olken, 2014 and Amirapu and Gechter, 2020). A reason for the greater visibility in France is because the laws are more strictly enforced through large numbers of bureaucratic enforcers and strong trade unions.
} 
crosses the regulatory threshold. In the first part of the paper we formalize this intuition using a simple version of the Klette and Kortum (2004) model of growth and firm dynamics, with discrete time and two-period lived individuals (but potentially infinitely lived firms). Our model delivers a number of predictions regarding the shape of the equilibrium relationship between innovation and firm size and the overall firm size distribution. In particular we obtain the intuitive prediction that the regulatory threshold discourages innovation most strongly for firms just below the threshold, although it also discourages and shallows the innovation-size gradient for all firms larger than the threshold. This is because the growth benefits of innovation are lower due to the implicit regulatory tax.

We use the discontinuous increase in cost at the regulatory threshold to test the theory in two ways when taking it to our rich panel data on the population of French firms. First, we investigate non-parametrically how innovation changes with firm size. As expected there is a sharp fall in the fraction of innovative firms just to the left of the regulatory threshold, an "innovation valley" that is suggestive of a chilling effect of the regulation on the desire to grow. Moreover, there is a flattening of the innovation-size relationship to the right of the threshold, consistent with a greater tax on growth. Although the cross-sectional evidence is suggestive, there could be many other reasons why firms are heterogeneous near the regulatory threshold, so we turn to a second and stronger test by exploiting the panel dimension of our data. Specifically, based on a wide class of models that predict that an increase in market size should have a positive effect on innovation (e.g. Acemoglu and Linn, 2004), we analyze the heterogeneous response of firms with different sizes to exogenous demand shocks. We use a shock based measure based on changes in growth in export product markets (disaggregated HS6 products by country destination) interacted with a firm's initial distribution of exports across these export markets (see Hummels et al., 2014 or Mayer et al., 2016). We first show that these positive market size shocks significantly raise innovative activity. We then examine the heterogeneity in firm responsiveness to these demand shocks depending on (lagged) firm size. We find a sharp reduction in firms' innovation response to the shock for firms with size just below the regulatory threshold. Consistent with intuition and our simple model, firms appear reluctant to take advantage of exogenous market growth through innovating when they will be subject to a wave of labor regulation.

Having established that the qualitative implications of the model are consistent with the data, we use the structure of our model (and empirical moments of the data) to quantitatively estimate the impact of the regulation on aggregate innovation and welfare. Our baseline estimates suggest that the regulation is equivalent to a tax on profit of about $2.6 \%$ that reduces 
aggregate innovation by around $5.8 \%$ (equivalent to cutting the annual growth rate from $1.7 \%$ to $1.6 \%$ ) and reduces welfare by at least $2.3 \%$ in consumption equivalent terms. This is partly through misallocation from lowering entry and shifting the size distribution downwards, but the vast majority of this aggregate impact is through lower innovation per firm once they reach a certain size. This implies that the existing structural static analyses of the output loss have significantly underestimated the cost of the regulation.

A caveat to our welfare conclusions arises when we generalize our model to allow firms to invest in a mixture of radical and incremental innovation. We find that the regulation deters incremental R\&D, but if a firm is going to innovate it will try to "swing for the fence" to avoid being only slightly to the right of the threshold. Measuring radical innovation by either future citations or a machine learning approach based on novelty in the patent text, we find that the negative effects of regulations are confined to incremental patents. Similarly, we find that regulation biases innovation towards automative labor-saving patents.

\section{Related literature}

Our paper relates to several strands of literature. More closely related to our analysis are papers that look at the effects of labor laws regulations on innovation. In Acharya et al. (2013a) higher firing costs reduce the risk that firms would use the threat of dismissal to hold their employees' innovative investments up. They find evidence in favor of this using macro time series variation on Employment Protection Law (EPL) for four OECD countries. Acharya et al. (2013b) also finds positive effects using staggered roll out of employment protection across US states. ${ }^{4}$ Griffith and Macartney (2014) use multinational firms patenting activity across subsidiaries located in different countries with various levels of EPL. ${ }^{5}$ Using this cross-sectional identification, they find that radical innovation was negatively affected by EPL, but incremental innovations were not. ${ }^{6}$ By contrast, Alesina et al. (2018) find that less regulated countries have larger high-tech sectors. All of these papers use macro (or at best, state-level) variation whereas we focus on cross-firm variation. Garcia-Vega et al. (2019) analyze a reform that relaxed a size contingent labor regulation in Spain and find an increase in innovation. Our empirical results

\footnotetext{
${ }^{4}$ This is the same empirical variation used by Autor et al. (2007) who actually found falls in TFP and employment from EPL. Bena et al. (2020) finds a positive impact on process innovation using the same design.

${ }^{5}$ See also Cette et al. (2016) who document a negative effect of EPL on capital intensity, R\&D expenditures and hiring of high skill workers. More generally, Porter and Van der Linde (1995) argue that some regulations, such as those to protect the environment, can have positive effects on innovation.

${ }^{6}$ Note that this is the opposite of what we find using our within-country identification. Labor regulation discourages low-value innovation, but has no impact on high-value innovation.
} 
are consistent with this, but we go beyond the analysis in this paper by developing a model of labor regulation and innovation with endogenous firm size distribution, that is matched with the data to obtain structural parameters, enabling us to perform aggregate counterfactuals.

Second, several structural papers look at the effects of labor regulations on employment and welfare, in particular Braguinsky et al. (2011) on Portugal, Gourio and Roys (2014) and Garicano et al. (2016) on France. However, these papers do not allow for endogenous innovation, nor try to quantify the welfare changes arising form such dynamic considerations. More generally, there is a large literature focusing on how various kinds of distortions can affect aggregate productivity through the resulting misallocation of resources away from more productive firms and towards less productive firms. As Restuccia and Rogerson (2008) and Parente and Prescott (2000) have argued, these distortions imply that more efficient firms produce too little and employ too few workers. Hsieh and Klenow (2009) show that the resulting misallocation accounts for a significant fraction of the differences in aggregate productivity between the US, China and India and Bartelsman et al. (2013) confirm this finding using micro data from OECD countries. ${ }^{7}$ Boedo and Mukoyama (2012) and Da-Rocha et al. (2019) have shown firing costs hinder job reallocation and reduce allocative efficiency and aggregate productivity. The additional effect of barriers to reallocation when productivity is endogenous is also the focus of Gabler and Poschke (2013), Da-Rocha et al. (2019), and Bento and Restuccia (2017). ${ }^{8}$ Mukoyama and Osotimehin (2019) is perhaps the most closely related paper to ours and finds a negative growth effect of the firing tax equivalent to a $5 \%$ labor tax (in the entrant-innovation model in the US) in a calibrated aggregate model with endogenous innovation. Unlike our approach, their paper does not have closed form solutions for the policy rules with taxes so has to rely on simulation methods. We contribute to this part of the literature by introducing an explicit source of distortion, namely the regulatory firm size threshold that goes beyond just firing costs, and by looking at how this regulation interacts with exogenous market size shocks using firm-level micro-econometric analysis.

Third, a body of work looks at the effects of EPL on the adoption of new technologies (e.g. Manera and Uccioli, 2020), especially information and communication technology. For

\footnotetext{
${ }^{7}$ In development economics many scholars have pointed to the "missing middle" , i.e. a preponderance of very small firms in poorer countries compared to richer countries (see Banerjee and Duflo, 2005, or Jones, 2011). Besley and Burgess (2000) suggest that heavy labor regulation in India is a reason why the formal manufacturing sector is much smaller in some Indian states compared to others.

${ }^{8}$ Samaniego (2006) highlights the effects of firing costs in a model with productivity growth. He considers, however, only exogenous productivity growth and studies how the effects of firing costs differ across industries. Poschke (2009) is one of the few papers that study the effects of firing costs on aggregate productivity growth.
} 
example, Bartelsman et al. (2016) argue that risky technologies require frequent adjustments of the workforce. By increasing the costs of such adjustments, EPL will deter technology adoption. Similarly Samaniego (2006) finds that EPL slows diffusion and Saint-Paul (2002) finds a smaller share of the economy in risky sectors when EPL are strong. Our approach is different as it focuses on technological innovation at the frontier rather than the adoption of existing technologies. Unlike emerging economies, advanced countries such as the US or France cannot rely solely on catch-up diffusion for long-run sustainable growth.

Fourth, our paper is related to public finance as we model regulation as an implicit tax, and a number of papers have examined how personal and business taxes affect innovation (see Akcigit and Stantcheva, 2020, for a recent survey). Like us, other tax papers use nonlinearities to identify behavioral parameters (e.g. Saez, 2010; Chetty et al., 2011; Kleven and Waseem, 2013; Kaplow, 2013 and Aghion et al., 2019b) and we contribute to this literature by bringing labor regulations, innovation and patenting into the picture. ${ }^{9}$

Fifth, there is an older literature looking at one form of labor regulation - union power - on innovation. ${ }^{10}$ These papers found ambiguous theoretical and empirical effects . Finally, the heterogeneous effects of demand shocks on types of innovation is also a theme in the literature of the effects of the business cycle on innovation (Schumpeter, 1939; Shleifer, 1986; Barlevy, 2007). Recent work by Manso et al. (2019) suggests that large positive demand shocks (booms) generate more R\&D, but this tends to "exploitative" (incremental) rather than "exploratory" (radical) innovation. We find that the impact of regulation following a demand shock discourages incremental (but not radical) innovation.

The structure of the paper is as follows. Section 2 develops a simple model of how innovation can be affected by size-contingent regulation. Section 3 confronts the main qualitative predictions of the model to the data, using both a non-parametric cross-sectional analysis and a dynamic econometric analysis of the response to exogenous shocks. Section 4 uses the theory and empirical moments (from both the static and dynamic analysis) to estimate the equilibrium effect of regulation on aggregate innovation and welfare. Section 5 presents a number of theoretical and empirical extensions and robustness tests, most importantly allowing for radical

\footnotetext{
${ }^{9}$ This is important as Hopenhayn (2014) has argued that tax-driven reallocation distortions typically have only second order welfare effects unless there is rank reversal. Changing innovation is potentially a way of generating larger negative welfare effects that goes beyond static models.

${ }^{10}$ See Menezes-Filho et al. (1998) for a survey and evidence. The common view is that the risk of ex post hold-up by unions reduces innovation incentives (Grout, 1984). But if employees need to make sunk investments there could be hold up by firms (this is the intuition of the Acharya et al., 2013a,b papers).
} 
and incremental innovation. Section 6 concludes. In Online Appendices, we present institutional details of the labor regulations (A), data details (B), further theoretical results (C) and additional empirical exercises (D).

\section{Theory}

In this section, we present our basic theory built around a discrete time version of the Schumpeterian growth model with firm dynamics by Klette and Kortum (2004) where we introduce size contingent regulations. This enables us to analytically characterize firms' innovation decisions depending on their size and the regulation. We next solve for the steady state firm size distribution incorporating both incumbent growth and entry/exit dynamics. Finally, we put both elements together to characterize how economy wide innovation changes with the stringency of the regulation. Throughout, we explore what the model implies for the steady state joint distributions of innovation and employment as well as how firms should respond to the exogenous demand shocks we will exploit in the empirical section.

\subsection{A simplified Klette-Kortum model}

We consider a simplified version of the two-period specification of Aghion et al. (2018b). We show that all results are theoretically and empirically robust to the longer lived owner model in the extension of subsection 5.3. In the first period of her life, a firm owner decides how much to invest in R\&D. In the second period, she chooses labor inputs, produces and realizes profits. At the end of the period, her offspring inherits the firm at its current size and a new cycle begins again. ${ }^{11}$

We assume that individuals have intertemporal log preferences:

$$
U=\sum_{t>0} \beta^{t} \log \left(C_{t}\right)
$$

associated with a budget constraint:

$$
w_{t}+\left(1+r_{t}\right) a_{t}=a_{t+1}+C_{t}
$$

where $w_{t}$ is the wage at time $t, C_{t}$ is consumption, and $a_{t}$ is an asset that yields an interest rate $r_{t}$. This immediately gives the Euler equation: $\beta\left(1+r_{t}\right)=1+g_{t}$. We consider the economy on a

\footnotetext{
${ }^{11}$ We do not consider bequest motives, but the extension to longer living owners which we present in Section 5.3 implicitly encompasses this incentive.
} 
balanced growth path where final output $y$ and consumption grow at a constant rate which we denote by $g$, so that the Euler equation can be expressed as $\beta=(1+g) /(1+r)$, where $\beta$ is the discount factor and $r$ is the steady-state level of interest rate. There is a continuous measure $L$ of production workers, and a mass 1 of intermediate firm owners every period. Each period the final good is produced competitively using a combination of intermediate goods according to the production function:

$$
\ln y=\int_{0}^{1} \ln \left(y_{j}\right) d j
$$

where $y_{j}$ is the quantity produced of intermediate $j$. Intermediates are produced monopolistically by the firm who innovated last within that product line $j$, according to the linear technology $y_{j}=A_{j} l_{j}$ where $A_{j}$ is the product-line-specific labor productivity and $l_{j}$ is the labor employed for production. This implies that the marginal cost of production in $j$ is simply $w / A_{j}$. A firm is defined as a collection of production units (or product lines/varieties) and expands in product space through successful innovation.

To innovate, an intermediate firm $i$ combines its existing knowledge stock that it accumulated over time $\left(n_{i}\right.$, the number of varieties it operates in) with its amount of R\&D spending $\left(R_{i}\right)$ according to the following Cobb-Douglas knowledge production function:

$$
Z_{i}=\left(\frac{R_{i}}{\zeta y}\right)^{\frac{1}{\eta}} n_{i}^{1-\frac{1}{\eta}}
$$

where $Z_{i}$ is the Poisson innovation flow rate, $\eta$ is a concavity parameter and $\zeta$ is a scale parameter. This generates the R\&D cost of innovation: $C\left(z_{i}, n_{i}\right)=\zeta n_{i} z_{i}^{\eta} y$, where $z_{i} \equiv Z_{i} / n_{i}$ is simply defined as the innovation intensity of the firm.

When a firm is successful in its current $R \& D$ investment, it innovates over a randomly drawn product line $j^{\prime} \in[0,1]$. Then, the productivity in line $j^{\prime}$ increases from $A_{j^{\prime}}$ to $A_{j^{\prime}} \gamma$ and the firm becomes the new monopoly producer in line $j^{\prime}$ and thereby increases the number of its production lines to $n_{i}+1$. At the same time, each of its $n_{i}$ current production lines is subject to the risk of being replaced by new entrants and other incumbents (a creative destruction probability that we denote $x$ ). Thus the number of production units of a firm of size $n_{i}$ increases to $n_{i}+1$ with probability $Z_{i}=n_{i} z_{i}$ and decreases to $n-1$ with probability $n_{i} x$. A firm that loses all of its product lines exits the economy.

Because of the Cobb-Douglas aggregator, the final good producer spends the same amount $y$ on each variety $j$. As a result, final good production function generates a unit elastic demand 
with respect to each variety: $y_{j}=y / p_{j}$. Combined with the fact that firms in a single product line compete a la Bertrand, this implies that a monopolist with marginal cost $w / A_{j}$ will follow limit pricing by setting its price equal to the marginal cost of the previous innovator $p_{j}=$ $\gamma w / A_{j} \cdot{ }^{12}$

The resulting equilibrium quantity and profit in product line $j$ are:

$$
y_{j}=\frac{A_{j} y}{\gamma w} \text { and } \Pi_{j}=\left(1-\frac{1}{\gamma}\right) y,
$$

and the demand for production workers in each line is given by $y /(\gamma w)$. Firm $i$ 's employment is then equal to its total manufacturing labor, aggregating over all $n_{i}$ lines where $i$ is active, $N_{i}$. Namely:

$$
l_{i}=\int_{j \in N_{i}} \frac{y}{w \gamma} d j=\frac{y n_{i}}{w \gamma}=\frac{n_{i}}{\omega \gamma},
$$

where $\omega=w / y$ is the output-adjusted wage rate, which is invariant on a steady state growth path. Importantly for us, a firm's employment is strictly proportional to its number of lines $n_{i}$.

\subsection{Regulatory threshold and innovation}

We model the regulation by assuming that a tax on profit must be incurred by firms with a labor force that is greater than a given threshold $\bar{l}$ (50 in our application in France). ${ }^{13}$ We suppose that $\bar{l}$ is sufficiently large that entrants do not incur this tax upon entry. There corresponds a cutoff number of varieties $\bar{n}=\bar{l} \omega \gamma$ to the employment threshold $\bar{l}$, such that if $n_{i} \geq \bar{n}$ profit is taxed at some additional positive marginal rate $\tau$ whereas the firm avoids this additional tax if $n_{i}<\bar{n} .{ }^{14}$ Because firm owners live only for two periods, they can only expand the number of varieties of the firm by one extra unit during their lifetime. Hence, all the firms that start

\footnotetext{
${ }^{12}$ We implicitly assume a competitive fringe of firms with access to the previous technology in each sector; and that entering the market involves an $\varepsilon$ entry cost. Then, as long as the new innovator sets a price which is less than the limit price equal to the marginal cost of fringe firms, no fringe firm will pay the entry cost. On the other hand, if the new innovator sets a price which is higher than the limit price, then she risks losing the market to a fringe firm.

${ }^{13}$ See Appendix A.3 for a discussion of alternative ways of modelling the regulation, such as including a fixed as well as a variable cost.

${ }^{14}$ Unlike in Aghion et al. (2014) where the innovation cost is modelled as a labor cost, here innovation uses the final good $y$ as an input. With labor as R\&D input, total employment is $l_{i}=\frac{n_{i}}{\omega \gamma}+\zeta n_{i} z_{i}^{\eta}$, and thus varies with innovation rather than being proportional to $n_{i}$. We consider this extension in subsection 5.5 where R\&D is labor. Increased R\&D will then affect the equilibrium wage.
} 
out with size $n_{i}<\bar{n}-1$ or $n_{i} \geq \bar{n}$ act exactly as if the regulatory threshold did not exist. For firms that start with $n=\bar{n}-1$, there is an additional cost to expanding by one extra variety.

The owner of a $n$-size firm therefore maximizes their expected net present value over its innovation intensity $z \geq 0:{ }^{15}$

$$
\max _{z \geq 0}\left\{n \pi(n) y-\zeta n z^{\eta} y+\frac{1}{1+r} \mathbb{E}\left[n^{\prime} \pi\left(n^{\prime}\right) y^{\prime}\right]\right\}
$$

where $y^{\prime}$ and $n^{\prime}$ denotes period 2's values for $y$ and $n$ and $r$ is the interest rate. Dividing by $y / n$ and using the fact that $\beta=(1+g) /(1+r)$, the above maximization problem can be re-expressed as:

$$
\begin{aligned}
& \max _{z \geq 0}\left\{\pi(n)(1+\beta)-\zeta z^{\eta}+\beta z[(n+1) \pi(n+1)-n \pi(n)]+\beta x[(n-1) \pi(n-1)-n \pi(n)]\right\}, \\
& \text { where } \pi(n)=\left(1-\frac{1}{\gamma}\right) \text { if } n<\bar{n} \text { and } \pi(n)=\left(1-\frac{1}{\gamma}\right)(1-\tau) \text { if } n \geq \bar{n} .
\end{aligned}
$$

The intuition behind this equation is straightforward. The first term, $\pi(n)(1+\beta)$ represents the gross flow profits per line today and the second term is the cost of research, $\zeta z^{\eta}$. The third term, $\beta z[(n+1) \pi(n+1)-n \pi(n)]$, is the (discounted) incremental profit gain tomorrow multiplied by the probability the firm innovates and thereby operates one more product line. The final term, $\beta x[(n-1) \pi(n-1)-n \pi(n)]$ is the (discounted) incremental profits loss per line tomorrow if the firm gets replaced in one of its product lines by a rival firm.

Whenever positive, the optimal innovation intensity is therefore given by:

$$
z(n)= \begin{cases}\left(\frac{\beta(\gamma-1)}{\gamma \zeta \eta}\right)^{\frac{1}{\eta-1}} & \text { if } n<\bar{n}-1 \\ \left(\frac{\beta(\gamma-1)(1-\tau \bar{n})}{\gamma \zeta \eta}\right)^{\frac{1}{\eta-1}} & \text { if } n=\bar{n}-1 \\ \left(\frac{\beta(\gamma-1)(1-\tau)}{\gamma \zeta \eta}\right)^{\frac{1}{\eta-1}} & \text { if } n \geq \bar{n}\end{cases}
$$

Much of the core economics of the paper can be seen in equation (4). Innovation intensity, $z(n)$, is highest for small firms a long way below the threshold (first row on right hand side of (4)), second highest for large firms over the threshold (third row) and lowest for middle sized firms just to the left of the threshold (middle row).

\footnotetext{
${ }^{15}$ Since we have shown that innovation per line is the same for firms of a given size, we drop the firm $i$ subscripts from here onwards for notational simplicity unless needed.
} 
What we observe in the data is the firm's total innovation (measured using patents) which is $Z(n)=n z(n)$. Since employment is directly proportional to the number of product lines, this implies that the slope of the innovation-size relationship will depend upon whether the firm lies above or below the regulatory threshold. Typically, the upward sloping relationship between innovation and firm size should be steeper for small firms than for large firms and should fall and flatten discontinuously at the threshold. Furthermore, the ratio of the slopes of the innovation-size relationship for large versus small firms, relates directly to the underlying parameters of the model, and in particular upon the regulatory tax. ${ }^{16}$ We will use this fact to empirically identify the magnitude of the regulatory tax, which we then use in our estimates of the aggregate impact of the regulation on innovation.

\subsection{Regulatory threshold and firm size distribution}

We now characterize the steady state distribution of firm size and look at how this distribution is affected by the regulatory tax. Let $\mu(n)$ be the share of firms with $n$ lines. We first have a steady state condition saying that the number of exiting firms equals the number of entering firms in steady-state, namely: $\mu(1) x=z_{e}$, where $z_{e}$ is the innovation intensity of entrants, which is the same as the probability of entry. Since $x$ is the rate of creative destruction for any line, the number of exiting firms is therefore given by $\mu(1) x$.

For all $n>1$, the steady state condition is that outflows from being a size $n$ firm is equal to the inflows into becoming a size $n$ firm. This can be expressed as:

$$
n \mu(n)(z(n)+x)=\mu(n-1) z(n-1)(n-1)+\mu(n+1) x(n+1)
$$

We know $z(n)$ for each $n$ from equation (4) but we need to find the two remaining endogenous objects $z_{e}$ and $x$. We close the model by considering the following two equations. First, the definition of $\mu$ gives $\sum_{n=1}^{\infty} \mu(n)=1$. Second, the rate of creative destruction on each line is equal to the rate of creative destruction by an entrant plus the weighted sum of the flow probabilities $z(n)$ of being displaced by an incumbent of size $n$, namely:

$$
x=z_{e}+\sum_{n=1}^{\infty} \mu(n) n z(n)
$$

\footnotetext{
${ }^{16}$ The ratio of the innovation intensity of the first to third row in $(4)$ is $(1-\tau)^{1 /(1-\eta)}$. This can be empirically recovered from the relative slopes of the patents to size relationship before and after the regulatory threshold (see Section 4).
} 


\subsection{Solving the model}

In Appendix $\mathrm{C}$ we detail how we solve the model numerically. The unknowns are $\mu(n)$ and $z(n)$ for all values of $n$ as well as $x$ and $z_{e}$, and the equations are those derived above. To illustrate the effects, we first show firm-level innovation $Z(n)=z(n) n$ as a function of the firm's employment size $l=n /(\omega \gamma)$ in Figure 1. We see that firm-level innovation increases linearly with firm size until the firm nears the regulatory threshold, at which point there is a sharp innovation valley. After this, innovation again increases with firm size once the firm passes the threshold.

Figure 1: Total Innovation by firms of different employment sizes

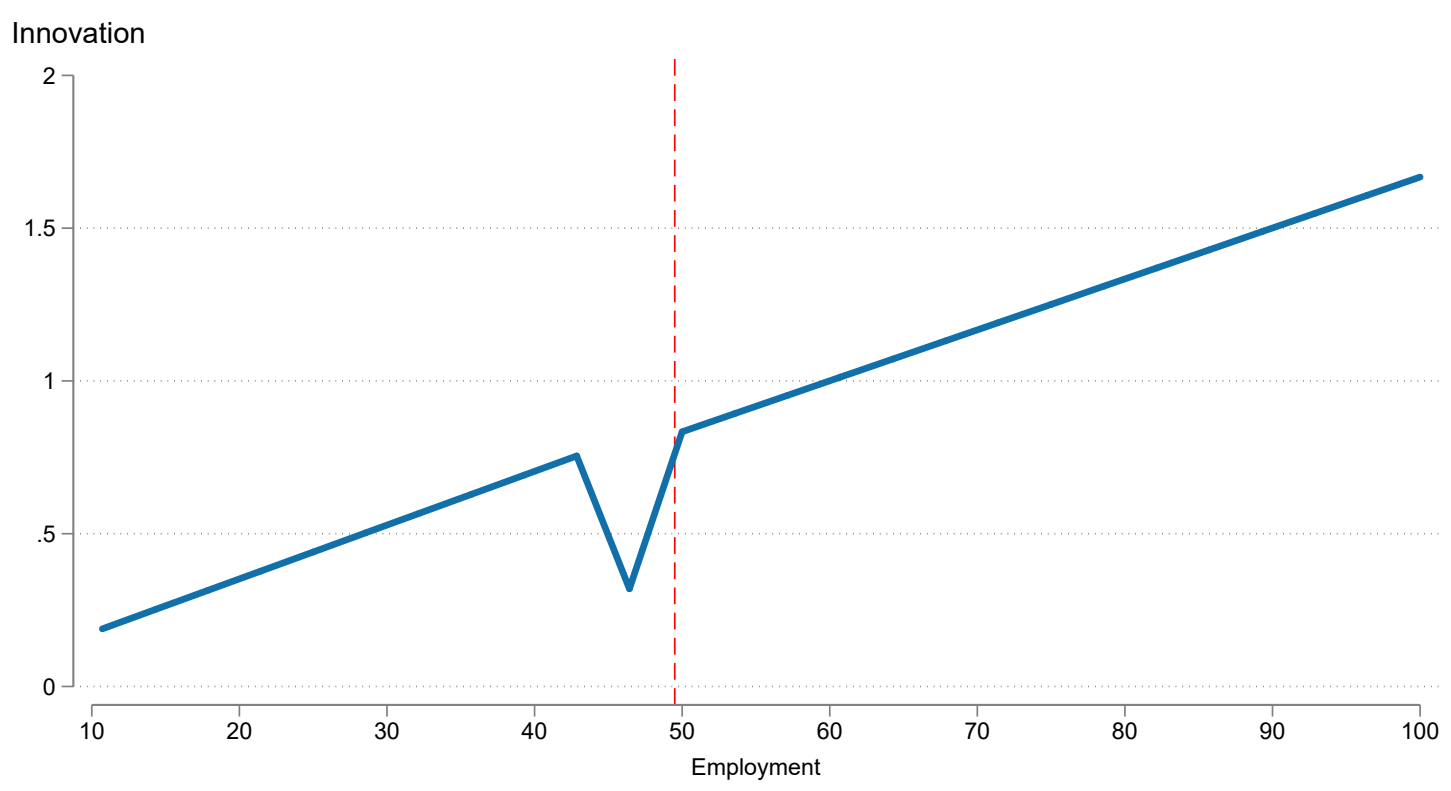

Notes: This is the total amount of innovation $(Z(n))$ by firms of different sizes (employment, $l=n /(\gamma \omega)$ ) by aggregating innovation intensities $z(n)$ across all its product lines $(n)$ according to our baseline theoretical model. The $\mathrm{y}$-axis is the corresponding value of total innovation $Z$. We use our baseline calibration values of $\tau=0.026, \gamma=1.3, \eta=1.5, \beta / \zeta=1.66$ and $\omega=0.22$ for illustrative purposes (see section 4 for a discussion).

In Figure 2 we plot the equilibrium firm size distribution, i.e. the value of the density $\mu(n)$ for each level of firm employment. Panel (a) uses a linear scale, but because the distribution is nonlinear we plot it on a log-log scale in Panel (b) where it is broadly log-linear (the well-know power law as documented by Axtell, 2001 and many others). Note the departure from the power law around the regulatory threshold. The distribution bulges a bit as firms approach 50 and then discontinuously drops before falling again once firms pass the threshold. Unlike the innovation-size discontinuity, this "broken power law" in the French size distribution has been noted before in the literature (e.g. Ceci-Renaud and Chevalier, 2011), but the shape has 
proven difficult to fully rationalize in a model without endogenous innovation. ${ }^{17}$

Figure 2: Distribution of firm size $(\mu(n))$

(a) Linear scale

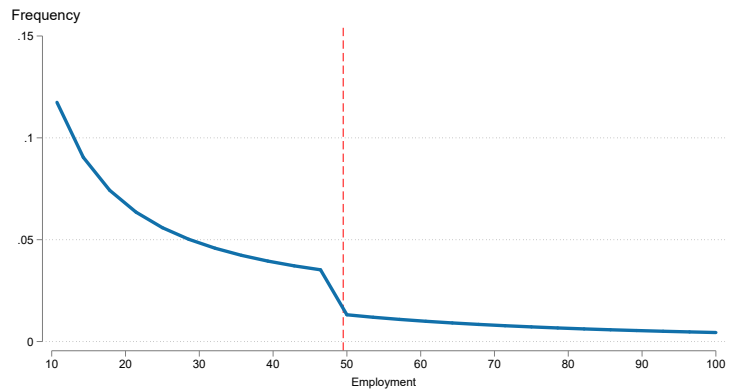

(b) Log scale

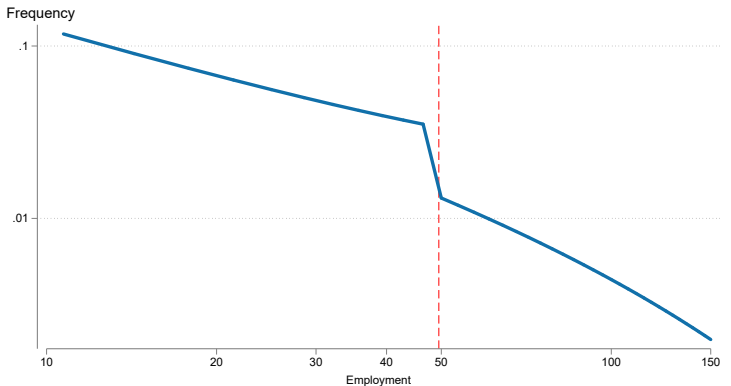

Notes: These figures plot the density of firm employment, $\mu(n)$ according to our baseline theoretical model. Panel (a) uses a linear scale and Panel (b) uses a log-log scale. The calibration values are the same as Figure 1.

Although we took particular values of the parameters for illustrative purposes in Figures 1 and 2 , these patterns are the same for any value of the regulatory $\operatorname{tax}(\tau) .{ }^{18}$ To see how $\tau$ qualitatively impacts the innovation-firm size relationship and the firm size distribution, we compare our results (solid blue) to an unregulated economy (i.e. $\tau=0$, dashed red) in Figures 3(a) and 3(b). Four points are worth emphasizing. First, as expected, we observe no innovation valley when we remove the regulation Figures 3(a). Second, the level of innovation when $\tau>0$ is lower than when $\tau=0$ even for large firms to the right of the threshold. This stems from the fact that the tax reduces innovation intensity even for these firms. Third, the total innovation gap between the regulated and unregulated economy gets larger as firm size increases because bigger firms have more product lines and the innovation intensity of each line is lower than that of small firms. This can be seen from (4), which showed that the slope of the line after the threshold is flatter than that for small firms with $n<\bar{n}-1$. Fourth, in terms of the size distribution in Figure 3(b), we see that moving from $\tau=0$ to $\tau>0$ increases the share of firms that are below 50 employees and decreases the fraction of large firms. The regulation also generates a larger mass of firms just below the threshold as these firms choose not to grow in order to avoid getting hit by the regulatory tax.

We now put together all the effects of regulation together to compute the overall impact of

\footnotetext{
${ }^{17}$ In particular, although a purely static model like Lucas (1978) with regulation can rationalize a discontinuity at 50 and a downwards shift of the line, there should be no firms of size 50 and no bulge at 48 (firms just fully shift to avoid the regulation and spike at 49). Garicano et al. (2016) had to introduce ad hoc measurement error to rationalize the smoother bulge we see in the data around 45-50. This bulge (and the positive mass at 50) emerges more naturally with our dynamic endogenous innovation model.

${ }^{18}$ From equation (4), we know that we can take $\tau$ to lie anywhere between 0 and $1 / \bar{n}$ in order to have an interior solution for $z(\bar{n})$.
} 
Figure 3: Innovation and firm size distribution, with and without regulations

(a) Innovation

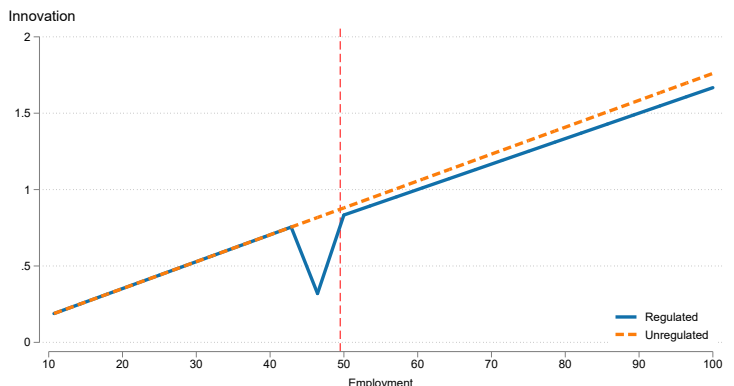

(b) Size distribution (log scale)

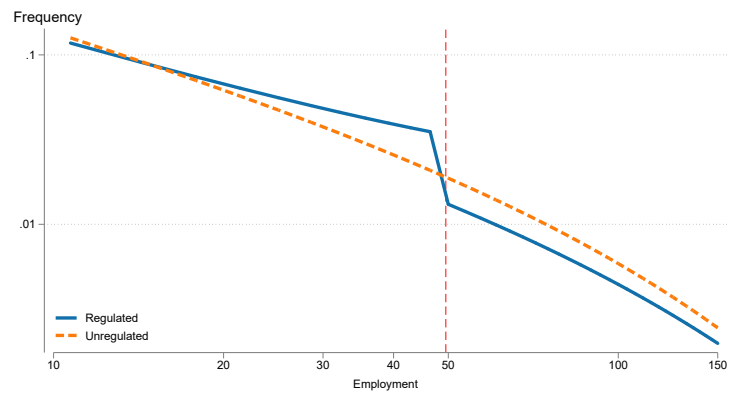

Notes: The blue solid line in this Figure reproduces Figure 1 in Panel (a) and Figure 2(b) in Panel (b). The orange dashed line is for an unregulated economy with all the same parameters in the regulated economy except $\tau=0$.

regulation on the economy-wide innovation, $\mathcal{Z}(\tau)=\sum_{i=1}^{\infty} \mu(i) z(i) i+z_{e}$. Figure 4 shows the fall in total innovation in the regulated economy compared to the counterfactual unregulated economy (where we normalize aggregate innovation at 1 ). The magnitude of the fall in innovation is clearly increasing in the intensity of the regulatory tax, $\tau$. For example, there is a reduction in total innovation of $4 \%$ if $\tau=0.02$ instead of zero. This fall in aggregate innovation comes from three sources. First, for a given firm size, the tax increase has a strong negative effect on innovation for firms just to the left of the threshold, and a smaller negative effect on innovation for all firms to the right of the threshold. Second, the tax increase reduces the mass of large firms, which are also the firms that do more innovation. Third, since lower incumbent innovation means less exit, this will mean there is less entry in steady state. When we use our data to quantify the model, we will decompose the fall of aggregate innovation into these different elements and show that the first element (incumbent innovation) dominates.

\subsection{Effect of a demand shock}

In the dynamic analysis below, we will examine the impact of market size shocks on innovation. In the theory, this can be seen as an exogenous idiosyncratic shock on the demand for one given product $j .{ }^{19}$ Let us denote this shock by $\tilde{\varepsilon}_{j}$ which shifts the value of $y_{j}$ for a given product $j$ to $y_{j}\left(1+\tilde{\varepsilon}_{j}\right)$. The firm producing $j$ anticipates that a shock will occur in next period but does not know in which product. As a result, the firm $i$ expects a shock of magnitude $\varepsilon_{i}=\tilde{\varepsilon}_{j} / n_{i}$ in the demand for each of its products.

\footnotetext{
${ }^{19} \mathrm{~A}$ common shock to all firms can be modeled as an increase in $y$. This will not have a differential effect on innovation in firms of different size, as all variables in our model are expressed in units of final output.
} 
Figure 4: Aggregate economy-wide innovation as a function of the intensity of regulation

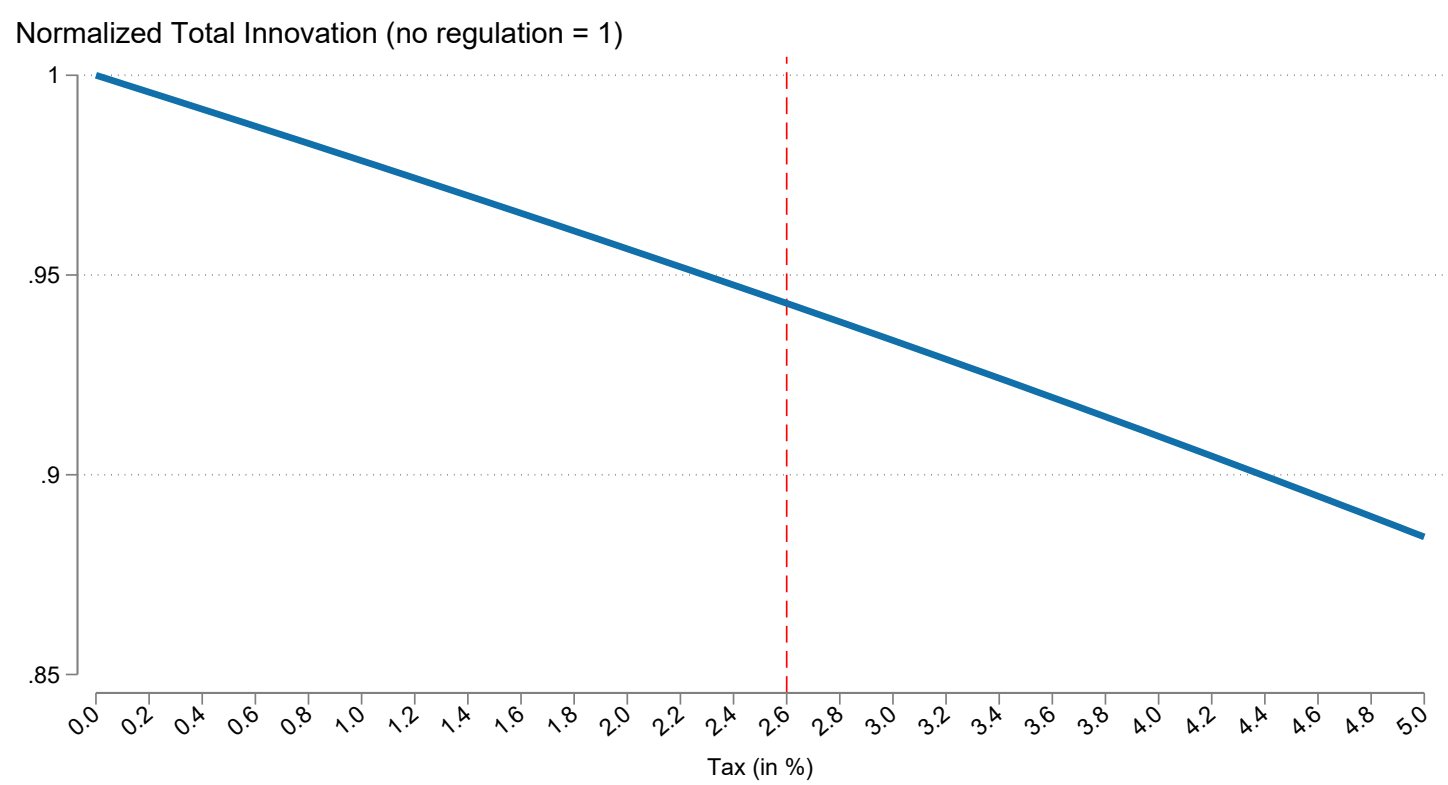

Notes: We simulate the amount of aggregate innovation in different economies relative to an unregulated benchmark economy as the intensity of regulation changes as indicated by the magnitude of the implicit tax $(\tau)$. For example, if $\tau=2 \%$, aggregate innovation is about 0.96 relative to the benchmark, i.e. $4 \%$ lower. Parameter values are the same in regulated and regulated economies (as in notes to Figure 1) except we vary the value of $\tau$.

Given the expected demand shock, future expected profit is shifted by $\left(1+\varepsilon_{i}\right)$. Hence, holding innovation fixed, there will be a positive impact of $\varepsilon_{i}$ on firm size in the short run, and this impact will be smaller for firms just to the left of the threshold as these firms will not want to cross the threshold and bear the extra regulatory cost.

What is the effect of the impact of the shock on firm-level innovation? Equation (4) is modified by having the shock factor $\left(1+\varepsilon_{i}\right)^{\frac{1}{\eta-1}}$ pre-multiplying each term of the equation. Formally, the value of $Z$ becomes (for $n \neq \bar{n}-1$ ):

$$
Z(n, \varepsilon)=\left(\frac{\beta \pi(n)}{\zeta \eta}\right)^{\frac{1}{\eta-1}} \omega \gamma l(n)(1+\varepsilon)^{\frac{1}{\eta-1}}
$$

where $l(n)=n /(\omega \gamma)$ is the level of employment without a shock. Hence, a shock $\varepsilon$ implies a change in $Z$ such that:

$$
\Delta Z(n, \varepsilon) \equiv Z(n, \varepsilon)-Z(n, 0)=\left(\frac{\beta \pi(n)}{\zeta \eta}\right)^{\frac{1}{\eta-1}} \omega \gamma l(n)\left[(1+\varepsilon)^{\frac{1}{\eta-1}}-1\right]
$$

The impact of the shock on innovation intensity will be largest for small firms far below the regulatory threshold. The second biggest effect will be on innovation in large firms well to the right of the threshold. And the smallest effect of the demand shock will be on firms just below 
the threshold. The overall increase in a firm's innovation (number of lines multiplied by the innovation intensity per line) in response to the shock will be greater for large firms as they have more product lines. However, even controlling for firm size (as we will do in the empirical work), and so concentrating on the marginal effect of the shock on innovation intensity, the model predicts that the effect of a market size shock on innovation should be significantly lower for firms just to the left of the threshold because:

$$
\frac{\partial^{2} \Delta Z}{\partial \varepsilon \partial l}=\left(\frac{\beta \pi(n)}{\zeta \eta}\right)^{\frac{1}{\eta-1}} \frac{\omega \gamma}{\eta-1}(1+\varepsilon)^{\frac{2-\eta}{\eta-1}}
$$

which continues to depend upon $\pi(n)$, the profit per line of a firm of size $n$.

Finally, the shock will affect the firm size distribution. If the shock is transitory, a shocked firm will grow larger for a short period of time before the economy will return to the initial steady state distribution. A permanent idiosyncratic shock will translate into a permanent change to the overall steady state size distribution. The dynamic empirical design is not well suited to analyzing the impact on the steady state firm size distribution as the Bartik-style shock is defined only for incumbents. Hence, we focus on entry effects only in the equilibrium calibration.

\section{$3 \quad$ Empirics}

We have combined multiple administrative datasets on firm employment size, innovation and trade. This will enable us to examine the predictions from the theory both statically (e.g. cross sectional distribution of firm innovation by firm size) and dynamically - i.e. how firm innovation responds heterogeneously across the size distribution to the same market size shock due to the regulation.

\subsection{Data}

Our main data comes from the French tax authorities, which consistently collect information on the balance sheets of all French firms on a yearly basis from 1994 to 2007 ("FICUS"). We restrict attention to non-government businesses and take patenting information from Lequien et al. (2017). This matches the PATSTAT (Spring 2016) database to FICUS using an algorithm, which matches the name of the assignee - the holder of the IP rights - on the patent front page to the firm whose name and address is closest to that of the patent holder. The accuracy of the algorithm is worse for firms that are below 10 employees so we focus on firms with more 
than 10 employees. Since we are interested in the effects of a regulation that affects firms as they pass the 50 employees threshold, we further restrict attention to firms with between 10 and 100 workers in 1994 (or the first year those firms appear in the data). ${ }^{20}$ More details about the data source are given in Appendix B.

Our main sample consists of 182,348 distinct firms and 1.66 million observations. We report some basic descriptive statistics in Table 1 for all firms in all parts of the market economy in Panel A (25\% are in manufacturing) and for the sub-sample of firms who filed at least patent between 1994-2007 in Panel B. We can see that on average, firms file 0.009 patents per year and, conditional on being an innovator, 0.28 per year. As is well known, the distribution of innovation is highly skewed, with a small number of firms owning a large share of the patents in our sample. However, since we do not include the largest French firms in our data, the skewness is less pronounced.

Table 1: Descriptive statistics

\begin{tabular}{|c|c|c|c|c|c|c|}
\hline \multicolumn{7}{|c|}{ Panel A: All firms } \\
\hline & Mean & p25 & $\mathrm{p} 50$ & p75 & p90 & p99 \\
\hline Employment & 29 & 12 & 19 & 35 & 56 & 151 \\
\hline Sales & 5,434 & 958 & 2,032 & 4,756 & 10,632 & 45,224 \\
\hline Patents & 0.0090 & 0 & 0 & 0 & 0 & 0 \\
\hline Innovative & 0.031 & 0 & 0 & 0 & 0 & 1 \\
\hline Manufacturing & 0.25 & 0 & 0 & 1 & 1 & 1 \\
\hline \multicolumn{7}{|c|}{ Panel B: Subset of innovative firms } \\
\hline & Mean & $\mathrm{p} 25$ & $\mathrm{p} 50$ & p75 & p90 & p99 \\
\hline Employment & 52 & 20 & 35 & 62 & 98 & 307 \\
\hline Sales & 11,795 & 2,500 & 5,208 & 10,492 & 21,326 & 115,145 \\
\hline Patents & 0.283 & 0 & 0 & 0 & 1 & 4 \\
\hline Manufacturing & 0.68 & 0 & 1 & 1 & 1 & 1 \\
\hline $\begin{array}{l}\text { Iotes: These are } \\
\text { a firms who file } \\
\text { strict to firms w } \\
\text { mple). There a } \\
1,192 \text { observatio }\end{array}$ & B & cs on ou & $\begin{array}{l}\text { a. } \mathrm{P} \\
\text { en } 1\end{array}$ & $\begin{array}{l}\text { is al } \\
d 2\end{array}$ & nd $P$ & $\begin{array}{l}3 \text { conditic } \\
\text { firms). }\end{array}$ \\
\hline
\end{tabular}

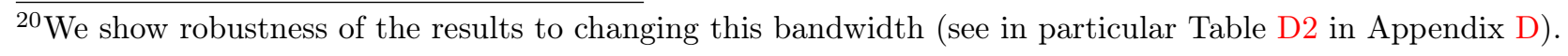




\subsection{Nonparametric evidence: Static Analysis}

Figure 5 shows, for each employment size bin, the fraction of firms within that bin with at least one patent (see also Panel A of Table 1). We see an almost linear relationship between firm size and the fraction of innovative firms. That larger firms are more likely to patent is in line with the analysis in Akcigit and Kerr (2018). The prediction of a linear relationship between firm size and innovation is consistent with our equation (4).

For firms just below the 50 employee threshold, the share of innovative firms suddenly decreases in an innovation valley. This is what the model predicts. It is also noteworthy that the slope of the innovation-size relationship is flatter for larger firms to the right of the threshold than for smaller firms below the threshold. This again is consistent with our theoretical predictions. Note that in the theory, the ratio between the slopes of the innovation-size relationship between a large and a small firm, varies with the $\operatorname{tax}(\tau)$ and with the concavity of the R\&D cost function $(\eta)$. We will exploit this variation to help recover the tax parameter later in this section. ${ }^{21}$

The innovation outcome measure is taken over the whole sample period from 1994 to 2007, but the same patterns emerge if we consider alternative definitions of an innovative firm (see Appendix Figure D2). The predictions over the size distribution also broadly match up to the data, but since these are relatively well known we relegate discussion to Appendix D.

\subsection{Dynamic analysis}

\subsubsection{Estimation equation}

Recall that the theoretical response of innovation to demand shock in the model is given by (6). As discussed in Section 2.5, the first derivative of $\Delta Z$ with respect to the shock will depends upon the value of $l$, and this value will depend on whether the firm is close to the threshold, far below it, or far above it. The second derivative of $\Delta Z$ with respect to employment and the shock will be significantly lower for firms located in the innovation valley.

\footnotetext{
${ }^{21} \mathrm{~A}$ concern with this approach is that the flattening of the innovation-size gradient could occur for nonregulatory reasons. For example, Akcigit and Kerr (2018) argue that larger firms invest in more 'internal' $\mathrm{R} \& \mathrm{D}$ to protect their market share that generates less knowledge than the 'external' $\mathrm{R} \& \mathrm{D}$ of smaller firms. We tackle this issue in two ways. First, we will look at the aggregate innovation losses using the dynamic moments derived in the next section that analyzes the responsiveness to shocks rather than just the cross sectional moment looking at levels in Figure 5. Second, we confirmed that the flattening of the gradient in Figure 5 does not seem to occur in micro-datasets from the UK and US (countries which do not have the large increase in labor regulations for firms with 50 or more employees).
} 
Figure 5: Share of innovative firms at different levels of employment

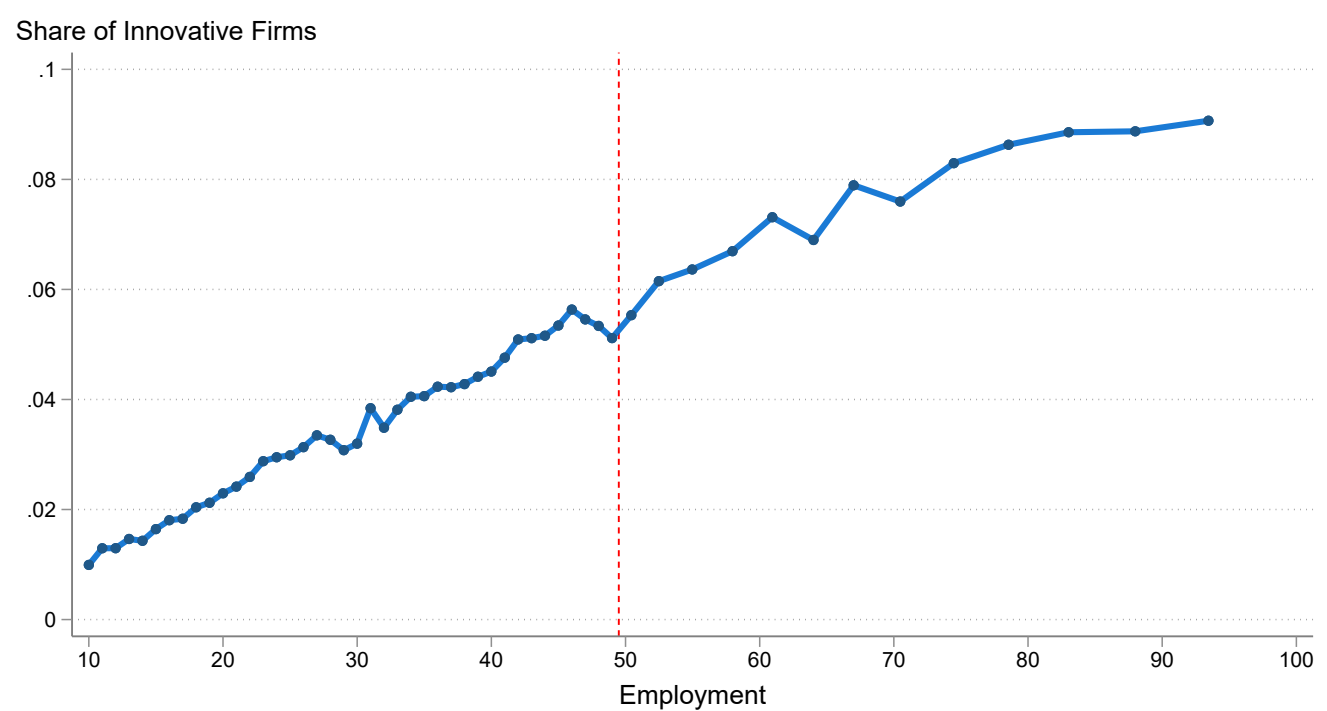

Notes: Share of innovative firms (i.e. with at least one priority patent) plotted against their employment. All observations are pooled together. Employment bins have been aggregated so as to include at least 10,000 firms. The sample is based on all firms with initial employment between 10 and 100 (182,347 firms and 1,658,762 observations, see Panel A of Table 1).

We take this into account in our empirical exploration of the effect of a demand shock and turn to a parametric investigation of how firms respond to market size shocks by considering the following regression:

$$
\begin{aligned}
\tilde{\Delta} Y_{i, t}= & b_{1} l_{i, t-2}^{\star}+b_{2}\left[\Delta S_{i, t-2} \times \mathcal{P}\left(\log \left(l_{i, t-2}\right)\right)\right]+b_{3}\left[\Delta S_{i, t-2} \times l_{i, t-2}^{\star}\right] \\
& +\phi \mathcal{P}\left(\log \left(l_{i, t-2}\right)\right)+\psi_{s(i, t), t}+\epsilon_{i, t}^{e r r}
\end{aligned}
$$

where $Y_{i, t}$ is a measure of innovation (based on patents) that is related to $Z$ in the theory and $l_{i, t}$ a measure of employment. $\Delta S_{i, t-2}$ is an exogenous demand shock to market size that should trigger an increase of innovation in a wide class of models (and in our own, is related to the demand shock $\varepsilon$ ) and $\psi_{s(i, t), t}$ is a set of industry-year dummies where $s(i, t)$ denotes the main sector of activity of firm $i$ at time $t$.

Our main focus is to see whether there is a discouraging effect of the regulation on innovation. For this reason, we include $l_{i, t}^{\star}$ in the model, a binary variable that takes value 1 if firm $i$ is close to, but below, the regulatory threshold at time $t$. Our baseline measure of $l_{i, t}^{\star}$ is a dummy for a firm having employment between 45 and 49 employees. In this specification, in order to capture the heterogeneous response across the different values of employment predicted by the model, we use a flexible functional form and include $\mathcal{P}\left(\log \left(l_{i, t-2}\right)\right)$ a polynomial in $\log \left(l_{i, t-2}\right)$. Finally, $\epsilon_{i, t}^{e r r}$ is an error term. We use a two year lag of the shock since there is likely to be some delay between the demand shock, the increase in research effort and the filing of a patent application. 
Finally, for the dependent variable, we need a data equivalent to $\Delta Z$. We proxy $Z$ as the $\log$ of the number of patents, and measure its growth by: ${ }^{22}$

$$
\tilde{\Delta} Y_{i, t}=\left\{\begin{array}{cc}
\frac{Y_{t}-Y_{t-1}}{Y_{t}+Y_{t-1}} & \text { if } Y_{t}+Y_{t-1}>0 \\
0 & \text { otherwise }
\end{array}\right.
$$

The key coefficient capturing the discouragement effect of the threshold in equation (7) is $b_{3}$, which we expect to be negative. Larger firms will likely respond more to a given shock, but this relationship should break down for the firms just to the left of the threshold as firms are reluctant to cross the threshold in response to an expansion in market size.

\subsubsection{Market Size Shocks}

To construct the innovation shifters $\Delta S_{i, t-2}$, we rely on international trade data to build export demand shocks following Hummels et al. (2014) and Mayer et al. (2016). In short, we look at how foreign demand in a given product by destination cell changes over time by measuring the change in imports from all countries (except France) into that product-country cell. We then build a product-destination portfolio for each French firm $i$, and weight the foreign demands for each product by the relative importance of that product for firm $i$. More specifically, firm $i$ 's export demand shock at date $t$ is defined as:

$$
\Delta S_{i, t}=\sigma_{i, t_{0}} \sum_{s, c \in \Omega\left(i, t_{0}\right)} \omega_{i, s, c, t_{0}} \tilde{\Delta} I_{s, c, t}
$$

where $\Omega\left(i, t_{0}\right)$ is the set of products and destinations associated with positive export quantities by firm $i$ in the first year $t_{0}$ in which we observe that firm in the customs data ${ }^{23}$ and $\omega_{i, s, c, t_{0}}$ is the relative importance of product $s$ and country destination $c$ for firm $i$ at $t_{0}$, defined as firm $i$ 's exports of product $s$ to country $c$ divided by total exports of firm $i$ in that year. $I_{s, c, t}$ is country $c$ 's demand for product $s$, defined as the sum of its imports of product $s$ from all countries except France and $\sigma_{i, t_{0}}$ is the initial export intensity (export divided by sales) of firm $i$. The basic idea behind the shock design is simply that a firm that was exporting, for example, many cars to China in 2000, would have benefited disproportionately from the boom

\footnotetext{
${ }^{22}$ This is essentially the same as in Davis and Haltiwanger (1992) for employment dynamics except that we set the variable equal to zero when a firm does not patent for two periods. The results are robust to considering other types of growth rates such as using the Inverse Hyperbolic Sine (see columns 7-9 of Table D2 in Appendix D).

${ }^{23}$ French customs data are available from 1994. So we use 1994 as the initial year, except for firms who enter after 1994 for which we use the initial year they enter the sample.
} 
in Chinese consumption of cars at the start of the twenty-first century. ${ }^{24}$

We fix the weights at the firm level taking initial period $t_{0}$ as the reference. This is done in order to exclude any variation in the portfolio of products and countries that could be endogenous. Our shock is therefore similar to a "Bartik"-type shift-share instrument. There is an important recent literature (e.g. Goldsmith-Pinkham et al., 2020 and Adao et al., 2019) which discusses inference and estimations with these designs. In particular, the sum of exposure weights across $(s, j)$ 's is not 1 (because of $\sigma_{i, t_{0}}$, except in the rare case of firms that do not sale domestically) and varies across-firms. We follow Borusyak et al. (2018) who argue that in such an "incomplete shift-share" case with panel data, it is important to control for this sum and allow the coefficient to change with time. ${ }^{25}$

\subsubsection{Testing the main prediction}

To estimate equation (7), we need to make some further restrictions in our use of the dataset. First, note that the market size shock $\Delta S$ is only defined for exporting firms, that is, firms that appear at least once in the customs data from 1994 to 2007. Second, in order to increase the accuracy of our shock measure, we restrict attention to the manufacturing sector. Not only is a large fraction of patenting activity located in manufacturing, but these firms are also more likely to take part in the production of the goods they export (see Mayer et al., 2016). Our main regression sample is therefore composed of 20,620 firms and 142,474 observations.

Table 2 presents the results from estimating equation (7), i.e. from regressing the growth rate of firm patents on the lagged market size shock. Column (1) shows that firms facing a positive

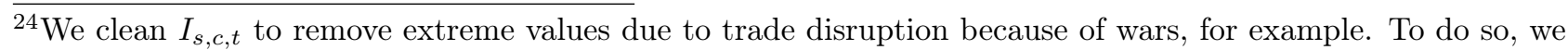
follow Aghion et al. (2018b) and look at the within product-country standard deviation of $\tilde{\Delta} I_{s, c, t}$, winsorizing values of $\tilde{\Delta} I_{s, c, t}$ that are above the $90 \%$ percentile. This mostly concerns pairs of country-product where French firms do not export and this impacts less than $0.15 \%$ of total observations. We then trim the shock $\Delta S_{i, t}$ at the 0.5 level. This procedure has has no material impact on our results (for example, see Table D2, column 10 in the Appendix).

${ }^{25}$ We have conducted many more extensive diagnostic tests showing the validity of this source of exogenous variation to market size. Borusyak et al. (2018) underline two assumptions underlying the validity of a shiftshare instrument: quasi-randomness of shock assignment and a high number of uncorrelated shocks. The first assumption is likely to hold in our setting due to the inclusion of narrow industry by year dummies in our regressions. The assumption is essentially that within industry, the expected value of $\tilde{\Delta} I$ is the same for all firms conditional on the country-product-level unobservables. The second assumption is warranted by the fact that we consider a very large number of shocks across many countries and products. In one robustness test, we follow the recommendations of Borusyak et al. (2018) and check that our main results are robust to using alternative shocks in which $\tilde{\Delta} I$ has been residualized on different combinations of year, country, product fixed effects. Moreover, note that our panel data structure allows us to include a firm fixed effect as an additional robustness check which further controls for potential correlations between permanent firm characteristics and future realizations of the shocks. See Aghion et al. (2018a) for more diagnostics.
} 
Table 2: Main regression results

\begin{tabular}{|c|c|c|c|c|c|c|c|c|c|}
\hline & (1) & $(2)$ & (3) & $(4)$ & (5) & (6) & (7) & $(8)$ & (9) \\
\hline Shock $_{t-2} \times L_{t-2}^{\star}$ & & & & $\begin{array}{c}-4.987^{* *} \\
(2.220)\end{array}$ & $\begin{array}{c}-6.040^{* * *} \\
(2.183)\end{array}$ & $\begin{array}{c}-5.544^{* *} \\
(2.255)\end{array}$ & $\begin{array}{c}-6.547^{* *} \\
(2.747)\end{array}$ & $\begin{array}{c}-3.673^{* *} \\
(1.772)\end{array}$ & $\begin{array}{c}-6.039^{* *} \\
(2.341)\end{array}$ \\
\hline$L_{t-2}^{\star}$ & & & & $\begin{array}{c}0.043 \\
(0.104)\end{array}$ & $\begin{array}{c}0.069 \\
(0.129)\end{array}$ & $\begin{array}{c}0.069 \\
(0.107)\end{array}$ & $\begin{array}{l}-0.011 \\
(0.185)\end{array}$ & $\begin{array}{c}0.081 \\
(0.054)\end{array}$ & $\begin{array}{c}0.068 \\
(0.109)\end{array}$ \\
\hline Shock $_{t-2}$ & $\begin{array}{c}1.092^{* *} \\
(0.485)\end{array}$ & $\begin{array}{c}-4.729^{* *} \\
(2.018)\end{array}$ & $\begin{array}{c}7.183 \\
(6.374)\end{array}$ & $\begin{array}{c}1.403^{* *} \\
(0.508)\end{array}$ & $\begin{array}{c}-5.244^{* *} \\
(2.512)\end{array}$ & $\begin{array}{c}5.924 \\
(6.262)\end{array}$ & $\begin{array}{c}-5.608^{* *} \\
(2.369)\end{array}$ & $\begin{array}{c}-3.300^{* *} \\
(1.247)\end{array}$ & $\begin{array}{c}-5.267^{* *} \\
(2.042)\end{array}$ \\
\hline $\log (L)_{t-2}$ & & $\begin{array}{l}-0.049 \\
(0.038)\end{array}$ & $\begin{array}{l}-0.017 \\
(0.162)\end{array}$ & & $\begin{array}{l}-0.053 \\
(0.035)\end{array}$ & $\begin{array}{l}-0.027 \\
(0.162)\end{array}$ & $\begin{array}{l}-0.111 \\
(0.189)\end{array}$ & $\begin{array}{l}-0.036 \\
(0.024)\end{array}$ & $\begin{array}{l}-0.057 \\
(0.034)\end{array}$ \\
\hline Shock $_{t-2} \times \log (L)_{t-2}$ & & $\begin{array}{l}1.737^{* *} \\
(0.637)\end{array}$ & $\begin{array}{l}-5.955 \\
(4.605)\end{array}$ & & $\begin{array}{l}2.003^{* *} \\
(0.819)\end{array}$ & $\begin{array}{l}-5.203 \\
(4.526)\end{array}$ & $\begin{array}{c}2.139^{* *} \\
(0.798)\end{array}$ & $\begin{array}{c}1.211^{* * *} \\
(0.440)\end{array}$ & $\begin{array}{c}2.007^{* * *} \\
(0.661)\end{array}$ \\
\hline $\log (L)_{t-2}^{2}$ & & & $\begin{array}{l}-0.005 \\
(0.029)\end{array}$ & & & $\begin{array}{l}-0.005 \\
(0.029)\end{array}$ & & & \\
\hline Shock $_{t-2} \times \log (L)_{t-2}^{2}$ & & & $\begin{array}{c}1.162 \\
(0.759)\end{array}$ & & & $\begin{array}{c}1.085 \\
(0.749)\end{array}$ & & & \\
\hline$\Delta \log (L)_{t-2}$ & & & & & & & & & $\begin{array}{c}0.050 \\
(0.225) \\
\end{array}$ \\
\hline \multicolumn{10}{|l|}{$\underline{\text { Fixed Effects }}$} \\
\hline $\begin{array}{l}\text { Sector } \times \text { Year } \\
\text { Firm }\end{array}$ & $\checkmark$ & $\checkmark$ & $\checkmark$ & $\checkmark$ & $\checkmark$ & $\checkmark$ & $\begin{array}{l}\checkmark \\
\checkmark\end{array}$ & $\checkmark$ & $\checkmark$ \\
\hline Number Obs. & 142,474 & 142,474 & 142,474 & 142,474 & 142,474 & 142,474 & 140,989 & 330,063 & 142,393 \\
\hline
\end{tabular}

exogenous export shock are significantly more likely to increase their innovative activity. The coefficient implies that a $10 \%$ increase in market size increases patents by about $1.1 \%$. Column (2) includes a control for the lagged level of $\log$ (employment) and also its interaction with the shock. The interaction coefficient is positive and significant, indicating that there is a general tendency for larger firms to respond more to the shock than smaller firms. Although it is not of direct interest, this is what we should expect given our discussion in 2.5. Column (3) generalizes this specification by adding in a quadratic term in lagged employment and its interaction with the shock.

Column (4) of Table 2 returns to the simpler specification of column (1) and includes a dummy for whether the firm's employment is just below the regulatory threshold in the 45-49 employees range (defined as $l^{\star}$ ) at $t-2$, and the interaction of this dummy with the shock. Our key coefficient is on this interaction term, and it is clearly negative and significant as our model implies. This is one of our key results: innovation in firms just below the regulatory threshold is significantly less likely to respond to positive demand opportunities than in firms further away from the threshold. Our interpretation is that when a firm gets close to the employment threshold, it faces a large "growth tax" due to the regulatory cost of becoming larger than 50 
Figure 6: Marginal effect of a market size shock on innovation

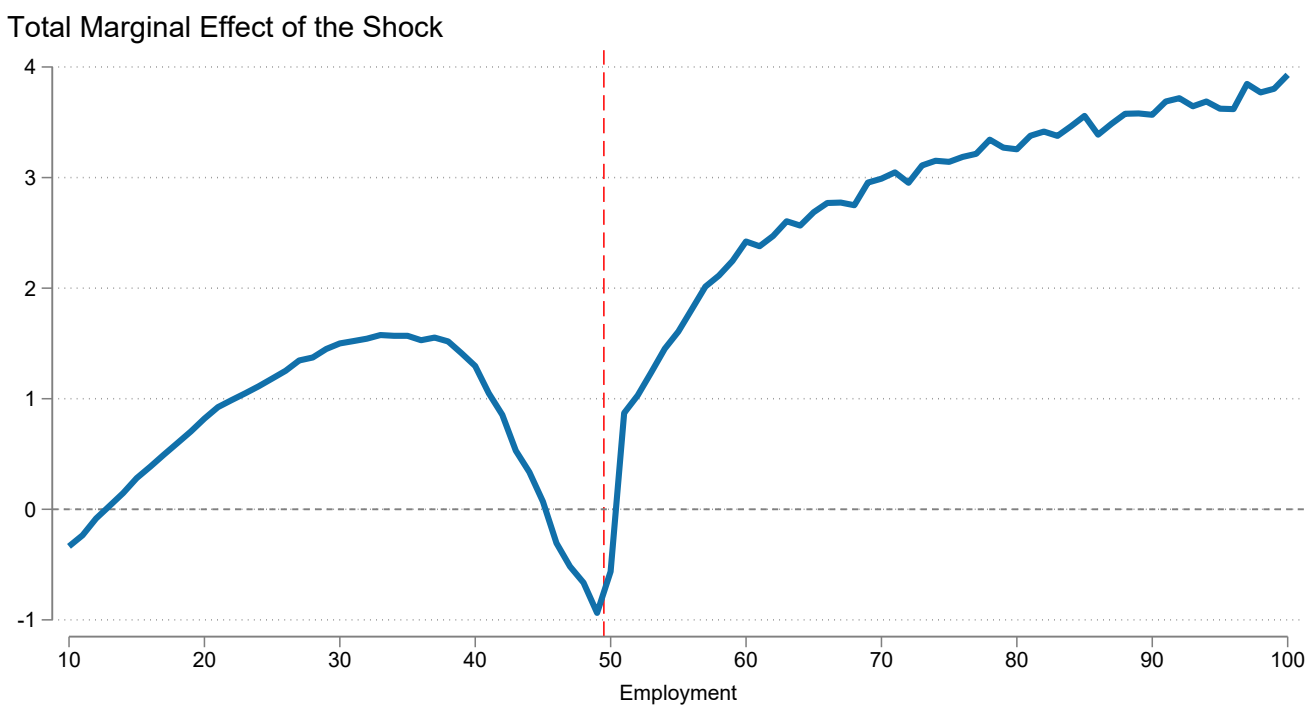

Notes: marginal effect of a shock at $t-2$ at different level of employment at $t$, based on the model in column 5 of Table 2 .

employees. Consequently, such a firm will be more reluctant to invest in innovation in response to this new demand opportunity. The firm might even simply cut its innovative activities altogether to avoid the risk of crossing the threshold. We depict the relationship between innovation and the shock in Figure 6. The figure plots the implied marginal effect of the market size shock on innovation (at $t-2$ ) for different firm sizes (at $t$ ) using the coefficients in column (5) of Table 2. We see that innovation in larger firms tends to respond more positively to the market size shock than in smaller firms, but at the regulatory threshold there is a sharp fall in the marginal effect of the demand shock, consistent with our model (e.g. see subsection 2.5).

It might be the case that the negative interaction between the threshold and the shock could be due to some omitted non-linearities. Hence in column (5) we also include lagged employment and its interaction with the shock (as in column (2)). These do have explanatory power, but our key interaction coefficient remains significant and negative and we treat this as our preferred specification. Column (6) adds a quadratic employment term and its interaction following column (3). Our key interaction remains significant and these additional non-linearities are insignificant.

\subsubsection{Robustness of the dynamic empirical model}

We have subjected our results to a large number of robustness tests, many of which are detailed in Appendix D. Column (7) of Table 2 shows the results from a tough robustness test where we 
include a full set of firm dummies. Given that the regression equation is already specified in first differences, this amounts to allowing firm-specific time trends. The key interaction between the market size shock and the threshold dummy remains significant. The data sample underlying Table 2 is limited to manufacturing firms, so column (8) also adds in non-manufacturing firms. The relationship remains negative, though with a smaller coefficient. This is likely to be due to the fact that patents are a much more noisy measure of innovation in non-manufacturing firms. We also experimented with including manufacturing firms who do not export by using the industry-level equivalent of our market size shock in equation (8). The coefficient on the key interaction remained negative and significant in column (6) of Table D2.

Does the number of patents grow more slowly for firms to the left of the threshold who experience a demand shock simply because their employment grows by less? Column (9) of Table 2 provides a crude test of this hypothesis by including the growth of employment on the right hand side of the regression. This variable is endogenous, of course, yet it is interesting to observe from a purely descriptive viewpoint that the interaction between the market size shock and the threshold remains significant. This suggests that it is patenting per worker, which is reacting negatively to the interaction between the shock and the threshold: our effect on patenting is not simply reflecting differential changes in firm size.

\section{The aggregate effects of regulation on Innovation}

So far, we have established that many of the qualitative predictions of our simple model are consistent with the data both from a cross-sectional analysis and a more challenging dynamic analysis of the response to shocks. In this section, we use the data, the structure of our theoretical model and some external calibration values to estimate the general equilibrium effects of the regulation on aggregate innovation and welfare. This clearly requires stronger assumptions as we are extrapolating well away from the threshold. ${ }^{26}$ Our baseline approach uses static moments from the non-parametric analysis covering the whole private sector. But in an extension we consider using the dynamic estimates from the exporting manufacturing sub-sample to calibrate the implicit cost of the regulatory tax.

\footnotetext{
${ }^{26} \mathrm{~A}$ very conservative approach would then be to say we calculate aggregate losses for the sub-sector of the economy with firms under 100 employees (just under $50 \%$ of all jobs are in such firms in France). However, Appendix D shows that our findings are robust to extending the sample to include firms of up to 250,500 or even 1,000 employees. Given this, we feel that labelling our estimates as "macro-economic" is reasonable.
} 


\subsection{Quantitative Strategy}

We sketch some of the important elements here. The threshold number of product lines, $\bar{n}$, can be calculated from the known regulatory employment threshold of 50, i.e. $\bar{n}=50 \omega \gamma$ (see equation (3)), so we have six unknown parameters: $(\eta, \omega, \gamma, \beta, \zeta, \tau)$. Since we only need the ratio $\beta / \zeta$ to calculate the aggregate innovation loss, we only need to quantify five parameters $(\eta, \omega, \gamma, \beta / \zeta, \tau)$. We use the existing literature to obtain two of them $(\eta$ and $\gamma)$ and the remaining three are chosen to match moments from the data as detailed in Table 3.

Table 3: Calibration values and moments

\begin{tabular}{|c|c|c|c|}
\hline Parameter & Value & Name & Source \\
\hline \multicolumn{4}{|c|}{ From the literature } \\
\hline$\eta$ & 1.5 & Concavity of Innovation cost function & Dechezlepretre et al. (2016) \\
\hline$\gamma$ & 1.3 & Productivity step size & Aghion et al. (2019a) \\
\hline \multicolumn{4}{|c|}{ Using our data } \\
\hline$\tau$ & 0.0263 & Regulatory tax & Innovation-Firm size relationship $\left(\hat{\beta_{1}}, \hat{\beta_{2}}\right)$ \\
\hline$\beta / \zeta$ & 1.66 & Discount factor/scale parameter & Long-term growth of GDP \\
\hline$\omega$ & 0.22 & Output adjusted wage & Gap in the firm size distribution \\
\hline
\end{tabular}

Notes: Long-term growth of GDP is taken from the national accounts and corresponds to the average growth between 1990 and 2019 . The gap in the first size distribution is estimated by dividing the number of firms at 45 employees by the number of firms of size 50 in 2000 and is equal to 3.03 . See Figure D1.

Concavity of the $\mathbf{R} \& \mathbf{D}$ cost function $\eta \quad$ In order to calibrate the concavity of the $R \& D$ cost function, $\eta$, we draw upon existing work that has estimated the innovation production function (the relationship between patents and R\&D). Acemoglu et al. (2018) use a value of $\eta=2$ based on Blundell et al. (2002). However, these estimates typically come from very large US firms (publicly listed companies from Compustat), so may exaggerate $\eta$, which is likely to be lower for the small and medium sized enterprises that are the vast bulk of our sample. ${ }^{27}$ The estimates of Dechezlepretre et al. (2016) look at firms of similar sizes to the ones we use here, suggest a value of $\eta=1.5$, using their Regression Discontinuity Design, which should produce cleaner causal estimates of the impact of $R \& D$ on innovation. This value is also consistent with some of the estimates in Crépon and Duguet (1997) on French firm panel data.

Regulatory $\operatorname{tax} \tau$ To quantify the regulatory $\operatorname{tax}(\tau)$, we estimate empirically the changing slope of the relationship between innovation and firm size from equation (4). Our theory implies

\footnotetext{
${ }^{27}$ Labelling the estimated elasticity between patents and $\mathrm{R} \& \mathrm{D}$ as $\theta, \eta=1 / \theta$. Since $\theta$ is likely larger for small firms (e.g. due to financial constraints) or in countries with less developed risk capital markets (e.g. France vs. the US) this implies a smaller $\eta$.
} 
that the ratio of the innovation-size slope for small firms (before the innovation valley) to large firms (to the right of the regulatory threshold) should be equal to $(1-\tau)^{\frac{1}{\eta-1}}$. In other words, for any given value of $\eta$, a larger tax will mean a greater flattening of the positive relationship between innovation and firm size. Figure 5 shows this flattening very clearly and we recover this through a simple regression of patents on lagged size for firms under 45 employees and firms firms over 50 employees (to abstract from the innovation valley), allowing the coefficient on size to be different for these two size groups. Empirically, we average the number of patent applications filed by a firm over a five-year window for each possible value of employment $l$ between 10 and 100. Our baseline estimation uses the same mapping between $Z$ and patents as in Section 3, i.e. we measure $Z$ using the logarithm of the number of patents. We then jointly estimate two slopes for $L \in[10 ; 45)$ and $L \in[50 ; 100]$. We respectively denote $\hat{\beta}_{1}$ and $\hat{\beta}_{2}$ the OLS estimate of these two slopes. We find $\hat{\beta}_{1} / 1000=0.1804$ with a standard error $\left(\hat{\sigma}_{1} / 1000\right)$ of 0.0105 and $\hat{\beta}_{2} / 1000=0.1709$ with a standard error $\left(\hat{\sigma}_{2} / 1000\right)$ of 0.00381 . Hence, according to our model we have:

$$
\frac{\hat{\beta}_{2}}{\hat{\beta}_{1}}=(1-\tau)^{\frac{1}{\eta-1}}=0.947
$$

Given the calibrated value of $\eta=1.5$ this yields an estimate of $\tau=0.0263$, a regulatory tax of 2.63 percent. There are several ways to estimate this slope and we discuss the sensitivity to the choice of alternative empirical models extensively in Appendix D.4. Alternative models generate implicit taxes in the range of $1 \%$ to $5 \%$, so we are effectively choosing a calibration value just below the midpoint of this range.

Step size $\gamma$ The productivity step size $\gamma$ following innovation is set to 1.3 using based on estimates in Aghion et al. (2019a). This is derived from various estimates of the average markup, which in our model is the reward from innovation.

Productivity adjusted wage rate $\omega$ A larger $\omega$ means a higher cost of labor and therefore a smaller mass of large firms. Therefore to set the value of $\omega$, we use the empirical firm size distribution. In particular, we match the fall in the density of employment of smaller vs. larger firms to the left and right of the innovation valley. In our data there are about three times as many firms between 40 and 45 employees than between 50 and 55 and the value of $\omega$ that reproduces this gap is 0.22 . 
Scale parameter and discount factor $\beta / \zeta$ We calibrate $\beta / \zeta$ in order to match the measured value of $g$ in the data that we take to be equal to the average growth of GDP in France over the period 1990-2019 (1.62\%). In our model, growth $g$ is defined as follow:

$$
g=\exp \left(\left[z_{e}+\sum_{i=1}^{N} \mu(i) z(i) i\right] \log (\gamma)\right)-1
$$

This yields a value of $\beta / \zeta$ of 1.66 .

\subsection{Results}

\subsubsection{Measuring and Decomposing Innovation Losses: Baseline Estimates}

Plugging in these quantitative estimates of the key parameters implies a loss of aggregate innovation of about $5.8 \%$ percent compared to the no regulation benchmark (see the first row of Table 3). The implied regulatory tax of $\tau=0.0263$, is the key parameter as can be seen from Figure 4. Since this maps back into growth rates, it means that the steady state growth rate in France would rise from its current average annual rate of $1.62 \%$ to $1.72 \%$, a nontrivial change. As discussed in the modeling section, the aggregate innovation loss is driven by three major elements:

1. The decline in the incumbent innovation rate $(z(n))$ for a given firm size. For any given size distribution of firms, the regulation reduces innovation rates for firms above the threshold and just to the left of the threshold.

2. The change in the size distribution $\mu$. Since the regulation pushes the size distribution to the left and smaller firms do less innovation, this reduces aggregate innovation.

3. The decline in the innovation rate by entrants $z_{e}$.

Recall that we have denoted $\mathcal{Z}(\tau)=\sum_{i=1}^{\infty} \mu(i) z(i) i+z_{e}$ total innovation in the economy when the regulation tax is set to $\tau$ and the value of other variables are taken from Table 3 . Analogously to a shift-share decomposition analysis we have: 


$$
\begin{aligned}
\mathcal{Z}(\tau)-\mathcal{Z}(0) & =\sum_{n>0}(Z(n, \tau)-Z(n, 0)) \mu(n, 0) \\
& +\sum_{n>0}(\mu(n, \tau)-\mu(n, 0)) Z(n, 0) \\
& +\sum_{n>0}(\mu(n, \tau)-\mu(n, 0))(Z(n, \tau)-Z(n, 0)) \\
& +z_{e}(\tau)-z_{e}(0),
\end{aligned}
$$

where $\mu(n, \tau)$ and $Z(n, \tau)$ are the share of firm of size $n$ where the economy has a regulation tax of $\tau$ and their total innovation respectively. The first term in the right hand side of equation (10) is the innovation intensity (evaluated at the size distribution in the unregulated economy) and the second term is the effect on size (evaluated at a firm's innovation intensity rate in the unregulated economy). The third term is the interaction effect between the first two terms and the final term is the effect on entrants (since an entrant must innovate by definition to displace an incumbent).

Dividing equation $(10)$ by $\mathcal{Z}(0)$, we can have an approximation of where the $5.8 \%$ loss of aggregate innovation comes from. We find that most (80\%) of the effect comes from the change in the innovation intensity (the first term in the right hand side of the previous equation). The covariance and entry terms (third and last terms) account for roughly $10 \%$ each, while the change in the size distribution has almost no effect. The virtual absence of any effect of the size distribution is due to the relatively small value of the tax.

\subsubsection{Robustness of the Baseline Aggregate Calculations}

We now explore how the $5.8 \%$ loss in innovation is affected when we consider variations in the parameters from Table 3. In Table 4, we consider the effect of changes in $\eta, \gamma, \omega, \tau$ and $\beta / \zeta$. With respect to $\eta$, we consider the range interval $\eta \in[1.3,2]$ to reflect the variety of values found in the literature (see above). With respect to $\gamma$, we explore values from 1.2 to 1.5. A value of 1.5 corresponds to a labor share of $66 \%$ in our model. ${ }^{28} \operatorname{Regarding} \omega$, and $\beta / \zeta$, we consider a relative change of $15 \%$ (upward and downward) .

\footnotetext{
${ }^{28}$ In a wide class of models the ratio of price to marginal cost (the markup) is equal to the output elasticity with respect to a variable factor of production divided by the variables factor's share of revenue (e.g. De Loecker et al., 2020; Hall, 1988). Since labor is the only factor in our model, the markup is simply the reciprocal of the labor share. Aghion et al. (2019a) use a a US labor share of GDP of $77 \%$ to obtain $\gamma=1.3$. The French labor share after 1995 is more like $65 \%$ (see e.g. Cette et al., 2019), suggesting $\gamma=1.5$. These values encompass most of the other estimates of the aggregate markup using other methods.
} 
Table 4: Sensitivity analysis

Robustness

Loss in total innovation

Panel A: Baseline (full sample)

$5.79 \%$

1. $\gamma=1.2$

$5.77 \%$

2. $\gamma=1.50$

$5.82 \%$

3. $\eta=2$

$2.89 \%$

4. $\eta=1.3$

$9.23 \%$

5. $\omega=0.19$

$5.74 \%$

6. $\omega=0.25$

$5.81 \%$

7. $\beta / \zeta=1.40$

$5.79 \%$

8. $\beta / \zeta=1.90$

$5.78 \%$

9. $\tau$

Percentile $75^{\text {th }}(\tau=0.046)$

$10.53 \%$

Percentile $25^{t h}(\tau=0.006)$

$1.28 \%$

Panel B: Sub-sample of Exporting manufacturing firms

10. Static estimation $(\tau=0.062)$

11. Using dynamic model $(\tau=0.060)$

$14.20 \%$

Notes: baseline uses parameter values: $(\eta=1.5, \gamma=1.3, \tau=0.026, \beta / \zeta=1.66$ and $\omega=0.22)$, see Table 3 . In the robustness where $\gamma, \eta, \omega$ or $\beta / \zeta$ are changed, we keep $\tau$ as in the baseline. Line 9 reports the $25^{t h}$ and $75^{t h}$ percentile for the loss of innovation in a sample computed from 100,000 independent draws of $\tau$ from two normal distribution. The corresponding value of $\tau$ and $\beta / \zeta$ are computed as an average for each percentile. Lines 10-11 report the loss in total innovation when the sample is restricted to exporting manufacturing firms and Line 11 assumes a value of $\tau$ as computed using the alternative calibration presented in Section 4.2.3.

Given that $\tau$ has been calculated using estimates of the slopes of the cross-sectional innovationsize relationship, we use our estimates of $\beta_{1}$ and $\beta_{2}$ to derive confidence intervals for $\tau$. Specifically, we draw 100,000 values of $\beta_{1}$ and $\beta_{2}$ from two independent normal distribution $\mathcal{N}\left(\hat{\beta_{1}}, \hat{\sigma_{1}}\right)$ and $\mathcal{N}\left(\hat{\beta}_{2}, \hat{\sigma}_{2}\right)$, where $\hat{\beta}_{i}$ and $\hat{\sigma}_{i}$ respectively designate the point estimates and corresponding standard errors. For each of these 100,000 draws, we compute a value for $\tau$ and infer the loss in total innovation by running the model.

The results from this exercise can be found in Panel A of Table 4. As we would expect, the most important parameter is the regulatory tax, $\tau$. From the values of $\beta_{1}$ and $\beta_{2}$, the loss is $10.5 \%$ for the $75^{\text {th }}$ percentile of the distribution and $1.3 \%$ for at the $25^{\text {th }}$ percentile (the median is the same as the baseline: $5.8 \%$ ). Interestingly, $\eta$ also matters: as the parameter moves from 1.3 to 2 , the aggregate innovation losses falls from $9.2 \%$ to $2.9 \%$. This is because changing $\eta$ determines the elasticity of innovation with respect to R\&D: as $\eta$ increases, the impact of R\&D on innovation decreases. Since the impact of the tax comes from reducing the incentive to do R\&D to grow, if R\&D has little effect on growth there will be little impact of the tax. Hence, increasing $\eta$ makes total innovation less sensitive to changes in $\tau$. 
By contrast, the loss in total innovation is only modestly affected by changes in $\gamma, \omega$ and $\beta / \zeta$. This is because the tax elasticity of $z$ (equal to $\frac{d z}{d(1-\tau)} \frac{1-\tau}{z}$ ) only depends upon $\eta$, not on $\omega, \gamma$ or $\beta / \zeta$. From equation (4), we see that the elasticity of innovation with respect to the regulatory tax is $\frac{1}{\eta-1}$ for large firms. Hence, changing the values of $\omega, \gamma$ and $\beta / \zeta$ only affects total innovation loss through their effects on the firm size distribution and on entry, which we know from the previous subsection plays a relatively minor quantitative role. ${ }^{29}$

\subsubsection{Alternative calibration using the dynamic econometric analysis to estimate the implicit regulatory tax}

Given the importance of the implicit tax for the overall impact of the regulation, we also considered estimating $\tau$ using the dynamic moments from the responsiveness to shocks rather than the static moments of the innovation-size relationship. An advantage of this approach is that it uses a better identified estimate using exogenous variation. A disadvantage is that whereas the static moment is across the whole economy, this dynamic moment is solely from the sub-sample of manufacturing firms who export (where we could construct the exogenous shifter). Re-estimating the regulatory tax using the static method from our baseline in row 1 of Table 4 in Panel B (row 10) shows that the implied $\tau=0.0623$ in this sub-sample which is associated with a $14.7 \%$ fall in innovation. This is much larger than in the whole economy because trading manufacturing firms have a much higher level of innovation, so the cost of the regulation will be much more important.

The dynamic estimation of $\tau$ relies on the fact that after a shock $\varepsilon$, innovation of a firm of size $n \neq \bar{n}-1$ will be:

$$
\Delta Z(n, \varepsilon)=\left(\frac{\beta \pi(n)}{\zeta \eta}\right)^{\frac{1}{\eta-1}} \omega \gamma l(n)\left((1+\varepsilon)^{\frac{1}{\eta-1}}-1\right)
$$

This implies that we can calculate the cross partial of the demand shock for firms of size $n<\bar{n}$ as:

$$
\frac{\partial^{2} \Delta Z(n, \varepsilon)}{\partial \varepsilon \partial l} \propto(1+\varepsilon)^{\frac{2-\eta}{\eta-1}} \frac{1}{\eta-1}
$$

Similarly the cross partial for for firms of size $n \geq \bar{n}$ is:

$$
\frac{\partial^{2} \Delta Z(n, \varepsilon)}{\partial \varepsilon \partial l} \propto(1+\varepsilon)^{\frac{2-\eta}{\eta-1}} \frac{1}{\eta-1}(1-\tau)^{\frac{1}{\eta-1}}
$$

\footnotetext{
${ }^{29}$ For example, as already noted a higher $\omega$ reduces the relative numbers of large firms. Since there are more firms just to the left of the regulatory threshold (whose innovation is most affected by the regulation), this makes the marginal impact of the tax slightly larger.
} 
We estimate the value of $\frac{\partial^{2} \Delta Z(n, \varepsilon)}{\partial \varepsilon \partial l}$ using the procedure in Section 3.3. Specifically, we estimate:

$$
\begin{aligned}
\Delta Z(n, \varepsilon)_{i, t}= & c_{1} l_{i, t-2}+c_{2}\left[\mathbb{1}\left(l_{i, t-2} \geq \bar{l}\right) * l_{i, t-2}\right]+c_{3} \mathbb{1}\left(l_{i, t-2} \geq \bar{l}\right) \\
& +c_{4}\left[\mathbb{1}\left(l_{i, t-2} \geq \bar{l}\right) * l_{i, t-2} * \Delta S_{i, t-2}\right]+c_{5}\left[\mathbb{1}\left(l_{i, t-2}<\bar{l}\right) * l_{i, t-2} * \Delta S_{i, t-2}\right] \\
& +c_{6} \Delta S_{i, t-2}+\epsilon_{i, t} .
\end{aligned}
$$

where $\mathbb{1}\left(l_{i, t-2} \geq \bar{l}\right)$ is an indicator function for employment being larger than the threshold value 50. As in our baseline dynamic estimation in Section 3.3, we measure $Z_{i, t}$ with $\log$ (patents), approximate the change by $\tilde{\Delta} Y_{i, t}$ and use employment and the shock at $t-2$. Details are given in Appendix D.4. Finally, we assume that $\Delta S$ is equal to the demand shock $\varepsilon .^{30}$ We then have:

$$
c=\frac{c_{5}}{c_{4}}=\frac{\mathbb{E}\left[(1+\varepsilon)^{\frac{2-\eta}{\eta-1}} \mid l \geq \bar{l}\right](1-\tau)^{\frac{1}{\eta-1}}}{\mathbb{E}\left[(1+\varepsilon)^{\frac{2-\eta}{\eta-1}} \mid l<\bar{l}\right]}
$$

where $\mathbb{E}$ is the expectations operator and is estimated using the unweighted mean from firm-year observation in the data.

We can recover $\tau$ using equation (12). Note that equation (12) is similar in form to (9) as both equations indicate how the responsiveness of large firms relative to small firms falls when the cost of regulation is higher. The expectations terms on the right hand side of equation (12) are simply adjusting the ratio to reflect the possibility that the average demand shocks hitting large firms could be different than those hitting smaller firms.

We retrieve $c$ from $c_{4}$ and $c_{5}$ through an OLS estimation of equation (11). We add sectoryear fixed effects and remove observations corresponding to firms that have a value of $l_{i, t-2}$ between 45 and 49 (as we did in the static version). We replace the expectations by their empirical counterparts and use the value of $\eta$ from Table 3. This yields a value of $\tau=0.060$ shown in row 11 of Table 4. This is extremely close to the static estimation of $\tau$ on the same sample shown in the previous row (0.062). Again, this implies a large decline of innovation

\footnotetext{
${ }^{30}$ We also considered an alternative approach using the fact that the theoretical elasticity of a demand shock to employment is 1 . Consequently, the coefficient of a regression of $\Delta l$ on $\Delta S$, gives the link between $\varepsilon$ and $\Delta S$. In practice, this made no material difference to our estimate of $\tau$.
} 
in this sub-sector, but confirms a very similar estimate whether we use a static or dynamic moment.

In Appendix D.4, we also discuss several alternative dynamic estimations of $\tau$. For example, we look at (1) restricting the sample to firms that are closer to the threshold to have a set of more comparable observations and (2) use the observations in the innovation valley and their theoretical innovation response to a shock to infer a value of $\tau$. In all our cases, we estimate very similar estimates of the regulatory implicit tax to our dynamic baseline of $6 \%$.

\subsection{Welfare}

Innovation increases growth which is a benefit to welfare, but it must also be paid for by diverting current consumption into R\&D investments. In Schumpeterian growth models, the impact of a reduction in innovation on welfare is theoretically ambiguous. Although positive knowledge externalities generate the traditional underinvestment in $R \& D$, the business stealing effect can generate too much investment. Which dominates in our setting? Using the utility of the representative agent in equation (1), $C_{t}$ is determined by the final good market clearing condition which states that each unit of final good that is produced should be used either for consumption $C_{t}$ or $R \& D$. Recall that to produce an innovation intensity of $Z=n z$, a firm must spend $\zeta n z^{\eta}$ units of final good. We therefore have the following identity:

$$
Y_{t}=C_{t}+\sum_{i \geq 1} \zeta \mu(i) i z(i)^{\eta} Y_{t}
$$

i.e. we take away R\&D expenditures (there are $\mu(i)$ firms of size $i$ ) from the final good $Y_{t}$, and the residual is consumed. Denoting aggregate $\mathrm{R} \& \mathrm{D} R \equiv \sum_{i \geq 1} \zeta \mu(i) i z(i)^{\eta}$ and plugging this into the utility function yields:

$$
U=\sum_{t>0} \beta^{t} \log \left(Y_{0}(1+g)^{t}(1-R)\right)
$$

which can be rewritten:

$$
U=\frac{\log \left(Y_{0}\right)}{1-\beta}+\frac{\log (1+g) \beta}{(1-\beta)^{2}}+\frac{\log (1-R)}{1-\beta}
$$

Since growth is $g=\left(z_{e}+\sum_{i \geq 1} i z(i) \mu(i)\right) \log (\gamma)$ and using the definition of $R$, we can compute total utility for any value of $Y_{0}$ using vectors $z$ and $\mu$ and the value of $z_{e}$.

We define $g(\tau), R(\tau)$ and $Y_{0}(\tau)$ the values of $g, R$ and $Y_{0}$ in an economy with a regulation level equal to $\tau$. Let $\Delta U \equiv U(\tau)-U(0)$, so 


$$
\Delta U=\log \left(\frac{1+g(\tau)}{1+g(0)}\right) \frac{\beta}{(1-\beta)^{2}}+\log \left(\frac{1-R(\tau)}{1-R(0)}\right) \frac{1}{1-\beta}+\log \left(\frac{Y_{0}(\tau)}{Y_{0}(0)}\right) \frac{1}{1-\beta},
$$

denotes the difference in utility between an economy with regulation $\tau$ and an economy without regulation at the steady-state. The corresponding difference in terms of consumption equivalent is given by $\exp ((1-\beta) \Delta U)$. Initial production $Y_{0}$ is equal to initial quality times the amount of labor used in production. In our baseline model, the whole labor force is employed in production with and without the regulation, as R\&D does not require labor. ${ }^{31}$ Hence, abstracting from initial quality, the effect of the regulation on welfare is governed by the first two terms in the above equation.

The first term is negative since $g(\tau)<g(0)$ due to lower innovation, hence a welfare loss from introducing the regulation. The second term is positive $(R(\tau)<R(0))$ : the corresponding welfare gain stems from the fact that spending less on R\&D leaves more output for consumption. The third term, although complex to quantify without stronger assumptions, can clearly be signed as negative as it is the static (non-innovation related) welfare loss that has been the focus of previous work. Hence if the sum of the first two 'dynamic' terms are negative, this will be a lower bound to the welfare loss from regulation.

With our parameter values from Table 3 and a standard value of $\beta=0.96$, we can compute the difference in welfare in terms of the consumption equivalent. In our baseline regulated economy, welfare is $2.3 \%$ lower than in the unregulated economy. This must be added to the static efficiency losses which Garicano et al. (2016) estimated to be between $1.3 \%$ to $3.4 \%$. Hence the dynamic losses from lower innovation approximately double the conventional static losses.

Table D4 in Appendix D.4 shows the welfare losses under the various alternative assumptions on the calibration values. ${ }^{32}$

\footnotetext{
${ }^{31}$ This is no longer true if labor is used in production and in R\&D (see section 5.5). Then the tax regulation will affect $Y_{0}$ even controlling for initial quality as it will affect the fraction of labor used in production.

${ }^{32}$ Measuring welfare requires a separate estimation of $\beta$ and $\zeta$. The measure of welfare is obviously sensitive to the choice of $\beta$. Specifically, the welfare loss will increase as $\beta$ is closer to 1 as agent gives more weight to future consumption and therefore care more about growth. When $\beta=0.94$, welfare losses are $1.4 \%$ while when $\beta=0.98$, welfare loss is $4.8 \%$ (see Table D4 in Appendix D.4).
} 


\subsection{Summary on the Aggregate innovation effects of regulation}

The effects of regulation on aggregate innovation appear non-trivial. The losses are around 5.8\% in our baseline estimates and even more in traded manufacturing. Four-fifths of the losses come from a lower amount of innovation across all affected firms, with the residual fifth accounted for by lower entry and a leftwards shift of the firm size distribution. Our baseline results find a (lower bound) fall in welfare of $2.3 \%$ from these dynamic losses, approximately doubling the conventional static losses. This conclusion is consistent with the important findings of Konig et al. (2022) who also emphasise that losses from skewing innovation incentives may be much greater than the conventional static misallocation losses.

\section{The Nature of Innovation and Other Extensions}

Our baseline model focuses on the impact of regulation on the rate of innovation. But there are various ways in which regulations may affect the nature of innovation. In subsection 5.1, we consider an extension of our model which allows firms to invest simultaneously in two types of innovation: incremental or radical. After developing the theory we implement this empirically using two proxies for how radical a patent is: (i) a traditional future citations measure and (ii) a more novel machine learning algorithm based on the full text of the patent. Secondly, we also use textual patent analysis to measure automation as one response to the regulation may be to invest in labor saving innovations. Finally, we extend our analysis to allow for longer-lived owners and to consider R\&D as scientists.

\subsection{Radical versus incremental innovation}

Although regulation seems to discourage overall innovation, it may also alter the type of innovation. A firm just below the threshold has a reduced incentive to innovate, but it might be that if she does innovate she will "swing for the fence" by investing in radical innovation. Minor, incremental innovations that just push the firm over the threshold will be strongly discouraged by the regulation. We now formalize this intuition and then test whether it has any relevance in the data.

\subsubsection{Theory}

In our baseline model, firms could only increase their number of product lines by one line in each period. In this extension, we assume that firms can now choose between: (i) Investing in 
an incremental innovation which augments the firm's size by one additional product line and (ii) Investing in more radical innovation which is more costly but augments the firm's size by $k>1$ product lines. We now have four cases depending on the value for $n$ :

1. $n<\bar{n}-k$ in which case the firm is never taxed in period 2 .

2. $n<\bar{n}$ and $n \geq \bar{n}-k$ in which case the firm is taxed in period 2 only if it successfully innovated with a radical innovation.

3. $n=\bar{n}-1$ in which case the firm is taxed in period 2 if it innovates, regardless of the type of innovation.

4. $n \geq \bar{n}$ in which case the firm is taxed in period 1 and 2 (except if the firm is at $\bar{n}+1$ but this will not affect the firm's decision)

The firm therefore chooses $z$ and $u$ so as to maximize:

$$
\begin{aligned}
& n \pi(n)+\beta n z(n)((n+1) \pi(n+1)-n \pi(n))+\beta n u(n)((n+k) \pi(n+k)-n \pi(n)) \\
& +\beta n x((n-1) \pi(n-1)-n \pi(n))-n \zeta(z(n)+u(n))^{\eta}-n \alpha u(n)^{\eta},
\end{aligned}
$$

where $\alpha$ denotes the additional cost of radical innovation. In Appendix C, we solve formally for $u$ and $z$ and in particular derive the ratio of radical over total innovation that will be use to calibrate this model.

The steady-state firm size distribution is computed in exactly the same way as in the baseline model, except that the flow equation needs to be adjusted to account for radical innovation:

$n \mu(n)(u(n)+z(n)+x)=\mu(n-1) z(n-1)(n-1)+\mu(n+1) x(n+1)+\mu(n-k)(n-k) u(n-k)$,

with $u(n-k)$ implicitly set to 0 if $n<k$.

\subsubsection{Calibration and Solving the model}

The calibration in the model extension with two types of innovation can be done in a very similar way as in the baseline. For the additional parameters, we draw on the seminal work of Akcigit and Kerr (2018). Taking the first order condition implies:

$$
u(n)=\left(\frac{\beta}{\alpha \eta}[(n+k) \pi(n+k)-(n+1) \pi(n+1)]\right)^{\frac{1}{\eta-1}}
$$


and

$$
z(n)=\left(\frac{\beta}{\zeta \eta}[(n+1) \pi(n+1)-n \pi(n)]\right)^{\frac{1}{\eta-1}}-\left(\frac{\beta}{\alpha \eta}[(n+k) \pi(n+k)-(n+1) \pi(n+1)]\right)^{\frac{1}{\eta-1}}
$$

In this model, the ratio of total innovation $u(n)+z(n)$ of small firms (producing less than $\bar{n}-k$ goods) over large firms is still equal to $(1-\tau)^{\frac{1}{\eta-1}}$ (see Table C1). The calibration strategy to estimate $\tau$ remains identical in this model, and its value will be the same.

Additionally for small firms, the share of radical innovation over total innovation $u(n) /(z(n)+$ $u(n))$ is equal to $\zeta / \alpha(k-1)$. In the data this ratio depends on our definition of a radical innovation. Our baseline approach is to proxy for radical innovation by selecting the top 10\% patents in each technology in terms of future citations. This is consistent with Akcigit and Kerr (2018) who estimate the probability of "major advance" to be equal to $10.3 \%{ }^{33}$ We continue to target the gap in the size distribution for $\omega$ and the long-run growth rate for $\beta / \zeta$. In theory, we could estimate $k$ using estimates of the differential step size of a radical vs incremental innovation (in our setting: $\gamma$ and $\gamma^{k}$ ). Drawing again on Akcigit and Kerr (2018) finding that "External innovations that open up a new technology cluster are estimated to have more than twice the potency of internal innovations." suggests a value of $k$ of around $4(3.6=(1+\log 2 / \log \gamma))$ : a successful radical innovation corresponds to a jump of 4 lines.

We solve the model numerically using these calibration values and plot the new firm size distribution compared to the unregulated economy $(\tau=0)$ in Figure C1 (Appendix C.2). This is qualitatively similar to the model without radical innovation.

In Figure 7(a) we look at how the levels of incremental and radical innovation varies with firm employment size and also plot the share of radical innovation over total innovation in Figure 7(b). This figure suggests that the discouraging effect of regulation is substantial for incremental innovation, but close to zero for radical innovations.

\subsubsection{Evidence I: Citations}

We first repeat the static analysis in Figure 8 using the quality of patents as the measure of innovation output. Measuring quality using the number of future citations. For each patent within a technology class by cohort-year we determine whether the patent was in the top $10 \%$ most cited patents or in the bottom 90\% (using future cites through to 2016). The two curves

\footnotetext{
${ }^{33}$ This is also consistent with Acemoglu et al. (2020) who also find a value between $7.8 \%$ and $13.9 \%$ (see their Table 6)
} 
Figure 7: Innovation for incremental and radical innovations

(a) Level

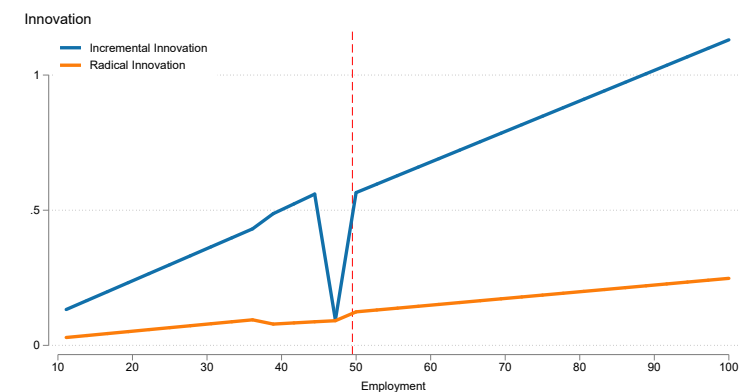

(b) Share

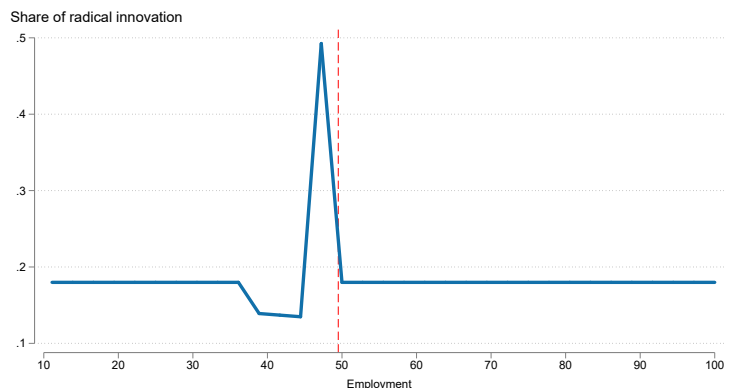

Notes: Left-hand side panel plots total incremental innovation $z(n) n$ (blue solid line) and total radical innovation $u(n) n$ (orange dashed line) for firms of $n$ lines against employment in the extension where firms can choose between two types of innovations. Right-hand side panel plots the ratio of radical over total innovation $u(n) /(z(n)+u(n))$. Parameters are chosen following the calibration strategy described in Section 5.1, see Table C2 in Appendix C.2.

in Figure 8 correspond to the fractions of firms in each employment size bin respectively with patents in the top $10 \%$ cited and with patents in the bottom $90 \%$ cited. We clearly see that the drop in patenting just below the regulatory threshold is barely visible for radical innovations. This is consistent with the idea that the regulation discourages low-value innovation but not higher value innovation. ${ }^{34}$ It is also clear from the figure that the innovation-size relationship is steeper for incremental innovation than for high-value innovation. This is consistent with smaller firms accounting for a higher share of more radical innovation (e.g. Akcigit and Kerr, 2018, on US data and Manso et al., 2019).

Next, we repeat our preferred dynamic specification of column (5) of Table 2, but now distinguish patents of different value using their future citations. Table 5 does this for patents in the top $10 \%, 15 \%$ and $25 \%$ of the citation distribution in the first three columns and the patents in the complementary sets in the last three columns (i.e. the bottom $75 \%, 85 \%$ and $90 \%$ of the citation distribution). We clearly see that the negative effect of regulation on innovation is only statistically and economically significant for low quality patents in columns (4), (5) and (6). There are no such significant effects for patents in the top decile or quartile of the patent quality distribution (the coefficient on the interaction is even positive in column (2)). ${ }^{35}$

To visualize these results, we plot the marginal effect of the demand shock on innovation by the level of firm employment in Figure 9. The blue line is the marginal effect of the shock on

\footnotetext{
${ }^{34}$ As for Figure 5, Figure 8 considers the innovation outcome over the whole period of observations. Variants around this can be found in Figure D3 in the Online Appendix D.

${ }^{35}$ We show the diminishing effect of the shock around the threshold for many other quantiles of the patent value distribution in five percentile intervals in Figure D4. This shows a clearly declining pattern.
} 
Figure 8: Share of innovative firms at each employment level and quality of innovation

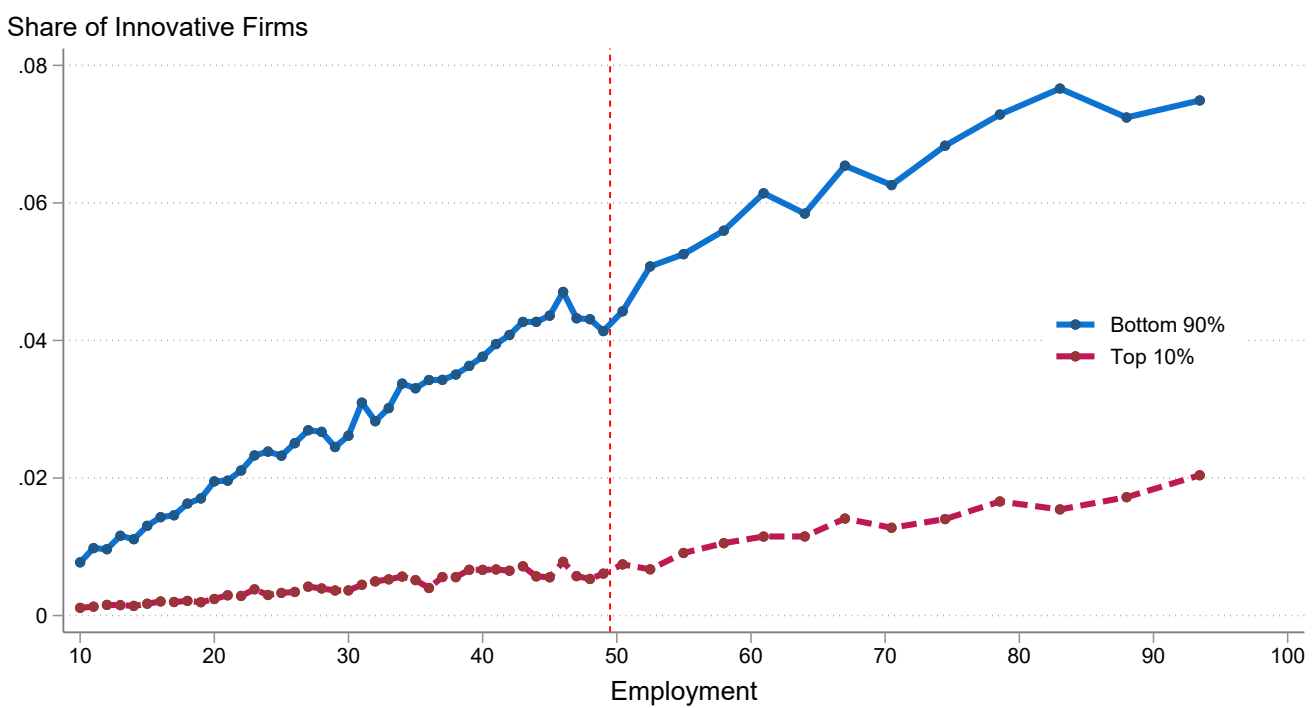

Notes: Share of firms with at least one priority patent in the top $10 \%$ most cited (dashed line) and the share of firms with at least one priority patent among the bottom $90 \%$ most cited in the year (solid line). All observations are pooled together. Employment bins have been aggregated so as to include at least 10,000 firms. The sample is based on all firms with initial employment between 10 and 100 (82,347 firms and 1,658,762 observations, see Panel A of Table 1).

Table 5: Regression results for different levels of the quality of innovation

\begin{tabular}{lcccccc}
\hline Quality & Top 10\% & Top 15\% & Top 25\% & Bottom 75\% & Bottom 85\% & Bottom 90\% \\
& $\mathbf{( 1 )}$ & $\mathbf{( 2 )}$ & $\mathbf{( 3 )}$ & $\mathbf{( 4 )}$ & $\mathbf{( 5 )}$ & $\mathbf{( 6 )}$ \\
\cline { 2 - 7 } Shock $_{t-2} \times L_{t-2}^{\star}$ & -0.208 & 0.689 & -0.824 & -4.733 & $-5.998^{* *}$ & $-6.141^{* *}$ \\
& $(0.847)$ & $(0.841)$ & $(0.935)$ & $(2.792)$ & $(2.679)$ & $(2.539)$ \\
$L_{t-2}^{\star}$ & -0.043 & -0.019 & -0.046 & 0.162 & 0.093 & 0.070 \\
& $(0.040)$ & $(0.068)$ & $(0.075)$ & $(0.124)$ & $(0.104)$ & $(0.109)$ \\
Shock $_{t-2}$ & -1.576 & -2.275 & $-5.606^{* *}$ & -1.808 & -3.870 & -3.707 \\
& $(1.083)$ & $(1.528)$ & $(2.099)$ & $(2.909)$ & $(2.501)$ & $(2.300)$ \\
$\log (L)_{t-2}$ & 0.017 & -0.010 & -0.042 & -0.018 & -0.044 & $-0.060^{*}$ \\
& $(0.015)$ & $(0.024)$ & $(0.031)$ & $(0.023)$ & $(0.034)$ & $(0.034)$ \\
Shock $k_{t-2} \times \log (L)_{t-2}$ & 0.529 & 0.735 & $1.796^{* *}$ & 0.913 & $1.526^{*}$ & $1.486^{*}$ \\
& $(0.338)$ & $(0.473)$ & $(0.667)$ & $(1.021)$ & $(0.856)$ & $(0.797)$ \\
Fixed Effects & & & & & & \\
Sector $\times$ Year & $\checkmark$ & $\checkmark$ & $\checkmark$ & $\checkmark$ & $\checkmark$ & $\checkmark$ \\
Number Obs. & 142,474 & 142,474 & 142,474 & 142,474 & 142,474 & 142,474 \\
\hline
\end{tabular}

Notes: estimation results of the same model as in column 5 of Table 2. The dependent variable is the Davis and Haltiwanger (1992) growth rate in the number of priority patent applications between $t-1$ and $t$, restricting to the top $10 \%$ most cited in the year (column 1 ), the top $15 \%$ most cited in the year (column 2), the top $25 \%$ most cited in the year (column 3 ), the bottom $85 \%$ most cited in the year (column 4), the bottom $75 \%$ most cited in the year (column 5) and the bottom $90 \%$ most cited in the year (column 6). All models include a 2-digit NACE sector interacted with a year fixed effect and a time fixed effect interacted with the initial level of export intensity. Estimation period: 1998-2007 . Standard errors are clustered at the 2-digit NACE sector level. ${ }^{* * *},{ }^{* *}$ and ${ }^{*}$ indicate p-value below $0.01,0.05$ and 0.1 respectively.

patents in the bottom $90 \%$ of the quality distribution based on column (6) of Table 5. Overall, the impact of the shock is positive and larger for bigger firms. However, when we approach the regulatory threshold at 50, this relationship breaks down and the marginal effect of the shock falls precipitously (and actually becomes negative). The orange line plots the marginal effect 
Figure 9: Total marginal effect of a shock

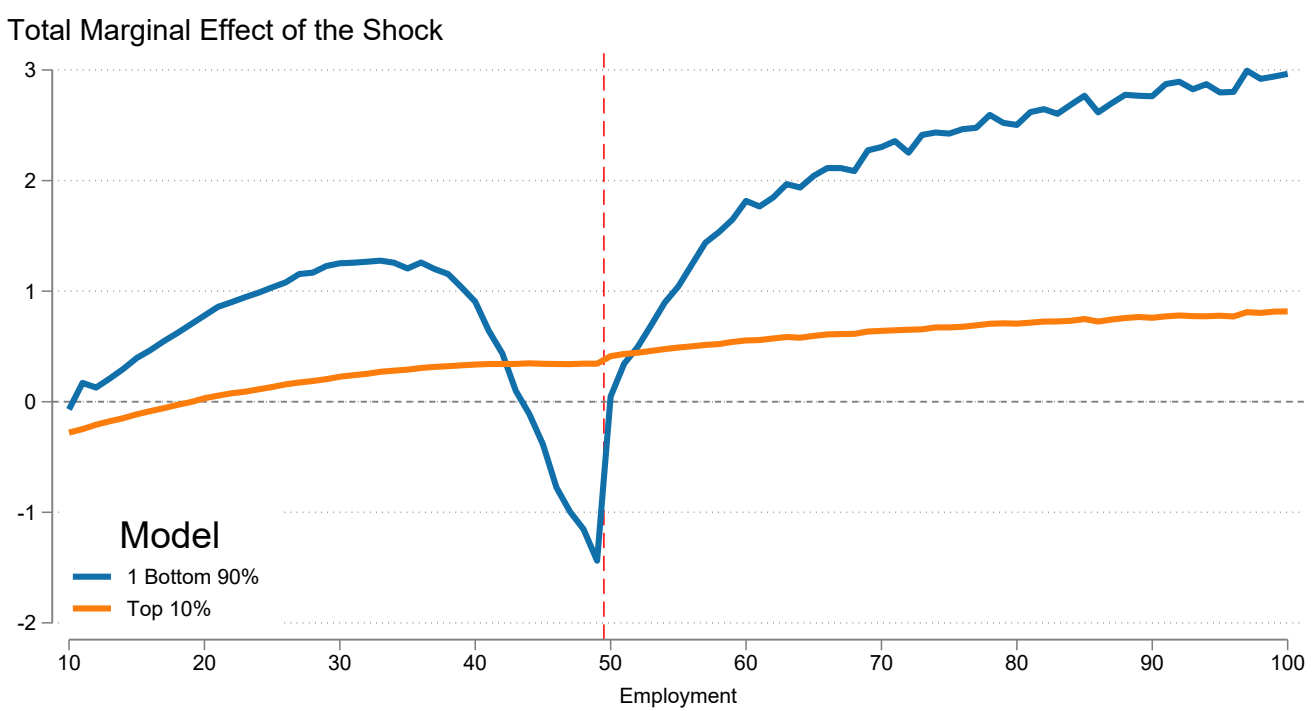

Notes: marginal effect of a shock at different level of employment, based on the model in column 1 and 6 of Table 5 . Marginal effect is calculated on top $10 \%$ and bottom $90 \%$ most cited patents.

of the demand shock on high quality patents in the top decile of the citation distribution from column (1) of Table 5. This line is also positive for almost all firms and rises with firm size. By contrast, with low-value patents, there is no evidence of any sharp downturn just below the regulatory threshold. ${ }^{36}$

In short, there seems to be evidence that the chilling effect of regulation on innovation is not an issue for radical innovation and is instead confined to incremental patents, which is broadly consistent with the generalization of the model we developed for two types of R\&D.

\subsubsection{Evidence II: Patent text measures of novelty}

We construct an alternative measure of radical innovation that is made to reflect the level of novelty of a patent using the text describing the patent (in the abstract and main body). We follow Kelly et al. (2018) who build an index of novelty by looking at how much the text of a given patent differs from the current state of knowledge in the technological classes using machine learning text-to-data techniques. This measure has been shown to capture features missed by citation-based indicators (see Bergeaud et al., 2017 for a review). For example, using many detailed industry case studies, the novelty measure has been shown to better reflect breakthrough technologies than citations (or other originality measures).

\footnotetext{
${ }^{36}$ The stronger relationship between demand growth and incremental (rather than radical) innovation is consistent with the earlier cross-sectional Figure 8 and also Manso et al. (2019).
} 
To implement this method we exploit the work of Google Patent (GP) who recently released a quantitative description of every patent (or embedding representation see Srebrovic, 2019 for details). GP embeddings use artificial intelligence analysis of text to summarize the most important features of the patent text into a vector of 64 numbers bounded between -1 and 1 . We can then calculate the "distance" between any pair of patents by simply taking the dot product between the two vectors. Full details are provided in Appendix D.5, but the basic idea is that we calculate novelty by computing the distance between a patent and a reference point from past patents in the same technological field. A more novel patent will use words that are further away from the current state of the art as indexed by the typical descriptions of patents.

We replicate all the analyses of the previous subsection on citations using this new measure in Appendix D and find broadly similar results. Note that this is not because the two measures are almost identical: the correlation between the two measures (cites vs. novelty) is only 0.1. First, in Figure D6, we show that the cross-sectional patterns show no innovation valley or a falling the innovation-size gradient at 50 employees for novel patents (in fact the gradient, if anything, is steeper after 50), whereas the usual patterns emerge for non-novel patents. Second, we replicate Table 5 and split patents between the top 10\%, 15\% and 25\% and bottom 90\%, $85 \%$ and $75 \%$ based on their novelty score. Table D6 shows that the least novel (bottom 90\%) patents have a significantly lower response rate to the exogenous demand shock whereas there is a small and insignificant response of the top $10 \%$ most novel.

\subsubsection{Calculation of aggregate effects in the two types of innovation model}

The finding that the main effects of regulations are on incremental innovation would seem to imply some reduction in the magnitude of the losses. A reduced form approach is given in Appendix D.5 containing firm-level employment growth regressions (Table D5) that show how although both types of innovations have a significant and positive effect on firm growth, the effect of a radical innovation is two to three times larger than that of an incremental innovation. Since most patents are incremental, this implies that innovation might only fall by about $4.5 \%$ instead of the baseline $5.8 \%$.

A more rigorous approach is in Appendix C.2 that re-calibrates all parameters to the new model. The new losses in welfare and total innovation are in Figure C2 and are indeed lower than those in the baseline model. The differences are less pronounced that what the reduced form approach would predict (loss of $5.5 \%$ in total innovation and $2.1 \%$ for welfare) which is mainly because the full model takes into account that although radical innovation creates more 
growth, it also uses more resources.

\subsubsection{Summary on radical versus incremental innovation}

Broadly, both citation and novelty based measures of radical patents are consistent with the extension to the model to allow for endogenous types of R\&D. In both the theory and the data, the main effect of the regulation is to discourage only incremental innovation. This reduces the negative impact of the regulation to some degree, but far from eliminates it as even incremental innovations have social value.

\subsection{Labor-Saving Technology}

There are many ways in which firms can respond to the regulation other than by reducing the pace of innovation. In addition to cutting back employment growth, Garicano et al. (2016) document how firms approaching the threshold also increase over time, capital investment, outsourcing and the skill mix. These might mitigate some of the costs, but will not eliminate the regulatory tax, as these are imperfect substitutes for job growth. Yet another strategy may be to develop labor saving automation technologies, that will enable the firm to increase output with less labor inputs.

To address the challenge of determining the degree to which a patent is about automation we again use textual analysis. In particular, we draw on Mann and Püttmann (2018) who used a supervised machine learning technique to classify automation and non-automation patents. Since their work was on the USPTO which is only a subsample of our data, we train an algorithm based on their classification using the GP embedding vector discussed in the previous subsection and then extrapolate this predicted measure of automation for all our sample. With this measure in hand, we again replicate all the analyses of the previous subsections. Consistent with our expectations, we find that the regulation only affected non-automation patenting (full results are presented in Appendix D.5). For example, Table D7 shows that faced with a positive demand shock, firms were significantly less likely to innovate in non-automation patents (bottom quartile), but were more likely to respond with automation patents (top quartile). Finally, we draw on a measure of process innovation developed by Arora et al. (2020), which are more likely to be labor saving (see Appendix D.5 for more details). This generates similar qualitative results to automation patents. 


\subsection{Longer lived owners}

In our baseline model, although firms can live forever we simplified the analytical problem by assuming the owners of firms only live for two periods. We now show that the qualitative and quantitative predictions of the model carry over to a more complex environment where owners live longer. Appendix C.3 gives the details, but our strategy is to consider extending the lifetime of the owner by one extra period, solve for the new equilibrium, examine the qualitative predictions and then re-calibrate the quantitative model to look at aggregate innovation and welfare. Finally, we show that these findings extend naturally when adding an arbitrary number of additional time periods. ${ }^{37}$

Consider extending our baseline model to allow the firm owner to live for three periods instead of the two period baseline. In the first period, the owner inherits a firm of size $n_{1}$. She then chooses her level of innovation $Z_{1}\left(n_{1}\right)=n_{1} z_{1}\left(n_{1}\right)$ and enters period 2 with a size $n_{2}$ (which can be either equal to $n_{1}, n_{1}+1$ or $n_{1}-1$ ). She chooses the level of innovation for period 2 , $Z_{2}\left(n_{2}\right)=n z_{2}\left(n_{2}\right)$. Finally, the owner collects profits, exits and ownership passes on to a new agent. Because the firm's owner only produces for two periods, we refer to this model as "the two period model" while the baseline model is denoted the "one period model".

It is thus possible to solve for equilibrium innovation given the number of lines in each period. Compared to the baseline case, the regulation will not only impact firms with a size $\bar{n}-1$ but also firms with a size $\bar{n}-2$ in period 1. Figure 10(a) plots the value of $\frac{z_{1}+z_{2}}{2}$, the average value of innovation per period, along with the value of $z$ in the baseline model against employment. The main differences between the two is that in the extended model, the "innovation valley" is wider immediately before the 50-employee threshold, as firms anticipate the costs of being closer to the threshold at lower sizes. However, for the same reason, it makes the magnitude of the innovation drop at around 49 shallower as firms begin responding earlier in the size distribution to the threat of crossing the threshold. The fall of innovation to the right of the threshold is broadly unaltered. As the number of periods extends, the valley becomes increasingly wider and shallower (see Appendix Figure C3).

To solve for the size distribution, we look for solution where the distribution of firms in their period 2 is the same as the distribution of firms in their first period. The flow equation that determines the equilibrium size distribution is the same as in the baseline case. Figure

\footnotetext{
${ }^{37}$ In the working paper version, we show that qualitatively similar results are also found when considering another approach to modelling infinitely lived owners (Aghion et al., 2021). Unfortunately, this model does not lend itself to quantitative calibration in any straightforward manner.
} 
Figure 10: Innovation and firm size distribution: Comparing baseline model with longer-lived owner model

(a) Innovation

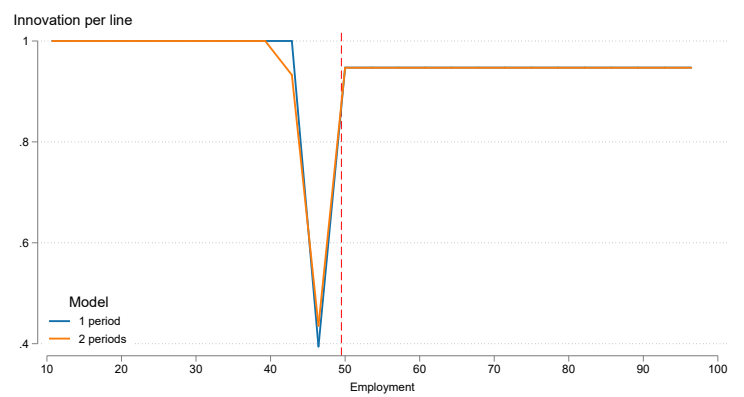

(b) Size distribution (log scale)

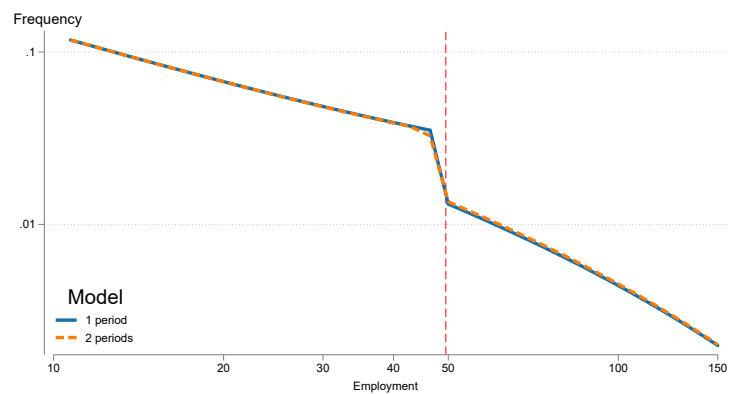

Notes: The left-hand side panel plots total innovation per line (compared to firm employment) in our baseline model (blue solid line) compared to a model with two production periods (orange dashed line). In the latter case the average innovation over the two periods is plotted. The right-hand side panel plots the corresponding size distribution. Parameters are chosen following the calibration strategy described in Section 5.3, see Table C3 in Appendix C.3.

10(b) plots this distribution against the value of employment in the baseline case and in the two period model.

In the baseline model, the calibration of $\tau$, which governed the aggregate innovation loss followed directly from the comparison of the slopes of the innovation - firm size cross-sectional relationship in large vs. small firms. In our extended multi-period model, the calibration is slightly more involved and all parameters need to be estimated simultaneously. The resulting parameter values are presented in Table C3 and are very similar to those in the baseline model in Table 3.

The loss in total innovation and total welfare are shown in Figures 11(a) and 11(b) along with the corresponding loss in the baseline model. The figures show that the loss in total innovation and welfare remains very similar in the new multi-period model compared to the baseline, especially since the value of the implicit regulatory tax remains at $2.6 \%$.

The model can be naturally extended to adding more periods to the firm owner's life through induction and Appendix C.3 shows how the results carry over.

In summary, adding extra periods to a firm owner's life extends the "shadow" of the regulation further down the firm size distribution: the innovation valley becomes wider and flatter. A model calibration shows very similar aggregate innovation and welfare losses to our baseline case, however, suggesting that our simpler, more analytically tractable approach does not mislead us. Moreover, the theoretical findings on the shape of the innovation-size relationship generalize to having many more periods. Hence, we think our simple approach delivers losses in the right order of magnitude and would not be changed from moving to more complex dynamic 
Figure 11: Aggregate Innovation and Welfare in a model with two period lived owners

(a) Total Innovation

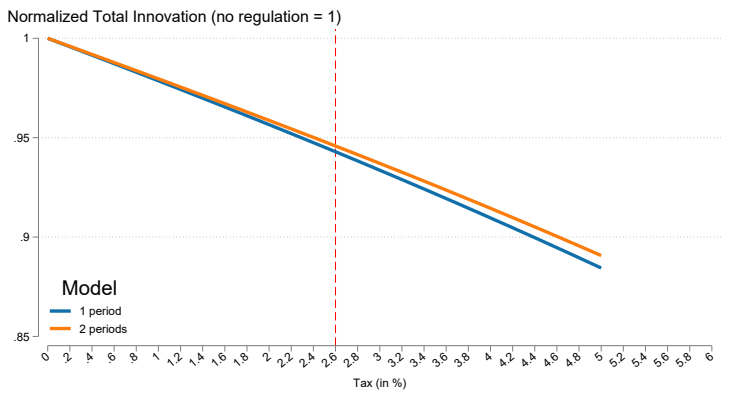

(b) Welfare

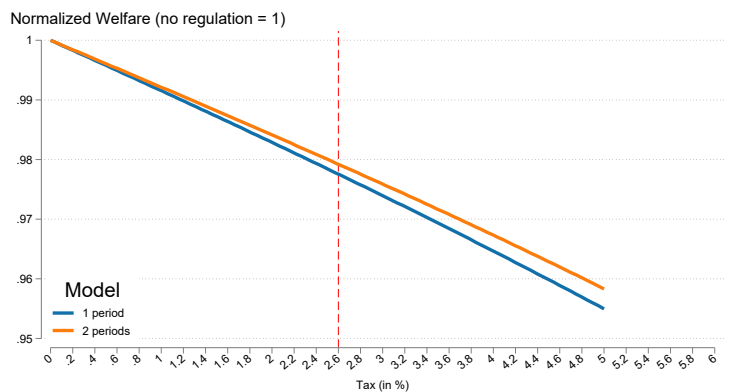

Notes: The left-hand side panel plots total innovation loss against the value of the regulation threshold $\tau$ in our baseline model (blue solid line) and in a model with two production periods (orange dashed line). The right-hand side panel plots the loss in consumption equivalent welfare. Parameters are chosen following the calibration strategy described in Appendix Section C.3, except for $\tau$, see Table C3 in Appendix C.3.

models.

\subsection{Under-reporting of employment}

Given the cost of regulation firms have incentives to under-report employment. In Appendix A.2 we discuss these issues in detail. There is a lot of scrutiny of the employment numbers by unions, government and other agents as well as significant fines for non-compliance. This makes non-compliance costly.

An alternative dataset to FICUS is DADS, which are social security declarations. Garicano et al. (2016) show that the same breaks in the firm size distribution are visible in DADS as FICUS (see their Figure 4), in particular there is a clear downward shift in the power law (in log-log space) at the threshold.

The bunching of firm density at 49 employees is less visible in DADS than FICUS. Askenazy et al. (2022) argue that this is because DADS is harder to manipulate than FICUS. But the blunting of the spike is particularly strong when using DADS hours data as this has much measurement error, which could cause the impression of less bunching.

Rather than viewing any employment measure from FICUS or DADS as the single "correct" one for regulatory purposes, we should regard the employment data as a signal with measurement error. Fortunately, the methods in our paper do not require to obtain the precise value of the cut-off in the empirical data. In particular, our approach utilizes differences away from the discontinuity at 50. In our baseline calibration we use the change in the gradient of the innovation-size relationship for firms in the 10 to 45 range vs. the 50-100 range to help identify the implicit tax of regulation. Similarly, in the extension where we calibrate the implicit tax 
using the dynamic analysis of the responses to export market size shocks, we use the data away from the threshold, again comparing responsiveness of smaller to larger firms. Hence, the identification of the aggregate costs of the regulation does not rely closely on the firms to the left of the threshold, and is therefore robust to possible under-reporting.

In summary, although there is no perfect measure of employment, the use of FICUS appears adequate for our purposes.

\subsection{R\&D as Scientists: Endogenizing Equilibrium Wages}

In the baseline model, R\&D is a "lab equipment" model where the equipment is bought on the world market, labor supply is fixed and the labor force is all employed as production workers. This means the labor share, $\omega$, is constant and unaffected by the regulation. In this extension, we consider the case where $R \& D$ uses scientists as an input, which means that the labor share can change with regulation. Full details are in Appendix C.4, but we sketch the main results here.

Workers can choose to supply labor to the R\&D sector or to the production sector. In this case the total employment of firm $i$ is given by:

$$
l_{i}=\frac{n_{i}}{\omega \gamma}+\zeta n_{i} z_{i}^{\eta} \equiv L\left(n_{i}, z_{i}\right)
$$

where $\zeta$ is now a labor cost. Therefore $l_{i}$ depends directly upon current innovation, instead of only through past innovation as reflected in its size $\left(\frac{n_{i}}{\omega \gamma}\right)$. The employment threshold $\bar{l}$ no longer corresponds to a single number of products, but rather to a set of pairs $(z, n)$ such that:

$$
z=\frac{1}{\zeta n}\left(\bar{l}-\frac{n}{\gamma \omega}\right)^{\frac{1}{\eta}}
$$

whenever $n \leq \bar{n}$.

As employment directly depends upon the level of $z$, so does the profit per line which is now equal to:

$$
\pi(n, z)=\frac{\gamma-1}{\gamma}(1-\mathbb{1}[L(n, z) \geq l] \tau)
$$

The firm's problem is otherwise the same, but again the model needs to be solved numerically. Appendix C.4 shows that the qualitative effects again go through in terms of the size distribution and the firm innovation-size relationships. However, an important additional result is that the regulation reduces the equilibrium wage: the greater the tax, the greater the fall in the wage. This will mitigate the shift to the left in the size distribution. 


\section{Conclusion}

In this paper, we have developed a framework to analyze the impact of regulation on innovation. We applied this to France, where strong labor regulations affect firms who employ 50 or more workers. We showed both theoretically and empirically that the prospect of these regulatory costs discourages firms just below the threshold from innovating, where innovation is measured by the volume of patent applications. This relationship emerges both when looking non-parametrically at patent density around the threshold and in a parametric exercise where we examine the heterogeneous response of firms to exogenous market size shocks (from export markets). On average, firms innovate more when they experience a positive shock, but this relationship significantly weakens when a firm is just below the regulatory threshold. We then use moments from our data and the literature to calibrate the structural parameters in the model. For example, using estimates of the R\&D cost function, we can back out the magnitude of the regulatory tax from the ratio between the slopes of the innovation-size relationship for large firms compared to small firms. Our baseline estimates imply an aggregate innovation (and therefore growth) loss of about 5.8\% and a lower bound on the loss of welfare of about $2.3 \%$.

This suggests larger welfare losses than existing analyses that take technology as exogenous. A caveat to this conclusion is that when we use information on citations we find that the labor regulation deters incremental innovation, but has little effect on more radical innovation. This is consistent with a generalization of the model which allows for simultaneous investment in two types of $\mathrm{R} \& \mathrm{D}$, and slightly mitigates the welfare loss of the regulation.

The analysis in this paper can be extended in several directions. First, our focus in this paper was on the long-run steady state, but it is perhaps equally important to analyze the transitional dynamics triggered by policy changes, and to factor in adjustment costs. Second, the framework can be applied to many other countries and regulatory settings. Third, our analysis remained focused on the costs of the labor regulation. However, such a regulation may also bring benefits in the form of better insurance and deeper involvement of employees in the management of the firm, which in turn fosters trust between employers and employees. Future work should take such benefits into account to see if they are sufficient to overcome the costs we have identified here. 


\section{References}

Abowd, John M. and Francis Kramarz, "The costs of hiring and separations," Labour Economics, 2003, 15 (5), 499-530.

Acemoglu, Daron and Joshua Linn, "Market Size and Innovation: Theory and Evidence from the Pharmaceutical industry," Quarterly Journal of Economics, August 2004, 119 (3), 1049-1090.

_, Ufuk Akcigit, and Murat Alp Celik, "Radical and Incremental Innovation: The Roles of Firms, Managers and Innovators," AEJ Macroecon (forthcoming), 2020.

_, _, Harun Alp, Nicholas Bloom, and William Kerr, "Innovation, reallocation, and growth," American Economic Review, 2018, 108 (11), 3450-91.

Acharya, Viral V, Ramin P Baghai, and Krishnamurthy V Subramanian, "Labor laws and innovation," The Journal of Law and Economics, 2013, 56 (4), 997-1037.

_ , _, and _ , "Wrongful discharge laws and innovation," The Review of Financial Studies, 2013, 27 (1), 301-346.

Adao, Rodrigo, Michal Kolesár, and Eduardo Morales, "Shift-share designs: Theory and inference," The Quarterly Journal of Economics, 2019, 134 (4), 1949-2010.

Aghion, Philippe, Antonin Bergeaud, and John Van Reenen, "The impact of regulation on innovation," Technical Report w28381, National Bureau of Economic Research 2021.

_, _, Matthieu Lequien, and Marc Melitz, "The Impact of Exports on Innovation: Theory and Evidence," NBER Working Paper 24600, National Bureau of Economic Research 2018.

_ , _ , Timo Boppart, Peter J Klenow, and Huiyu Li, "A theory of falling growth and rising rents," Technical Report, National Bureau of Economic Research 2019.

_, Ufuk Akcigit, and Peter Howitt, "What do we learn from Schumpeterian growth theory?," in "Handbook of economic growth," Vol. 2, Elsevier, 2014, pp. 515-563.

_ , _, Antonin Bergeaud, Richard Blundell, and David Hémous, "Innovation and top income inequality," The Review of Economic Studies, 2018, 86 (1), 1-45.

_ , _, Matthieu Lequien, and Stefanie Stantcheva, "Monetary Incentives, Tax Evasion and the Quest for Simplicity," 2019. mimeo College de France.

Akcigit, Ufuk and Stefanie Stantcheva, "Taxation and Innovation: What Do We Know?," Working Paper 27109, National Bureau of Economic Research May 2020.

_ and William R Kerr, "Growth through heterogeneous innovations," Journal of Political Economy, 2018, 126 (4), 1374-1443.

Alesina, Alberto, Michele Battisti, and Joseph Zeira, "Technology and labor regulations: theory and evidence," Journal of Economic Growth, 2018, 23 (1), 41-78.

Amirapu, Amrit and Michael Gechter, "Labor Regulations and the Cost of Corruption: Evidence from the Indian Firm Size Distribution," Review of Economics and Statistics, March 2020, $102(1), 34-48$.

Arora, Ashish, Sharon Belenzon, Wes Cohen, and Honggi Lee, "Big Firms and the Direction of Technical Change," 2020. Mimeo Duke University.

Askenazy, Philippe, Thomas Breda, and Vladimir Pecheu, "Under-Reporting of Firm Size Around Size-Dependent Regulation Thresholds: Evidence from France," Working Paper 2211, AMSE 2022. 
Autor, David H, William R Kerr, and Adriana D Kugler, "Does employment protection reduce productivity? Evidence from US states," The Economic Journal, 2007, 117 (521), F189-F217.

Axtell, Robert L, "Zipf distribution of US firm sizes," science, 2001, 293 (5536), 1818-1820.

Banerjee, Abhijit and Esther Duflo, "Growth Theory through the lens of development," in Philippe Aghion and Steven Durlauf, eds., Handbook of Economic Growth, Amsterdam: Elsevier, 2005, chapter 7, pp. 474-544.

Barlevy, Gadi, "On the cyclicality of research and development," American Economic Review, 2007, $9^{\text {r7 }}$ (4), 1131-1164.

Bartelsman, E., J. Haltiwanger, and S. Scarpetta, "Cross-country differences in productivity: The role of allocation and selection," The American Economic Review, 2013, 103 (1), 305-334.

Bartelsman, Eric J, Pieter A Gautier, and Joris De Wind, "Employment protection, technology choice, and worker allocation," International Economic Review, 2016, 57 (3), $787-826$.

Bassanini, Andrea, Luca Nunziata, and Danielle Venn, "Job protection legislation and productivity growth in OECD countries," Economic policy, 2009, 24 (58), 349-402.

Bena, Jan, Hernan Ortiz-Molina, and Elena Simintzi, "Shielding firm value: Employment protection and process innovation.," 2020. mimeo University of British Columbia.

Bento, Pedro and Diego Restuccia, "Misallocation, establishment size, and productivity," American Economic Journal: Macroeconomics, 2017, 9 (3), 267-303.

Bentolila, Samuel and Giuseppe Bertola, "Firing costs and labour demand: how bad is eurosclerosis?," The Review of Economic Studies, 1990, 57 (3), 381-402.

Bergeaud, Antonin, Yoann Potiron, and Juste Raimbault, "Classifying patents based on their semantic content," PloS one, 2017, 12 (4), e0176310.

Besley, Timothy and Robin Burgess, "Can Labor Regulation Hinder Economic Performance? Evidence from India," Quarterly Journal of Economics, 2000, 119 (1), 91-134.

Blundell, Richard, Rachel Griffith, and Frank Windmeijer, "Individual effects and dynamics in count data models," Journal of econometrics, 2002, 108 (1), 113-131.

Boedo, Hernan J Moscoso and Toshihiko Mukoyama, "Evaluating the effects of entry regulations and firing costs on international income differences," Journal of Economic Growth, 2012, $17(2), 143-170$.

Borusyak, Kirill, Peter Hull, and Xavier Jaravel, "Quasi-Experimental Shift-Share Research Designs," Working Paper 24997, National Bureau of Economic Research September 2018.

Braguinsky, Serguey, Lee G Branstetter, and Andre Regateiro, "The Incredible Shrinking Portuguese Firm," Working Paper 17265, National Bureau of Economic Research July 2011.

Ceci-Renaud, Nila and Paul-Antoine Chevalier, "L'impact des seuils de 10, 20 et 50 salariés sur la taille des entreprises Françaises," Economie et Statistique, 2011, 437, 29-45.

Cette, Gilbert, Jimmy Lopez, and Jacques Mairesse, "Labour Market Regulations and Capital Intensity," Working Paper 22603, National Bureau of Economic Research September 2016. 
- Lorraine Koehl, and Thomas Philippon, "Labor Shares in Some Advanced Economies," Working Paper 26136, National Bureau of Economic Research August 2019.

Chetty, Raj, John Friedman, Tore Olsen, and Luigi Pistaferri, "Adjustment Costs, Firm Responses, and Micro vs. Macro Labor Supply Elasticities: Evidence from Danish Tax Records," Quarterly Journal of Economics, 2011, 126 (2), 749-804.

Crépon, Bruno and Emmanuel Duguet, "Estimating the innovation function from patent numbers: GMM on count panel data," Journal of Applied Econometrics, 1997, 12 (3), 243263.

Da-Rocha, José-María, Diego Restuccia, and Marina Mendes Tavares, "Firing costs, misallocation, and aggregate productivity," Journal of Economic Dynamics and Control, 2019, 98, 60-81.

Davis, Steven J and John Haltiwanger, "Gross job creation, gross job destruction, and employment reallocation," The Quarterly Journal of Economics, 1992, 107 (3), 819-863.

Dechezlepretre, Antoine, David Hemous, Morten Olsen, and Carlo Zanella, "Automating labor: evidence from firm-level patent data," CEP Discussion Papers dp1679.pdf, Centre for Economic Performance, LSE February 2020.

_, Elias Einiö, Ralf Martin, Kieu-Trang Nguyen, and John Van Reenen, "Do tax Incentives for Research Increase Firm Innovation? An RD Design for R\&D," Working Paper 22405, National Bureau of Economic Research July 2016.

Gabler, Alain and Markus Poschke, "Experimentation by firms, distortions, and aggregate productivity," Review of Economic Dynamics, 2013, 16 (1), 26-38.

Garcia-Vega, Maria, Richard Kneller, and Joel Stiebale, "Labor Market reform and innovation: Evidence from Spain," Working Paper 201917, University of Nottingham 2019.

Garicano, Luis, Claire Lelarge, and John Van Reenen, "Firm Size Distortions and the Productivity Distribution: Evidence from France," American Economic Review, November 2016, 106 (11), 3439-79.

_ , _ , and John Van Reenen, "A Response to âUnder- Reporting of Firm size around Size Dependent Thresholds: Evidence from France by Askenazy, Breda and Pecheu," 2022. LSE mimeo.

Goldsmith-Pinkham, Paul, Isaac Sorkin, and Henry Swift, "Bartik instruments: What, when, why, and how," American Economic Review, 2020, 110 (8), 2586-2624.

Gourio, Francois and Nicolas Roys, "Size-Dependent Regulations, Firm size distribution and Reallocation," Quantitative Economics, 2014, 5 (2), 377-416.

Griffith, Rachel and Gareth Macartney, "Employment protection legislation, multinational firms, and innovation," Review of Economics and Statistics, 2014, 96 (1), 135-150.

Grout, Paul A, "Investment and wages in the absence of binding contracts: A Nash bargaining approach," Econometrica: Journal of the Econometric Society, 1984, pp. 449-460.

Gust, Christopher and Jaime Marquez, "International comparisons of productivity growth: the role of information technology and regulatory practices," Labour economics, 2004, 11 (1), 33-58.

Hall, Bronwyn, Adam Jaffe, and Manuel Trajtenberg, "Market Value and Patent Citations," RAND Journal of Economics, 2005, 36 (1), 16-38.

Hall, Robert E, "The relation between price and marginal cost in US industry," Journal of political Economy, 1988, 96 (5), 921-947. 
Hopenhayn, Hugo A, "On the Measure of Distortions," Working Paper 20404, National Bureau of Economic Research August 2014.

Hsieh, C. and P. Klenow, "Misallocation and Manufacturing TFP in China and India," The Quarterly Journal of Economics, 2009, pp. 1403-1448.

Hsieh, Chang-Tai and Benjamin A Olken, "The missing "missing middle"," Journal of Economic Perspectives, 2014, 28 (3), 89-108.

Hummels, David, Rasmus Jørgensen, Jakob Munch, and Chong Xiang, "The wage effects of offshoring: Evidence from Danish matched worker-firm data," American Economic Review, 2014, 104 (6), 1597-1629.

INSEE, "NAF REV. 2 et CPF REV. 2 : Guide d'utilisation," 2016.

Jones, Charles I, "Misallocation, Economic Growth, and Input-Output Economics," Working Paper 16742, National Bureau of Economic Research 2011.

Kaplow, Louis, "Optimal regulation with exemptions and corrective taxation," 2013. Harvard University mimeo.

Kelly, Bryan, Dimitris Papanikolaou, Amit Seru, and Matt Taddy, "Measuring technological innovation over the long run," Technical Report w25266, National Bureau of Economic Research 2018.

Klette, Tor Jakob and Samuel Kortum, "Innovating firms and aggregate innovation," Journal of political economy, 2004, 112 (5), 986-1018.

Kleven, Henrik and Mazhar Waseem, "Using Notches to Uncover Optimization Frictions and Structural Elasticities: Theory and Evidence from Pakistan," Quarterly Journal of Economics, 2013, 128 (2), 669-723.

Konig, Michael, Kjetil Storesletten, Zheng Song, and Fabrizio Zilibotti, "From Imitation to Innovation: Where is all that Chinese R\&D Going," Econometrica (forthcoming), 2022.

Kramarz, Francis and Marie-Laure Michaud, "The shape of hiring and separation costs in France," Labour Economics, 2010, 17 (1), 27-37.

Lequien, Matthieu, Martin Mugnier, Loriane Py, and Paul Trichelair, "Linking patents to firms: insights with French firms," 2017. mimeo.

Loecker, Jan De, Jan Eeckhout, and Gabriel Unger, "The rise of market power and the macroeconomic implications," The Quarterly Journal of Economics, 2020, 135 (2), 561-644.

Lucas, Robert E, "On the size distribution of business firms," The Bell Journal of Economics, 1978, pp. 508-523.

Manera, Andrea and Martina Uccioli, "Employment Protection and the Direction of Technology Adoption," 2020. mimeo MIT.

Mann, Katja and Lukas Püttmann, "Benign effects of automation: New evidence from patent texts," 2018. Available at SSRN 2959584.

Manso, Gustavo, Benjamin Balsmeier, and Lee Fleming, "Heterogeneous Innovation and the Antifragile Economy," 2019. mimeo, UC Berkeley.

Mayer, Thierry, Marc J. Melitz, and Gianmarco I. P. Ottaviano, "Market Size, Competition, and the Product Mix of Exporters," American Economic Review, 2014, 104 (2), $495-536$. 
${ }_{-},{ }_{-}$, and _ , "Product Mix and Firm Productivity Responses to Trade Competition," NBER Working Papers 22433, National Bureau of Economic Research, Inc July 2016.

Menezes-Filho, Naercio, David Ulph, and John Van Reenen, "The determination of R\&D: empirical evidence on the role of unions," European Economic Review, 1998, 42 (3-5), 919-930.

Moins, Laurent, Code Du Travail 2010, Lamy, 2010.

Mukoyama, Toshihiko and Sophie Osotimehin, "Barriers to reallocation and economic growth: the effects of firing costs," American Economic Journal: Macroeconomics, 2019, 11 (4), 235-70.

Parente, Stephen L. and Edward C. Prescott, Barriers to Riches, Cambridge: MIT Press, 2000.

Porter, Michael E and Claas Van der Linde, "Toward a new conception of the environment-competitiveness relationship," Journal of economic perspectives, 1995, 9 (4), $97-118$.

Poschke, Markus, "Employment protection, firm selection, and growth," Journal of Monetary Economics, 2009, 56 (8), 1074-1085.

Restuccia, Diego and Richard Rogerson, "Policy Distortions and Aggregate Productivity with Heterogeneous Plants," Review of Economic Dynamics, October 2008, 11 (4), 707-720.

Saez, Emmanuel, "Do Taxpayers Bunch at Kink Points?," American Economic Journal: Economic Policy, 2010, 2 (3), 180-212.

Saint-Paul, Gilles, "Employment protection, international specialization, and innovation," European Economic Review, 2002, 46 (2), 375-395.

Samaniego, Roberto M, "Employment protection and high-tech aversion," Review of Economic Dynamics, 2006, 9 (2), 224-241.

Schivardi, Fabiano and Tom Schmitz, "The IT revolution and southern Europe's two lost decades," Journal of the European Economic Association, 2020, 18 (5), 2441-2486.

Schumpeter, Josef, Business Cycles, New York: McGraw Hill, 1939.

Shleifer, Andrei, "Implementation cycles," Journal of Political Economy, 1986, 94 (6), 11631190.

Smagghue, Gabriel, "Heterogeneous Policy Distortions and the Labor Share," 2020. mimeo Banque de France.

Srebrovic, Rob, "Expanding your patent set with ML and BigQuery," 2019. Google Cloud Data Analytics https://cloud.google.com/blog/products/data-analytics/expandingyour-patent-set-with-ml-and-bigquery.

Webb, Michael, "The impact of artificial intelligence on the labor market," 2019. Available at SSRN 3482150. 


\section{ONLINE APPENDICES}

\section{Table of contents}

A More Details of some Size-Related Regulations in France

OA-1

A.1 Main Labor Regulations . . . . . . . . . . . . . . . . . . . OA-1

A.2 Misreporting and compliance with regulations . . . . . . . . . . . . OA-4

A.3 Alternative ways of modelling the regulation . . . . . . . . . . OA-6

$\begin{array}{ll}\text { B Data Appendix } & \text { OA-8 }\end{array}$

B.1 Patent data . . . . . . . . . . . . . . . . . . . . . . . . . . . .

B.2 Firm-level administrative data . . . . . . . . . . . . . . . . . . . OA-8

B.3 Trade data . . . . . . . . . . . . . . . . . . . . . . OA-9

$\begin{array}{ll}\text { C Theoretical Appendix } & \text { OA-11 }\end{array}$

C.1 Numerical Solutions for the baseline model . . . . . . . . . . . . . . . . OA-11

C.2 Radical vs. Incremental innovation . . . . . . . . . . . . . . OA-13

C.3 Longer lived owners . . . . . . . . . . . . . . . . . . . . . OA-15

C.4 R\&D as scientific labor . . . . . . . . . . . . . . . . OA-21

C.5 Modeling regulation as a tax on labor . . . . . . . . . . . . . . . . OA-24

$\begin{array}{lr}\text { D Additional Empirical Results } & \text { OA-26 }\end{array}$

D.1 Size distribution of French firms . . . . . . . . . . . . . . OA-26

D.2 Robustness of the cross-sectional innovation-size relationship . . . . . . . . OA-26

D.3 Robustness of the dynamic effects of the market size shock on innovation . . . OA-27

D.4 Details (and robustness) of the estimates of the regulatory tax parameter and implications . . . . . . . . . . . . . . . . . . OAA-34

D.5 Measuring different types of innovation . . . . . . . . . . . . . OA-40 


\section{A More Details of some Size-Related Regulations in France}

The size-related regulations are defined in four groups of laws. The Code $d u$ Travail (labor laws), Code du Commerce (commercial law), Code de la Sécurité Sociale (social security) and in the Code General des Impots (fiscal law). The main bite of the labor (and some accounting) regulations comes when the firm reaches 50 employees. But there are also some other sizerelated thresholds at other levels. The main other ones comes at 10-11 employees.

For this reason we generally trim the analysis below 10 employees to mitigate any bias induced in estimation from these other thresholds. For more details on French regulation see inter alia Abowd and Kramarz (2003) and Kramarz and Michaud (2010), or, more administratively and exhaustively, Moins (2010).

\section{A.1 Main Labor Regulations}

The unified and official way of counting employees has been defined since $2004^{38}$ in the Code $d u$ Travail, ${ }^{39}$ articles L.1111-2 and 3. Exceptions to the 2004 definition are noted in parentheses in our detailed descriptions of all the regulations below. Employment is taken over a reference period which from 2004 was the calendar year (January $1^{\text {st }}$ to December $31^{\text {st }}$ ). There are precise rules over how to fractionally count part-year workers, part-time workers, trainees, workers on sick leave, etc. (Moins, 2010). For example, say a firm employs 10 full-time workers every day but in the middle of the year all 10 workers quit and are immediately replaced by a different 10 workers. Although in the year as a whole 20 workers have been employed by the firm the standard regulations would mean the firm was counted as 10 employee firm.

In this case, this would be identical to the concept used in our main source of firm level data: FICUS. Garicano et al. (2016) extensively document that the discontinuity in the firm size distribution at 50 can be seen across a variety of alternative datasets with different definitions of employment. There is of course more measurement errors in some datasets than others due to differences in how the employment concept matches the regulatory definitions. Still, one concern is that there is under-reporting of employment in FICUS in order to avoid the regulation, we discuss this point in Appendix A.2. However, it is important to stress that what is crucial for our identification is not the exact position of the excess mass of firms at precisely 49 employees (which is subject to measurement error and possible misreporting), but rather

\footnotetext{
${ }^{38}$ Before that date, the concept of firm size was different across labor regulations.

${ }^{39}$ The text is available at the legifrance website
} 
that the size distribution shifts around the region of the regulatory threshold, which it does robustly across a wide variety of datasets and employment size concepts.

Finally, recall that the employment measure in the FICUS data is average headcount number of employees taken on the last day of each quarter in the fiscal year (usually but not always ending on December 31st). All of these regulations strictly apply to the firm level, which is where we have the FICUS data. Some case law has built up, however, which means that a few of them are also applied to the group level.

\section{From 200 employees}

- Obligation to appoint nurses (Code du Travail, article R.4623-51)

- Provision of a place to meet for union representatives (Code du Travail, article R.2142-8)

\section{From 50 employees:}

- Monthly reporting of the detail of all labor contracts to the administration (Code du Travail, article D.1221-28)

- Obligation to establish a staff committee ("comité d'entreprise") with business meeting at least every two months and with minimum budget $=0.3 \%$ of total payroll (Code $d u$ Travail, article L.2322-1-28, threshold exceeded for 12 months during the last three years)

- Obligation to establish a committee on health, safety and working conditions (known as CHSCT) (Code du Travail, article L.4611-1, threshold exceeded for 12 months during the last three years)

- Appointing a shop steward if demanded by workers (Code du Travail, article L.2143-3, threshold exceeded for 12 consecutive months during the last three years)

- Obligation to establish a profit sharing scheme (Code du Travail, article L.3322-2, threshold exceeded for six months during the accounting year within one year after the year end to reach an agreement)

- Obligation to do a formal "Professional assessment" for each worker older than 45 (Code du Travail, article L.6321-1)

- Higher duties in case of an accident occurring in the workplace (Code de la Sécurité sociale and Code du Travail, article L.1226-10) 
- Obligation to use a complex redundancy plan with oversight, approval and monitoring from Ministry of Labor in case of a collective redundancy for 9 or more employees (Code du Travail, articles L.1235-10 to L.1235-12; threshold based on total employment at the date of the redundancy)

\section{From 25 employees:}

- Duty to supply a refectory if requested by at least 25 employees (Code du Travail, article L.4228-22)

- Electoral colleges for electing representatives. Increased number of delegates from 25 employees (Code du Travail, article L.2314-9, L.2324-11)

\section{From 20 employees:}

- Formal house rules (Code du Travail, articles L.1311-2)

- Contribution to the National Fund for Housing Assistance;

- Increase in the contribution rate for continuing vocational training of $1.05 \%$ to $1.60 \%$ (Code du Travail, articles L.6331-2 and L.6331-9)

- Compensatory rest of $50 \%$ for mandatory overtime beyond 41 hours per week

\section{From 11 employees:}

- Obligation to conduct the election of staff representatives (threshold exceeded for 12 consecutive months over the last three years) (Code du Travail, articles L.2312-1)

\section{From 10 employees:}

- Monthly payment of social security contributions, instead of a quarterly payment (according to the actual last day of previous quarter);

- Obligation for payment of transport subsidies (Article R.2531-7 and 8 of the General Code local authorities, Code general des collectivités territoriales);

- Increase the contribution rate for continuing vocational training of $0.55 \%$ to $1.05 \%$ (threshold exceeded on average 12 months). 
Note that, in additions to these regulations, some of the payroll taxes are related to the number of employees in the firm.

The additional requirements depending on the number of employees of the firm, but also limits on turnover and total assets are as follows (commercial laws, Code du Commerce, articles L.223-35 and fiscal regulations, Code général des Impôts, article 208-III-3):

In addition to the labor laws there are also some accounting regulations which are relatively minor in scope. From 50 employees there is first, no longer the possibility of a simplified presentation of Schedule 2 to the accounts. Second, there is a Requirement for LLCs, the CNS, limited partnerships and legal persons of private law to designate an auditor. From 10 employees, the possibility of a simplified balance sheet and income statement is lost.

\section{A.2 Misreporting and compliance with regulations}

One concern is that firms would under-report their employment level in FICUS in order to avoid the regulation. As Garicano et al. (2016) discuss, there is a lot of scrutiny of the employment numbers by unions, government and other agents as well as significant fines for non-compliance.

In a recent work, Askenazy et al. (2022) argue that employment is systematically underreported in FICUS in order to avoid the regulation. They argue that discontinuities are not observed in the matched employer employee data which comes from the Social Security (DADS) when they have reconstructed it to match the labor regulations. By contrast, Garicano et al. (2016) extensively document that the discontinuity in the firm size distribution at 50 can be seen across a variety of firm datasets with different definitions of employment. For example, their Figure 6 shows that even in DADS there is evidence of a change in the power law of the firm size distribution at 50 employees.

The bunching of firm size just below 50 employees in DADS is less apparent than in FICUS, especially when the hours (rather than headcount) data are used to construct Full Time Equivalents. This is the measure re-constructed by Askenazy et al. (2022). Unfortunately, the hours data in DADS is problematic with up to $18 \%$ of the values imputed, no inclusion of agency workers (which are relevant for the regulation) before 2018, no way to distinguish 35 vs. 39 hour contracts, etc... Hence, the reconstructed measure using hours could also be generating significant measurement errors disguising the discontinuity at 50 .

Rather than viewing the employment measure as the single "correct" one for regulatory purposes, we must recognize that all available datasets and empirical employment measures whether from FICUS or DADS has an imperfect mapping to the regulation. As documented 
above there are differences in how the employment concept matches the (multiple) regulatory definitions.

Fortunately, the methods in our paper (and those in Garicano et al. 2016) do not require to obtain the precise value of the cut-off in the empirical data. First, we need to only approximate that there is a margin of firms of employment below 50 who look different, not that this is exactly at 49 . In the cross section, the innovation valley is around 45-49 employees, as is the differential response to market size shocks in the dynamic analysis.

Second, our approach utilizes differences away from the discontinuity at 50. In our baseline calibration we use the change in the gradient of the innovation-size relationship for firms in the 10 to 45 range vs. the 50-100 range to help identify the implicit tax of regulation. Similarly, in the extension where we calibrate the implicit tax using the dynamic analysis of the responses to export market size shocks, we use the data away from the threshold, again comparing responsiveness of smaller to larger firms. Hence, the identification of the aggregate costs of the regulation does not rely closely on the firms to the left of the threshold, and is therefore robust to possible under-reporting.

Askenazy et al. (2022) collect data on the presence of works councils and profit sharing schemes. They show, using the FICUS data that there is a discontinuous jump in the likelihood of such institutions exactly around the 50 threshold. This is clearly supportive of the fact that FICUS employment is relevant for the establishment of such institutions, and supports the idea that FICUS employment is very relevant.

Finally, it is possible to extend our approach to allow for misreporting. In particular, Garicano et al. (2022) augment Garicano et al. (2016) with a new "regime" in which firms can cheat by under-reporting their number of workers, but with a risk of being detected and of being fined for that behavior. They assume that the probability $p$ of detection is homogeneous across firms and that the fine in case of being caught lying is linear, but that the largest firms will for sure get caught if they lie. Specifically, with probability $(1-p)$ the firm gets away with misreporting, while with probability $p$ it pays a variable fine $\tau_{n c}$ (so the more you lie about size, the more you pay) plus a fixed fine $f_{n c}$. With these assumptions they prove that the estimation regime in Garicano et al. (2016) goes through. The only difference is in the interpretation of the magnitude of the fixed cost of regulation which now also includes a misreporting term. Since the estimates of the fixed cost are trivial in magnitude, the misreporting bias is also immaterial for the welfare calculations.

In summary, although there is no perfect measure of employment, the use of FICUS appears adequate for our purposes. 


\section{A.3 Alternative ways of modelling the regulation}

We have modelled the regulation as a variable tax on profits. We consider three possible extensions: (i) modelling the regulation having a fixed cost component; (ii) modelling the regulation as a labor tax rather than a profit tax; (iii) including capital inputs

Modelling the regulation as having a fixed cost component. Introducing a fixed cost component in our modelling of the regulation, generates new empirical implications. For example, the fixed component would still generate a hump in the size distribution below 50 and a subsequent sharp drop in the density of firm size to the right of 50. It would not, however, generate a permanent downward shift in the slope of the firm density by size distribution. Intuitively, the fraction of very large firms would be essentially unchanged, as such firms could spread the fixed cost over a very large number of units. The data, by contrast, shows this downward shift very clearly (see Figure D1). This is consistent with a strong role for the variable cost. Garicano et al. (2016) structurally estimate the magnitude of the fixed cost of the regulation using employment data and find it to be very small (less than the wage of a single worker), with just about all the regulatory cost loaded on the variable component.

Overall, adding a fixed cost would not generate markedly different slopes of the sizeinnovation relationship for large versus small firms.

Modelling the regulation as a labor tax rather than a profit tax. Modelling the regulation as a marginal tax on the labor input instead of a tax on profits, does not affect our main theoretical predictions, even though it somewhat complicates the model. Indeed, when the regulation is modelled as a labor tax, firms' marginal costs of production will depend upon the labor regulation they face, which in turn depends upon the firm's size. Limit pricing then implies that the equilibrium profit on each line will depend upon both, the labor tax of the current leader and the labor tax of the fringe firm on that line. Overall, moving from our baseline model to the model with labor tax amounts to introducing an extra state variable, namely the share of firms above the regulatory threshold which itself is endogenous. While assessing the magnitude of the effects, requires solving this more complicated variant of our baseline model ${ }^{40}$ nonetheless the logic remains the same as in our baseline model: namely, just below the threshold, firms will anticipate that if they successfully innovate then they will move

\footnotetext{
${ }^{40}$ In Appendix C.5 we compute the equilibrium innovation rate $z(n)$ where both the share of lines $S$ in which the current producer is a "large" firm beyond the threshold and the threshold number of lines $\bar{n}$ beyond which an $n$ - line firm is considered to be "large", are constant over time. We show that the expression for $z(n)$ is similar to that in the baseline model, except that it now also depends on $S$ which is endogenous.
} 
beyond the threshold and therefore be subject to the labor tax. An innovating firm does not know the labor tax of the fringe firm they will face on the corresponding line, yet they reason in expected terms and clearly the expected profit goes down when they themselves become subject to the labor tax. Hence we still predict an innovation valley just below the threshold. Similarly, the expected profit from innovating for firms above the threshold, is reduced when the regulatory labor tax is introduced, to an extent which increases with the size of the firm, i.e. with its level of employment. Hence, introducing the labor tax above the threshold should again reduce the slope of the size-innovation curve above the threshold.

Including capital inputs. The current model has only labor as a productive input. Adding capital (or other inputs) would not make any fundamental difference to our current set-up because the regulation is a profit tax, so increase size is isomorphic to getting a larger (absolute) profit, since there is only one producer per line and this monopolist earns a fixed markup per line. However, if we instead followed approach (ii) and modelled the regulation as an implicit tax on labor, then the regulation does have different effects on other inputs that are not taxed. In particular, there would be an incentive to substitute into non-labor factors of production in order to mitigate the regulatory cost. In our data, firms who are approaching the 50 threshold so tend to increase capital investments, so that they can grow without necessarily adding more employees. Similarly, they increase employee hours, add more skilled workers, etc.

If these margins of adjustment were perfect substitutes for raw labor this would completely unravel the effects of the regulation. However, since these factors are generally not perfect substitutes, there will be some cost to such strategies. To what extent this reduces the overall cost of the regulation and its impact on welfare is an empirical question, which will hinge on the elasticity of substitutability. The degree of substitutability is partly due to other regulations for example, there are strict rules in France on the number of hours a worker can work per week which limits the increasing hours margin. But it is partly also constrained by the technology of production.

Appendix D and subsection 6.4 of Garicano et al. (2016) introduced capital in the context of a CES production function with regulations modelled as a labor tax with fixed and variable components (so combining points (i) and (ii) above). For an elasticity of substitution of one (Cobb-Douglas) the output loss barely changed from the baseline case of no substitution (the implied variable tax fell from $3.1 \%$ to $3 \%$ ). Since most econometric estimates of the capitallabor substitution elasticity are less than unity, even this 0.1 percentage point change is likely to be an overestimate. This is in the context of a static model, but since the magnitudes are so small, it is unlikely that it would be so much larger in our dynamic model. 


\section{B Data Appendix}

\section{B.1 Patent data}

Our first database is PATSTAT Spring 2016's version which contains detailed information about patent applications from every patent office in the world. Among the very rich set of information available, one can retrieve the date of application, the technological class, the name of the patent holder (the assignee, the entity which owns the intellectual property rights) and the complete list of forward and backward citations.

We use a crosswalk built by Lequien et al. (2017) that associates each patent whose assignee is located in France with the official identifying number (or SIREN), which enables us to use most administrative firm level datasets. This matching use supervised learning based on a training sample of manually matched patents from the French patent office (INPI). It has the advantage over other matching protocols as it is specific to French firms to exploits additional information such as the location of innovative establishments (see Lequien et al., 2017 or Aghion et al., 2018a for more details). ${ }^{41}$

Because we stop our patent analysis in 2007, we are not affected by the truncation bias toward the end of the sample (see Hall et al., 2005) and we consider that our patent information are complete. In order to be as close to the time of the innovation as possible, we follow the literature and consider the filing year and not the granting year in our study. We use citations through to the last year (2016). When calculating a firm's quantile in the patent citation distribution, we do this based on a technology class (32 codes) by cohort-year.

Finally, we consider every patent owned by a French firm, regardless of the patent office that granted the patent rights, but we restrict to priority patents which correspond to the earliest patents which relate to the same invention. Therefore, if a firm successively fills the same patent in different patent offices, only the first application of this family will be counted.

\section{B.2 Firm-level administrative data}

Our second data source provides us with accounting data for French firms from the DGFiPINSEE, this data source is called FICUS. The data are drawn from compulsory reporting of firms and income statements to fiscal authorities in France. Since every firm needs to report every year to the tax authorities, the coverage of the data is all French firms from 1994 to

\footnotetext{
${ }^{41}$ If the firm shares a patent with another firm, then we only allocate a corresponding share of this patent to the firm.
} 
2007 with no limiting threshold in terms of firm size or sales. This dataset provides us with information on the turnover, employment, value-added, the four-digit NACE sector the firm belongs to. This corresponds to around 35 million observations.

The manufacturing sector is defined as category $\mathrm{C}$ of the first level of the NAF (Nomenclature d'Activités Franaise), the first two digits of which are common to both NACE (Statistical Classification of Economic Activities in the European Community) and ISIC (International Standard Industrial Classification of All Economic Activities). INSEE provides each firm with a detailed principal activity code (APE) with a top-down approach: it identifies the 1-digit section with the largest value added. Among this section, it identifies the 2-digit division with the largest value-added share, and so on until the most detailed 5-digit APE code (INSEE, 2016). It is therefore possible that another 5-digit code shows a larger value-added share than the APE identified, but one can be sure that the manufacturing firms identified produce a larger value-added in the manufacturing section than in any other 1-digit section, which is precisely what we rely on to select the sample of most of our regressions. The 2-digit NAF sector, which we rely intensively on for our fixed effects, then represents the most important activity among the main section of the firm. Employment each year is measured on average within the year and may therefore be a non-integer number.

\section{B.3 Trade data}

Customs data for French firms. Detailed data on French exports by product and country of destination for each French firm are provided by French Customs. These are the same data as in Mayer et al. (2014) but extended to the whole 1994-2012 period. Every firm must report its exports by destination country and by very detailed product (at a level finer than HS6). However administrative simplifications for intra-EU trade have been implemented since the Single Market, so that when a firm annually exports inside the EU less than a given threshold, these intra-EU flows are not reported and therefore not in our dataset. The threshold stood at 250000 francs in 1993, and has been periodically reevaluated (650 000 francs in 2001, 100000 euros in 2002, 150000 euros in 2006). Furthermore flows outside the EU both lower than 1 000 euros in value and $1000 \mathrm{~kg}$ in weight are also excluded until 2009, but this exclusion was deleted in 2010 .

Country-product bilateral trade flows. CEPII's database BACI, based on the UN database COMTRADE, provides bilateral trade flows in value and quantity for each pair of countries from 1995 to 2015 at the HS6 product level, which covers more than 5,000 products. To convert HS 
products into ISIC industries we use a United Nations correspondence table (when 1 HS code corresponds to 2 ISIC codes, we split the HS flow in half into each ISIC code). 


\section{Theoretical Appendix}

In this Theory Appendix we first present numerical solutions for our baseline (one innovation type) model and then more details of the two types of innovation (radical and incremental) model. Next, we detail the multi-period lived owner model and finally the extension to R\&D as scientists (rather than lab-equipment).

\section{C.1 Numerical Solutions for the baseline model}

We solve the model numerically. To do so, we need to discretize the problem. That is, we need to move from a model with a continuum of products of size 1 to a model with a finite number of products $K$ and a finite number of firms $N$.

The final good aggregator is adjusted as follows:

$$
\ln y=\int_{0}^{1} \ln y_{j} d j \text { becomes } \ln y=\frac{1}{K} \sum_{j=1}^{K} \ln y_{j}
$$

Unite price of a given intermediate good $j$ is unchanged, but the demand:

$$
y_{j}=\frac{y}{p_{j}} \text { becomes } y_{j}=\frac{y}{p_{j} K}
$$

And as a result:

$$
\pi_{j}=\left(1-\frac{1}{\gamma}\right) y \text { becomes } \pi_{j}=\left(1-\frac{1}{\gamma}\right) \frac{y}{K}
$$

Finally, firm $i$ 's employment $L_{i}$ is still equal to $n /(\omega \gamma)$ where:

$$
\omega=\frac{w K}{y}
$$

The firm's maximization problem is still:

$$
n \pi(n)+\beta n z[(n+1) \pi(n+1)-n \pi(n)]+\beta n x[(n-1) \pi(n-1)-n \pi(n)]-\zeta z^{\eta} n \frac{y}{K}
$$

where the R\&D cost function in our finite line model

$$
C(z, n)=\zeta n z^{\eta} y \text { has become } C(z, n)=\frac{\zeta}{K} n z^{\eta} y
$$


With these changes in mind, equation (4) still applies and we can numerically solve the model in steady state. We proceed as follows:

1. There is a finite number $N$ of firms and $K$ of product lines, with $K>N$

2. $\mu(n)$ denotes the number of firms producing in exactly $n$ product lines and $z(i)$ denotes its innovation intensity per line (which is taken from equation (4) in the model).

3. All firms produce at least one product, as a result, we must have $\mu(n)=0$ for all $n \geq$ $K-N$. For all $i$ larger than 1

We therefore have $K-N+1$ unknowns: $\mu(n)$ for $1 \leq n<K-N(K-N-1$ unknowns), $x$ and $z_{e}$. The corresponding $K-N+1$ independent equations are given by:

- The law of motion for $\mu$ :

$$
\mu(n)=\frac{(n-1) \mu(n-1) z(n-1)+\mu(n+1)(n+1) x}{n(x+z(n))},
$$

for all $n \geq 2$ and $n<K-N$, recalling that $\mu(K-N)=0$

- The definition of $\mu$ :

$$
\sum_{n=1}^{K-N-1} \mu(n)=N
$$

- The definition of $x$

$$
x=z_{e}+\sum_{n=1}^{K-N-1} z(n) n \mu(n) / K
$$

- The steady-state equation for the number of firms in the economy

$$
\mu(1) x=z_{e} K
$$




\section{C.2 Radical vs. Incremental innovation}

This details the summarized discussion in the main text in subsection 5.1 where we allow firms to choose to invest in radical vs. incremental innovation.

Innovation equation. we solve for $u(n)$ and $z(n)$ by taking the first order condition from equation (14), where $z$ is the output-adjusted effort invested in incremental R\&D and $u$ is the output-adjusted effort invested in radical $R \& D$. This yields the following two equations:

$$
u(n)=\left(\frac{\beta}{\alpha \eta}[(n+k) \pi(n+k)-(n+1) \pi(n+1)]\right)^{\frac{1}{\eta-1}}
$$

and

$$
z(n)=\left(\frac{\beta}{\zeta \eta}[(n+1) \pi(n+1)-n \pi(n)]\right)^{\frac{1}{\eta-1}}-\left(\frac{\beta}{\alpha \eta}[(n+k) \pi(n+k)-(n+1) \pi(n+1)]\right)^{\frac{1}{\eta-1}}
$$

With these two expressions, we can solve for the equilibrium size distribution and for the share of radical innovations over incremental innovations for each firm size. See Figures 7(a) and $7(b)$.

The equilibrium size distribution is depicted in Figure C1, first on a linear scale and then on a logarithmic scale. The size distribution is qualitatively similar to the baseline case.

Figure C1: Firm size distribution with two types of innovation

(a) Linear scale

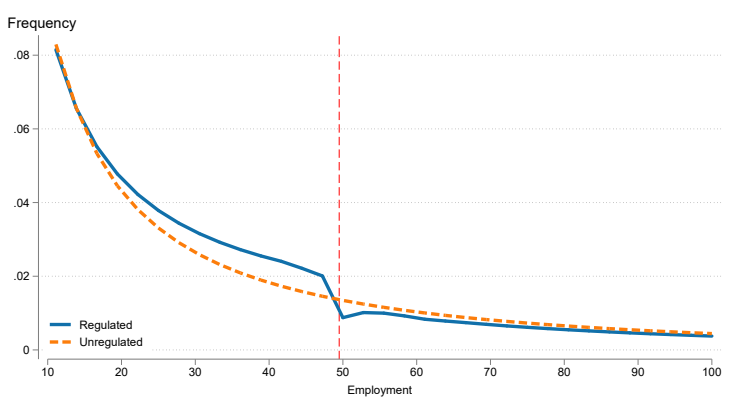

(b) Log scale

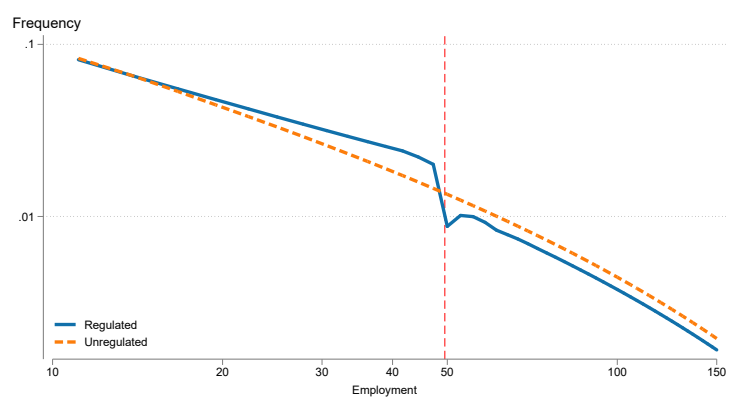

Notes: These figures plot the value of $\mu(n)$ as a function of employment $L=n /(\gamma \omega)$. Left-hand side panel uses a linear scale and right-hand side panel a log-log scale. Extension with two types of innovation with $k=4$ (see Section 5.1 )

A special case when $\eta=2$. To give the intuition of what is happening in the model with two types of innovation, we first solve formally for $u$ and $z$ in equation (14) in the simple case where we take the overall cost of $\mathrm{R} \& \mathrm{D}$ to be quadratic and equal to $\zeta(u+z)^{2} n / 2+\alpha u^{2} n / 2$. Thanks 
to the quadratic cost assumption, the first-order conditions can be conveniently summarized by the linear system:

$$
\left(\begin{array}{cc}
\zeta & \zeta \\
\zeta & \alpha+\zeta
\end{array}\right)\left(\begin{array}{l}
z \\
u
\end{array}\right)=\beta\left(\begin{array}{c}
(n+1) \pi(n+1)-n \pi(n) \\
(n+k) \pi(n+k)-n \pi(n)
\end{array}\right)
$$

As long as $\alpha$ and $\zeta$ are not equal to 0 , this linear system solves into:

$$
\left(\begin{array}{l}
z \\
u
\end{array}\right)=\frac{\beta}{\zeta \alpha}\left(\begin{array}{cc}
\zeta+\alpha & -\zeta \\
-\zeta & \zeta
\end{array}\right)\left(\begin{array}{l}
(n+1) \pi(n+1)-n \pi(n) \\
(n+k) \pi(n+k)-n \pi(n)
\end{array}\right)
$$

Hence, we can see that the values of $z$ and $u$ will be impacted by the threshold as long as $n+k \geq \bar{n}$ and $n<\bar{n}$, which means that the regulation has a larger range of effects, but at the same time has a positive effect on $u$ just before the threshold.

The solutions in the general case are presented in Table C1, where we have defined $\pi \equiv \frac{\gamma-1}{\gamma} \beta$

Figure C2: Total innovation and welfare with two types of innovation

(a) Total innovation

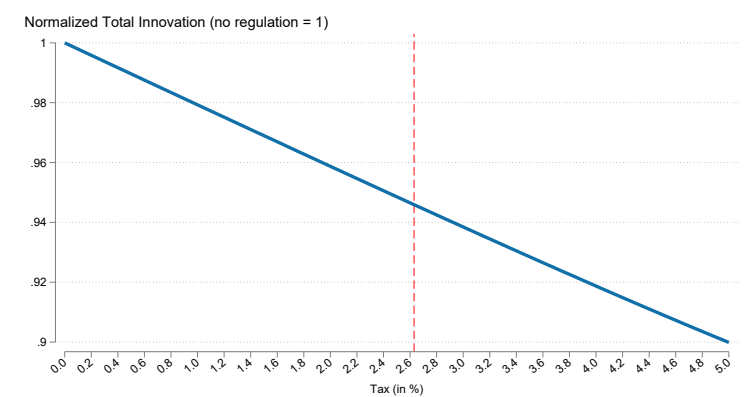

(b) Welfare

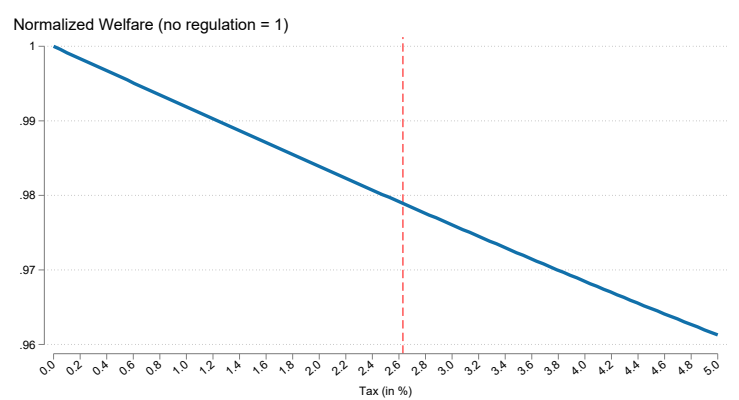

Notes: These figures plot total innovation loss and total welfare loss in consumption equivalent against the value of $\tau$. Parameter values can be found in Table $\mathrm{C} 2$.

Aggregate Effects on Innovation and Welfare. As discussed above and in the main text (see Section 5.1) we can calibrate the general model using moments in our data and the literature. The parameter values are in Table $\mathrm{C} 2$ and the relationship between aggregate innovation, welfare and the regulation are in Figure C2. The aggregate losses are smaller than in the baseline model: $5.5 \%$ lower innovation and $2.1 \%$ lower welfare in the new two types of innovation model, compared to $5.8 \%$ and $2.3 \%$ in the baseline model. The lower losses are because radical innovation which creates greater social welfare is not discouraged. However, since the bulk of innovation is incremental, the aggregate losses are only modestly impacted. 
Table C1: Solution in the Extended Model with two types of innovation (radical and incremental)

\begin{tabular}{|c|c|c|}
\hline & $u(n)$ & $z(n)$ \\
\hline$n<\bar{n}-k$ & $\left(\frac{\pi}{\alpha \eta}(k-1)\right)^{\frac{1}{\eta-1}}$ & $\left(\frac{\pi}{\zeta \eta}\right)^{\frac{1}{\eta-1}}-u(n)$ \\
\hline $\bar{n}-k \leq n<\bar{n}-1$ & $\left(\frac{\pi}{\alpha \eta}((k-1)-\tau(k+n))\right)^{\frac{1}{\eta-1}}$ & $\left(\frac{\pi}{\zeta \eta}\right)^{\frac{1}{\eta-1}}-u(n)$ \\
\hline$n=\bar{n}-1$ & $\left(\frac{\pi}{\alpha \eta}((k-1)+\tau(\bar{n}-k))\right)^{\frac{1}{\eta-1}}$ & $\left(\frac{\pi}{\zeta \eta}(1-n \tau)^{\frac{1}{\eta-1}}-u(n)\right.$ \\
\hline$n \geq \bar{n}$ & $\left(\frac{\pi}{\alpha \eta}(1-\tau)(k-1)\right)^{\frac{1}{\eta-1}}$ & $\left(\frac{\pi(1-\tau)}{\zeta \eta}\right)^{\frac{1}{\eta-1}}-u(n)$ \\
\hline & $u(n)+z(n)$ & $\frac{u(n)}{z(n)+u(n)}$ \\
\hline$n<\bar{n}-k$ & $\left(\frac{\pi}{\zeta \eta}\right)^{\frac{1}{\eta-1}}$ & $\left(\frac{\zeta}{\alpha}(k-1)\right)^{\frac{1}{\eta-1}}$ \\
\hline $\bar{n}-k \leq n<\bar{n}-1$ & $\left(\frac{\pi}{\zeta \eta}\right)^{\frac{1}{\eta-1}}$ & $\left(\frac{\zeta}{\alpha}(k-1)\left(1-\frac{\tau(k+n)}{k-1}\right)\right)^{\frac{1}{\eta-1}}$ \\
\hline$n=\bar{n}-1$ & $\left(\frac{\pi}{\zeta \eta}(1-n \tau)^{\frac{1}{\eta-1}}\right.$ & $\left(\frac{\zeta}{\alpha}(k-1)\left(1-\frac{\tau(\bar{n}-k)}{k-1}\right) \frac{1}{1-\tau \bar{n}}\right)^{\frac{1}{\eta-1}}$ \\
\hline$n \geq \bar{n}$ & $\left(\frac{\pi(1-\tau)}{\zeta \eta}\right)^{\frac{1}{\eta-1}}$ & $\left(\frac{\zeta}{\alpha}(k-1)\right)^{\frac{1}{\eta-1}}$ \\
\hline
\end{tabular}

Table C2: Calibrated parameter values in a model with two types of innovation

\begin{tabular}{lc} 
Parameter & Value \\
\hline$\gamma$ & 1.3 \\
$\eta$ & 1.5 \\
$\omega$ & 0.28 \\
$\beta / \zeta$ & 1.34 \\
$k$ & 4 \\
$\alpha$ & 6.92 \\
$\tau$ & 0.0263 \\
\hline
\end{tabular}

Notes: Calibration strategy is described in Section 5.1.

\section{C.3 Longer lived owners}

In our baseline model, although firms can live forever we simplified the analytical problem by assuming the owners of firms only live for two periods. In this subsection, we show that the 
qualitative and quantitative predictions of the model carry over to a more complex environment where owners live longer.

\section{C.3.1 Adding one extra period to the life of the owner}

We first show how to extend our model by allowing firm owner to live for three periods instead of the two period baseline. In the first period, the owner inherits a firm of size $n_{1}$. She then chooses her level of innovation $Z_{1}\left(n_{1}\right)=n_{1} z_{1}\left(n_{1}\right)$ and enters period 2 with a size $n_{2}$ (which can be either equal to $n_{1}, n_{1}+1$ or $\left.n_{1}-1\right)$. She chooses the level of innovation for period 2 , $Z_{2}\left(n_{2}\right)=n z_{2}\left(n_{2}\right)$. In period 3 , the owner collects profits, exits and ownership passes on to a new agent. Because the firm's owner only produces for two periods, we refer to this model as "the two period model" while the baseline model is denoted the "one period model".

We solve backwards: in period 2, the situation is the same as in the one period model and we know that for any size $n$, the innovation per line is:

$$
z_{2}(n)=\left(\frac{\beta \pi}{\eta \zeta}\right)^{\frac{1}{\eta-1}} \times\left\{\begin{array}{ll}
1 & \text { if } n<\bar{n}-1 \\
(1-\bar{n} \tau)^{\frac{1}{\eta-1}} & \text { if } n=\bar{n}-1 \\
(1-\tau)^{\frac{1}{\eta-1}} & \text { if } n \geq \bar{n}
\end{array} \quad \text { where } \pi=\frac{\gamma-1}{\gamma}\right.
$$

In period 1 , the firm maximizes the value function:

$$
V_{1}(n)=\max _{z_{1}>0}\left\{n \pi(n) y-n z_{1}^{\eta} \zeta y+\frac{1}{1+r} \mathbb{E}_{z_{1}}\left[V_{2}\left(n^{\prime}\right)\right]\right\}
$$

where $V_{2}(n)$ is the value of being of size $n$ in period 2 .

$$
V_{2}(n)=\max _{z_{2}>0}\left\{n \pi(n) y-n z_{2}^{\eta} \zeta y+\frac{1}{1+r} \mathbb{E}_{z_{2}}\left[\pi\left(n^{\prime}\right) y^{\prime}\right]\right\} \text {. }
$$

We denote $v_{i}(n) \equiv V_{i}(n) /(n y)$ for $i=1,2$. Then, using the Euler equation we have:

$$
v_{2}(n)=\pi(n)(1+\beta)+\beta z_{2}(\pi(n+1)-\pi(n))+\beta x(\pi(n-1)-\pi(n))-z_{2}^{\eta} \zeta
$$

and finally:

$$
z_{1}=\left(\beta \frac{(n+1) v_{2}(n+1)-n v_{2}(n)}{\zeta \eta}\right)^{\frac{1}{\eta-1}}
$$

It is thus possible to solve for equilibrium innovation given the number of lines in each period. Compared to the baseline case, the regulation will not only impact firms with a size 
$\bar{n}-1$ but also firms with a size $\bar{n}-2$ in period $1 .^{42}$

Figure 10(a) plots the value of $\frac{z_{1}+z_{2}}{2}$, the average value of innovation per period, along with the value of $z$ in the baseline model against employment. The main differences between the two is that in the two period model, the innovation valley is wider and extends to firms with an employment corresponding to $n=\bar{n}-2$. The fall in innovation at 49 employees is also less deep because the cost of the regulation is smoothed over two periods instead of one.

Size distribution. To solve for the size distribution, we look for solution where the distribution of firms in their period 2 is the same as the distribution of firms in their first period. We denote the share of firms of size $n$ as $\mu(n)$ and we have at the steady-state:

$$
\frac{\mu(n)}{2}\left(z_{1}(n)+z_{2}(n)\right) n=\frac{\mu(n-1)}{2}\left(z_{1}(n-1)+z_{2}(n-1)\right)(n-1)+(n+1) x \frac{\mu(n+1)}{2}
$$

Hence if we define $z=\frac{z_{1}+z_{2}}{2}$, the flow equation that determines the equilibrium size distribution is the same as in the baseline case. Figure 10(b) plots this distribution against the value of employment in the baseline case and in the two period model.

Calibration. In the baseline model, the calibration of $\tau$, which governed the aggregate innovation loss followed directly from the comparison of the slopes of the innovation - firm size cross-sectional relationship in large vs. small firms. In our extended multi-period model, the calibration is slightly more involved and all parameters need to be estimated simultaneously. To illustrate why, we write the average innovation observed for a given size $n$, taken as the mean of the level of innovation for firms in their first and second period, respectively for large and small firms and consider the ratio.

$$
\mathcal{R}=\frac{z_{1}(n \geq \bar{n})+z_{2}(n \geq \bar{n})}{z_{1}(n<\bar{n}-2)+z_{2}(n<\bar{n}-2)}
$$

\footnotetext{
${ }^{42}$ In principle, the regulation can also impact firms with a size $\bar{n}$ in period 1 as they can reach a size $\bar{n}-1$ in the next period. However, we make the assumption that once the firm has crossed the threshold, the regulation continues to be enforced during the lifespan of the firm's owner, even if the firm becomes smaller than 50 (i.e. the regulations are "grandfathered". This simplifying assumption seems reasonable given that the nature of the regulation imposes many important adjustment costs that are hard to reverse.
} 
For small firms, $z_{1}+z_{2}$ is equal to:

$$
\left(\frac{\beta \pi}{\zeta \eta}(1+\beta(1-x))+\left(\frac{\beta \pi}{\zeta \eta}\right)^{\frac{\eta}{\eta-1}} \frac{\eta-1}{\eta} \beta\right)^{\frac{1}{\eta-1}}+\left(\frac{\beta \pi}{\zeta \eta}\right)^{\frac{1}{\eta-1}}
$$

For large firms, $z_{1}+z_{2}$ is equal to:

$$
\left(\frac{\beta \pi(1-\tau)}{\zeta \eta}(1+\beta(1-x))+\left(\frac{\beta \pi(1-\tau)}{\zeta \eta}\right)^{\frac{\eta}{\eta-1}} \frac{\eta-1}{\eta} \beta\right)^{\frac{1}{\eta-1}}+\left(\frac{\beta \pi(1-\tau)}{\zeta \eta}\right)^{\frac{1}{\eta-1}}
$$

Hence:

$$
\mathcal{R}=(1-\tau)^{\frac{1}{\eta-1}}(1-\mathcal{A})
$$

where $\mathcal{A}>0$ is a function of model parameters and endogenous variable $x$ which is small for small values of $\tau .{ }^{43} \mathcal{A}>0$ also implies that the value of $\tau$ required to ensure that the ratio of slopes match the data will be smaller than in the baseline model.

We use the same calibration strategy as our baseline approach. We set $\eta$ and $\gamma$ to the same values in Table 3 and set $\beta$ to 0.96 . We then use three moments from the data: $\mathcal{R}$, the longterm growth and the gap in the size distribution around the threshold to estimate the three remaining parameters $\tau, \omega$ and $\zeta$. Top panel of Table C3 displays the corresponding moments in the data and in the calibration.

The resulting parameter values are presented in the bottom panel of Table C3. They are very similar to those in the baseline model in Table 3, with the exception of the innovation cost $\zeta$, which we discuss below. Most importantly, the key parameter $\tau$ is essentially unchanged, because we find $\mathcal{A}$ very close to 0 (0.0011), but slightly lower (2.62\% vs $2.63 \%$ in the baseline).

Aggregate Innovation and Welfare. Once the value of $\mu$ and $z$ are obtained using equation (C1), we can compute aggregate innovation and welfare. The formulae are the same as in the baseline model, but the value of innovation per line $z$ is replaced by the average innovation over the two periods of production $\left(z_{1}+z_{2}\right) / 2$. The loss in total innovation and total welfare

\footnotetext{
${ }^{43}$ Formally:

$$
\mathcal{A}=\frac{\left((1+\beta(1-x))+\left(\frac{\beta \pi}{\zeta \eta}\right)^{\frac{1}{\eta-1}} \frac{\eta-1}{\eta} \beta\right)^{\frac{1}{\eta-1}}-\left((1+\beta(1-x))+\left(\frac{\beta \pi}{\zeta \eta}\right)^{\frac{1}{\eta-1}} \frac{\eta-1}{\eta} \beta(1-\tau)^{\frac{1}{\eta-1}}\right)^{\frac{1}{\eta-1}}}{\left((1+\beta(1-x))+\left(\frac{\beta \pi}{\zeta \eta}\right)^{\frac{1}{\eta-1}} \frac{\eta-1}{\eta} \beta\right)^{\frac{1}{\eta-1}}+1}
$$
}


Table C3: Calibrated parameter values in a model with two periods

\begin{tabular}{|c|c|c|}
\hline Moments & Data & Model \\
\hline Growth rate of GDP & 1.62 & 1.62 \\
\hline Gap in the size distribution & 3.03 & 3.01 \\
\hline Ratio of slope $\mathcal{R}$ & 0.947 & 0.946 \\
\hline Parameter & Value & Baseline \\
\hline$\gamma$ & 1.3 & 1.3 \\
\hline$\eta$ & 1.5 & 1.5 \\
\hline$\omega$ & 0.22 & 0.22 \\
\hline$\beta / \zeta$ & 1.09 & 1.66 \\
\hline$\tau$ & 0.0262 & 0.0263 \\
\hline
\end{tabular}

are shown in Figures 11(a) and 11(b) along with the corresponding loss in the baseline model. The figures show that the loss in total innovation and welfare remains extremely similar in the new multi-period model compared to the baseline, essentially since the value of the implicit regulatory tax remains close to $2.6 \%$.

Figure 11(a) does show that the losses are slightly lower in the new model. This is because the calibration strategy must match the same empirical value of French growth of $1.62 \%$ (and hence total innovation). Because firms in the two period model will do more innovation on average each period, to be consistent with the empirical growth moment, the innovation cost parameter, $\zeta$ is estimated to be larger. Since $\zeta$ is held constant in the counterfactual unregulated economy, this means that overall innovation is reduced (slightly) less by any given regulatory $\operatorname{tax}^{44}$

\section{C.3.2 Adding more periods to the multi-period model}

The model can be naturally extended to adding more periods to the firm owner's life through induction. Consider a case where a firm owner live for $k+1$ periods ( $k$ periods of innovation and one period where they simply collect profit). Then the value of innovation intensity in the last period $z_{k}$ is the same as the value of $z$ in the baseline model. The value of $z_{k-1}$ comes from

\footnotetext{
${ }^{44}$ Note however, that the level of welfare for each value of $\tau$ is lower in the 2 period model than in the baseline model.
} 
Figure C3: Innovation per line when adding more periods

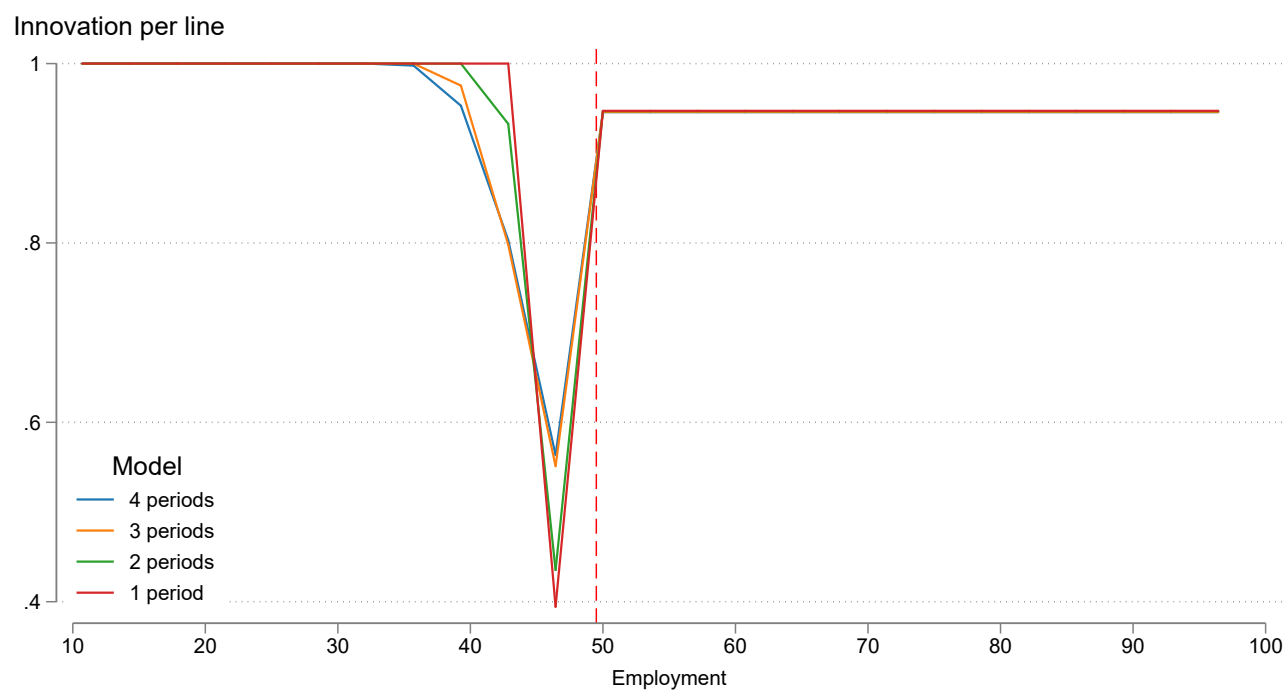

Notes: Innovation per line in the baseline model and in models with 2,3 and 4 production periods.

the difference between the value function in period $k$ as in the two period model. Then using the value of $z_{k-1}$ yields a value of $v_{k-1}$ which gives a value of $z_{k-2}$ and so on.

Formally, once we have solved for a $J$ period model, extending to a model with $J+1$ periods can be done easily in the following way. If $V(n, p, J)$ and $z(n, p, J)$ respectively denote the value and innovation intensity of a firm with $n$ lines in its period $p$ in a model with $J$ periods, then we have:

$$
\forall n>0, \forall p<J: V(n, p+1, J+1)=V(n, p, J) \text { and } z(n, p+1, J+1)=z(n, p, J) .
$$

Hence, to move to a model with one more period, all we need is to solve for the first period which we do as in the two period model. Intuitively, as we extend the number of periods, the innovation valley widens and its depth reduces. This is illustrated in Figure C3 where we have reported the average value of innovation against size in the case of a 2, 3 and 4 period models, along with the baseline one period model.

Regarding the size distribution, we can use the same strategy as in the two period model by considering:

$$
z=\frac{z_{1}+\ldots+z_{k}}{k}
$$

Generally speaking we have a sequence:

$z(n, k-p-1, k)^{\eta-1}=\frac{\beta \pi}{\zeta \eta}+\beta\left(z(n, k-p, k)^{\eta-1}(1-x)+z(n, k-p, k)^{\eta} \frac{\eta-1}{\eta}\right) \quad \forall p \in[[1, k-1]]$ 
and

$$
\left.z_{(} n, k, k\right)^{\eta-1}=\frac{\beta \pi}{\zeta \eta}
$$

Importantly, if $\beta$ is small enough, then extending the number of periods does not change the results materially from our baseline model.

\section{C.3.3 Summary on extension to multi-period lived owners}

We have shown that adding an extra period to a firm owner's life extends the "shadow" of the regulation further down the firm size distribution. As we might expect, the innovation valley becomes wider and flatter. A model calibration shows very similar aggregate innovation and welfare losses to our baseline case, however, suggesting that our simpler, more analytically tractable approach does not mislead us. Moreover, the theoretical findings on the shape of the innovation-size relationship generalize to having many more periods. Hence, our simple approach delivers losses in the right order of magnitude and is materially unchanged from moving to more complex dynamic models. ${ }^{45}$

\section{C.4 R\&D as scientific labor}

This section solves the model outlaid in Section 5.5. In this extension, R\&D is performed by scientists, hence the workforce is now split between production and innovation workers. For each firm $i$, employment $l_{i}$ is therefore given by:

$$
l_{i}=\frac{n_{i}}{\omega \gamma}+\zeta n_{i} z_{i}^{\eta}
$$

Aggregating over all firms, we get:

$$
\mathcal{L}=\int_{i} l_{i} d i=\frac{1}{\omega \gamma}+\zeta \int_{i} n_{i} z_{i}^{\eta} d i=\frac{1}{\omega \gamma}+\zeta \sum_{n>0} \mu(n) n z^{\eta}(n)
$$

Since $\mathcal{L}$ is fixed and exogenous, and since the right hand side terms of the above equation varies with the $\operatorname{tax} \tau$, then $\omega$ also varies with $\tau$. More precisely, the equilibrium wage $\omega$ decreases with $\tau$, since regulation costs decreases aggregate innovation (the second term of the right-hand side of the equation).

\footnotetext{
${ }^{45}$ In the working paper version, we show that qualitatively similar results are also found when considering another approach to modelling infinitely lived owners (Aghion et al., 2021).
} 
Given that employment is now a function of both the number of products $n$ and the intensity of innovation $z$, we denote it by $L(n, z)$. The cutoff threshold $\bar{l}=50$ is now defined by the set of points in the space $(n, z)$ such that:

$$
z=\frac{1}{\zeta n}\left(\bar{l}-\frac{n}{\gamma \omega}\right)
$$

Figures C4 shows the equilibrium relationship between the number of products, employment and innovation intensity (which indirectly relates to the number of $R \& D$ workers). It is no longer possible to use the number of products as a measure of the size of the firms and we need to define profit per unit of final output is now equal to:

$$
\pi(n, z)=\frac{\gamma-1}{\gamma}(1-\mathbb{1}[L(n, z) \geq \bar{l}] \tau)
$$

Hence, the firm's maximization problem remains the same as before but with the two state variables $n$ and $z$, that is:

$$
\max _{n \geq 0, z \geq 0}\left\{n \pi(n, z) y-\zeta n z^{\eta} y+\frac{1}{1+r} \mathbb{E}\left[n^{\prime} \pi\left(n^{\prime}, z^{\prime}\right) y^{\prime}\right]\right\} .
$$

Figure C4: Localization of employment threshold $\bar{l}$

(a) 3D plot

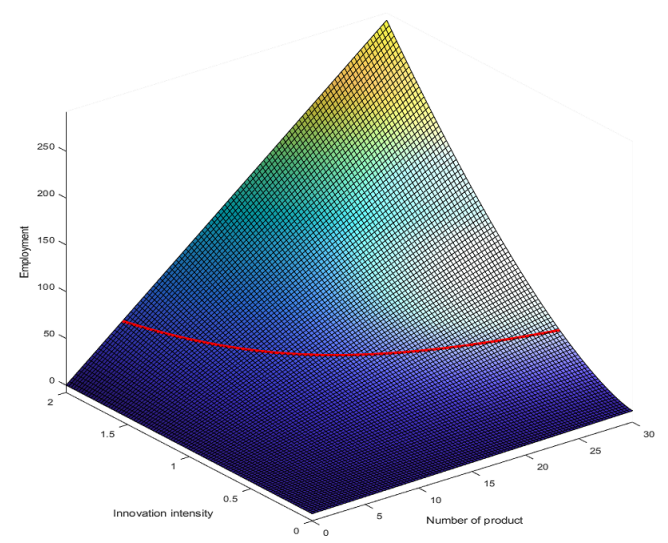

(b) $2 \mathrm{D}$ projection

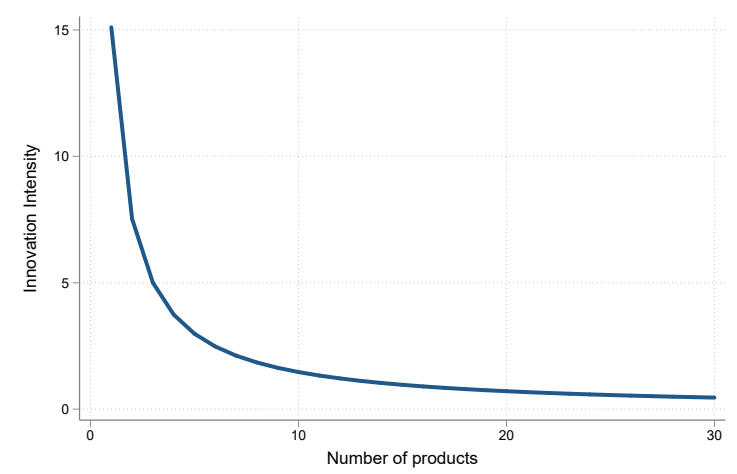

Notes: These Figures plot the relationship between employment $L$, innovation intensity $z$ and number of products $n$. The left-hand side panel shows the 3D plot corresponding to the surface defined by equation (C2), where the z-axis corresponds to $L$. The curve in red corresponds to the intersection of the surface $(n, z, L)$ with the surface $L=\bar{l}$. The right-hand side panel presents the set of pairs $(z, n)$ which corresponds to an employment level of $\bar{l}$ according to equation (C3).

Solving this maximization problem for every value of $n$ gives a function $Z(n)=n z(n)$ which we plot in Figure C5 against employment $L(n)$. We see that the innovation-employment cross- 
section relationship is qualitatively unchanged. In Figure C5, we also plot the corresponding relationship between firm's employment and its share of R\&D workers.

Figure C5: Innovation-Employment cross-section with scientists $\bar{l}$

(a) Innovation

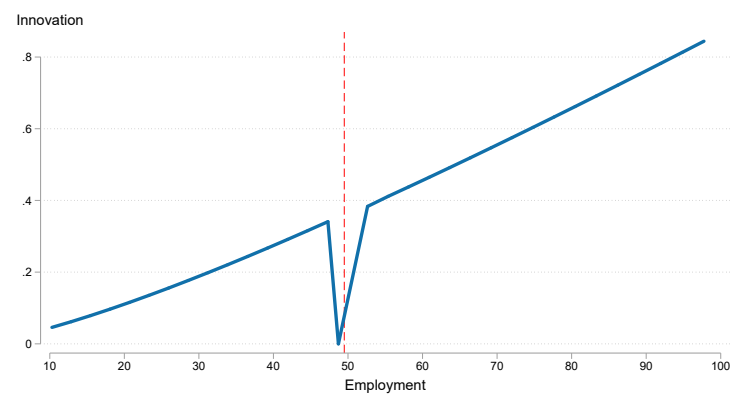

(b) Share of R\&D workers

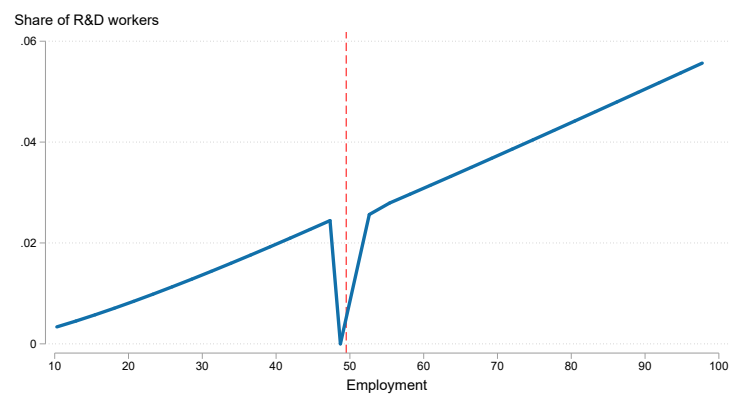

Notes: This is the total amount of innovation $(Z(n)$, left-hand side panel) and share of R\&D workers in total employment $\left(\zeta n z^{\eta}(n) / L(n)\right)$, right-hand side panel) by firms of different sizes (employment, $\left.L=n /(\omega \gamma)+\zeta n z^{\eta}\right)$ according to our theoretical model extension presented in Section 5.5. We use arbitrary parameter values for illustrative purposes. 


\section{C.5 Modeling regulation as a tax on labor}

In this extension, we let the regulation take the form of a marginal tax on the labor input so that the wage $w$ becomes $w(1+\tau)$ if the firm crosses the threshold. Then, given that on each product line firms compete a la Bertrand, the incumbent producer $i(j)$ on a line $j$ will set its price equal to the marginal cost of its competitor $i^{\prime}(j)$, namely:

$$
p_{j}=\frac{\gamma}{A_{j}} w\left(1+\tau_{i^{\prime}(j)}\right) \text { or } p_{j}=\frac{\gamma}{A_{j}} w
$$

depending on whether the competitor who was also the previous producer on the line, $i^{\prime}(j)$, was larger or smaller than the threshold size. This yields:

$$
y_{j}=\frac{A_{j} y}{\gamma w(1+\tau)} \text { or } y_{j}=\frac{A_{j} y}{\gamma w}
$$

The markup $m(j)$ on line $j$, defined as the unit price over unit cost depends on whether or not firm $i(j)$ is taxed and on whether the previous producer $i^{\prime}(j)$ would be taxed, namely:

$$
m(j)=\frac{\gamma\left(1+\tau_{i^{\prime}(j)}\right)}{1+\tau_{i((j))}} .
$$

Such a line generates a profit per unit of final good which depends on the both, the labor $\operatorname{tax} \tau_{i(j)}$ of the current producer and the labor tax of the previous producer $\tau_{i^{\prime}(j)}$, i.e. on both, the size of the current producer $i(j) \tau_{i^{\prime}(j)}$ and the size of the previous producer $i^{\prime}(j)$ on line $j$ :

$$
\pi(j)=1-\frac{1+\tau_{i(j)}}{\gamma\left(1+\tau_{i^{\prime}(j)}\right)}
$$

Next, the equilibrium number of workers on a line also depends on the size of the fringe firm on that line. A line with a small fringe firm requires $y /(\gamma w)$ workers whereas a line with a large fringe firm only requires $y /(\gamma w(1+\tau))$ workers. Let us restrict attention to an equilibrium where $S$, the share of lines operated by a large firm, is constant. By the law of large numbers $S$ also corresponds to the probability for an innovating firm, of facing a large firm as its competitive fringe on the corresponding line. It follows that total employment by a firm of size $n$ is then equal to:

$$
l(n)=n \frac{y}{\gamma w}\left(\frac{S}{1+\tau}+1-S\right) .
$$

This in turn implies that the threshold number of lines beyond which a firm is considered to be a large firm eligible to the regulatory labor tax, $\bar{n}$, is no longer constant but depends upon 
S. Namely:

$$
\bar{n}=\frac{\bar{l} \gamma w}{\left(\frac{S}{1+\tau}+1-S\right)}
$$

Moving back to the R\&D investment stage, for a given $S$ at the steady state, a firm of size $n$ will choose its innovation intensity $z$ to maximize:

$$
\Pi(n, S)+\beta n z(n)(\Pi(n+1, S)-\Pi(n, S))-\beta n x(\Pi(n-1, S)-\Pi(n, S))-n z^{\eta} \zeta
$$

where $\Pi(n, S)=n\left(1-\frac{1+\tau \mathbb{1}(n \geq \bar{n})}{\gamma}\left(\frac{S}{1+\tau}+(1-S)\right)\right)$

In equilibrium, $S$ is constant and equal to the share of products lines operated by large firms, namely:

$$
S=\sum_{i>\bar{n}} \mu(i) i
$$

where $\bar{n}$ itself depends upon $S$ (see the above expression) and where $\mu$ follows a law of motion as in the baseline model. At the moment, we consider $S$, and therefore $\bar{n}$, to be constant and taken as given by the firm. This yields the following innovation-size cross relationship:

$$
z(n, S)= \begin{cases}\left(\frac{\beta}{\zeta \eta}\left(1-\frac{B}{\gamma}\right)\right)^{\frac{1}{\eta-1}} & \text { if } n<\bar{n}-1 \\ \left(\frac{\beta}{\zeta \eta}\left(1-\frac{B(1+\tau \bar{n})}{\gamma}\right)\right)^{\frac{1}{\eta-1}} & \text { if } n=\bar{n}-1 \\ \left(\frac{\beta}{\zeta \eta}\left(1-\frac{B(1+\tau)}{\gamma}\right)\right)^{\frac{1}{\eta-1}} & \text { if } n \geq \bar{n}\end{cases}
$$

where $B=\frac{S}{1+\tau}+(1-S)=1-\frac{\tau}{1+\tau} S<1$

Hence the equilibrium $n \longrightarrow z(n, S)$ function looks similar to the equilibrium innovation-size relationship $z(n)$ in our baseline model with regulatory profit tax (see equation (4)). 


\section{Additional Empirical Results}

\section{D.1 Size distribution of French firms}

Figure D1 reports the size distribution of firms from FICUS in a log-log scale. In order to replicate results from Garicano et al. (2016), we use the year 2000, although choosing another year results in very similar relationship. The relationship is consistent with the well-know power law documented namely by Axtell (2001), but with two discontinuities: one at 50 employees and the other one at 10 employees, corresponding to size dependent regulation thresholds (see Appendix A).

Figure D1: Distribution of size

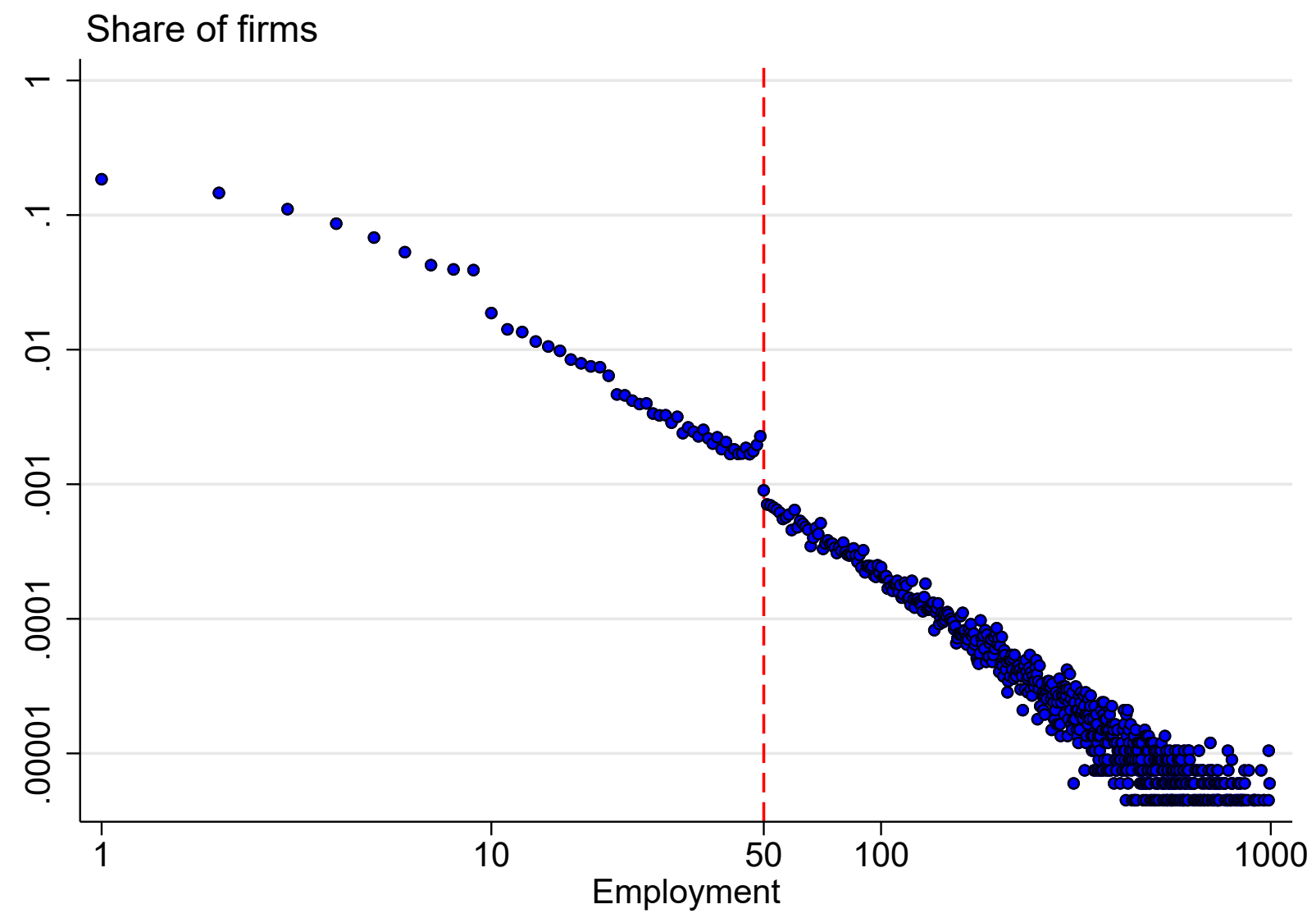

Notes: The data relate to the year 2000 for all firms.

\section{D.2 Robustness of the cross-sectional innovation-size relationship}

As noted in the main text the relationship between firm innovation and size are robust to a wide variety of alternative definitions. The baseline method in Figure 5 defines as innovative firm as 
one who has produced at least open patent over the sample period. In Figure D2 we consider using a narrower window around the year employment is measured. Panel A uses between patents in $t$, exactly the same year as employment as measured. Panel B uses patents filed two years before and two years after the employment measure (a five year window) and Panel $\mathrm{C}$ between four years before and after (a nine year window). Panel D measures innovation as $\log (1+$ patents count $)$ in the same year as employment. Although the measures are somewhat noisier than using the whole period (which smooths things out), the same basic pattern of an innovation valley and a fall in the gradient after the regulatory threshold are apparent.

Figure D3 repeats these four definitions for the Figures comparing incremental and radical patents as measured by future citations (analogous to Figure 9).

\section{D.3 Robustness of the dynamic effects of the market size shock on innovation}

In the main text we noted the robustness of the decline in the impact of demand shocks to the left of the threshold and reported some of our tests. Here, we detail some more of these.

First, it is possible that the changing relationship between innovation and the market size shock around the threshold is driven by some kind of complex non-linearities in the innovationemployment relationship, and our quadratic controls are insufficient. To investigate this issue, we allow interactions between the demand shock and different size bins of firms in Table D1. Of all the 14 different size bins, only the interaction of the shock with the size bin just below the threshold (45-49 employees) is significantly different from zero and large in absolute magnitude.

Second, our results are robust to the particular way in which we define the upper and lower size cutoffs for our sample. Appendix Table D2 reproduces the baseline specification in column (1). Column (2) uses employment at t-2 instead of the initial year to define the sample, column (3) relaxes the upper threshold to include firms of up to 500 employees (instead of 100 employees in the baseline) and column (4) includes all firms below 100 employees (instead of dropping the firms with between zero and 9 workers). Column (5) restricts the sample to firms exporting in 1994 (instead of the restriction that a firm has to export in at least one year over the period 1994-2007). Column (6) includes all the non-exporting firms (see below for more details). The last three columns use three different definitions of the dependent variable instead of our basic measure $\tilde{\Delta} Y$ : the log-difference in column (7), the difference in the Inverse Hyperbolic Sine in column (8) and the change in patents normalized on pre-sample patents in column (9). Our results are robust to all these tests.

Finally, one might be concerned that the quantiles of the citation distribution reported 
in Table 5 are arbitrary. Figure D4 reports the coefficient and confidence intervals on the key interaction term in our preferred specification for every quantile from the top 10th to the bottom 70th percentile in $5 \%$ intervals. As discussed in the text, it is clear that the negative effect of the regulation is only apparent for the less cited patents. There is no significant effect in a quantitative or statistical sense for patents in the top quartile of the citations distribution. The negative effect is driven by those in the bottom two-thirds of the citation distribution (with a monotonic decline of the effect for those between the 25 th and 35 th percentiles.

Extending to non-exporting firms. In column (6) of Table D2, we have extended the sample to all firms, while our baseline results restrict to exporting manufacturing firms. To do so, we need to calculate a demand shock for these firms that do not export. One natural way to do so would be to calculate the average demand shock at the sectoral level from firms that do export. However, our model includes sector-year fixed effects and even if the demand shock can be aggregated at a smaller sectoral level, most of the variance would be captured by these fixed effects.

To gain statistical power, we proceed as follows. We recalculate the same quantity as in equation (8) but at the sectoral level:

$$
\Delta S_{k, t}=\sum_{s, c \in \Omega(k, 1994)} \omega_{k, s, c, 1994} \tilde{\Delta} I_{s, c, t}
$$

for each 5-digit sector $k$ and year $t$. We use weights at the sector level taken during the year 1994 and covering all pairs of product-countries that firms in sector $k$ exported to in 1994. Contrary to the baseline shock at the firm level $\Delta S_{i, t}$, we do not weight by the level of export intensity. Instead, we construct a weighted shock that used both $\Delta S_{k, t}$ and $\Delta S_{i, t}$ with weights depending on the level of export intensity of the firms:

$$
\Delta S_{i, t}^{(k)}=\sigma_{i, t_{0}} \sum_{s, c \in \Omega\left(i, t_{0}\right)} \omega_{i, s, c, t_{0}} \tilde{\Delta} I_{s, c, t}+\left(1-\sigma_{i, t_{0}}\right) \Delta S_{k, t}
$$

Hence, a non-exporting firms will have a shock equal to the sectoral component while an exporting firms will have a shock equal to a weighted average of the two components. Besides, the larger its export intensity, the closer this new shock is to the baseline one. As shown in column (6) of Table D2, our results are robust to using this shock which allows us to include much more observations (about 925,000 instead of 142,000). 
Figure D2: Innovative firms at each employment level - robustness

(a) Alternative A

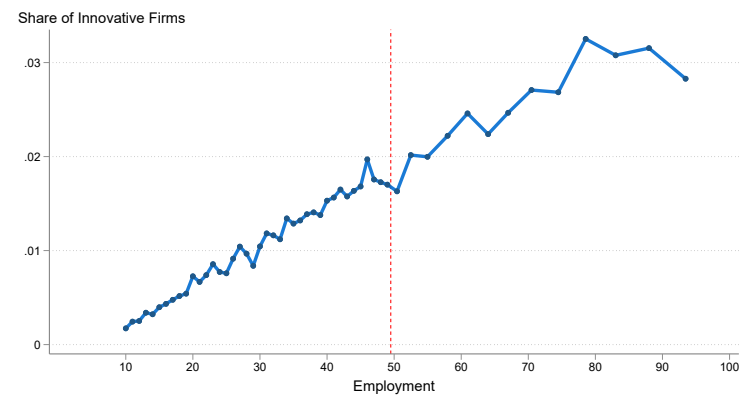

(c) Alternative C

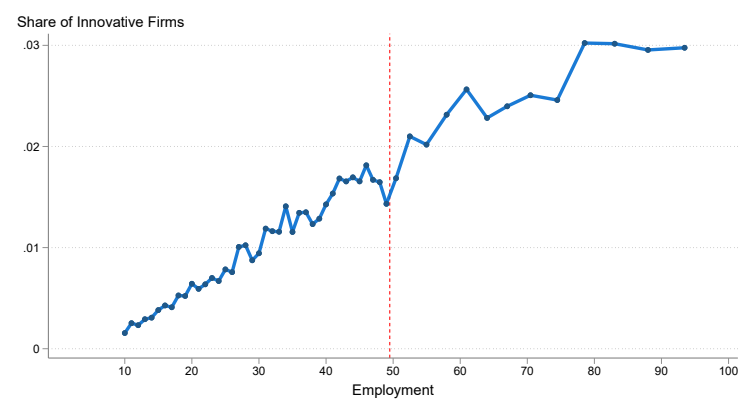

(b) Alternative B

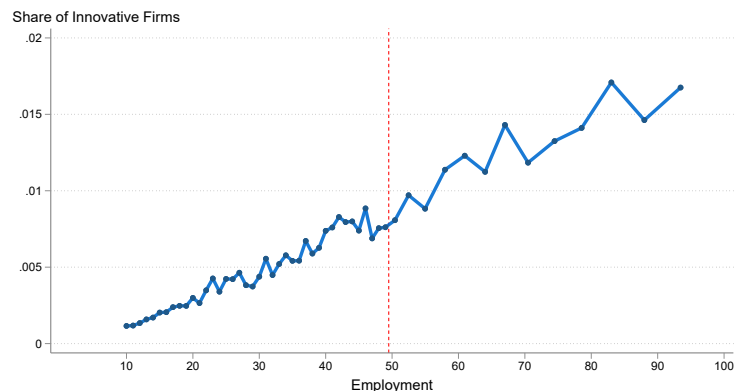

(d) Alternative D

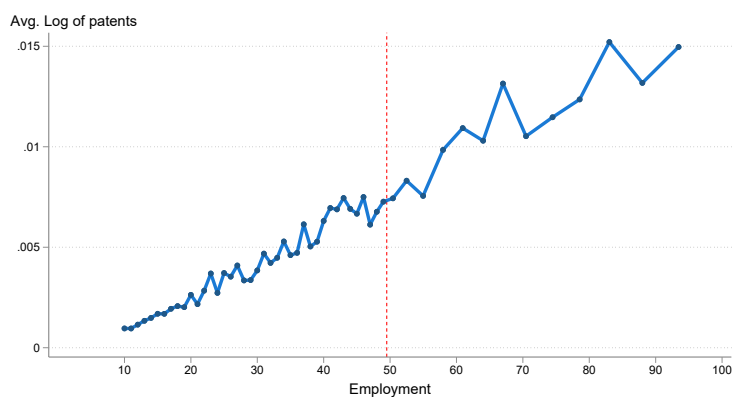

Notes: These Figures replicate Figure 5 using different definitions of the what counts as an innovative firm, based on the timing of patents. Alternatives $\mathrm{A}, \mathrm{B}, \mathrm{C}$ and $\mathrm{D}$ define an innovative firm as a firm having filed a priority patent application between $t-2$ and $t+2(\mathrm{~A})$, at $t(\mathrm{~B})$, between $t-4$ and $t(\mathrm{C})$. Alternative $\mathrm{D}$ uses the logarithm of 1 plus the number of patent application at $t$. 
Figure D3: Innovative firms at each employment level and quality of innovation- robustness

(a) Alternative A

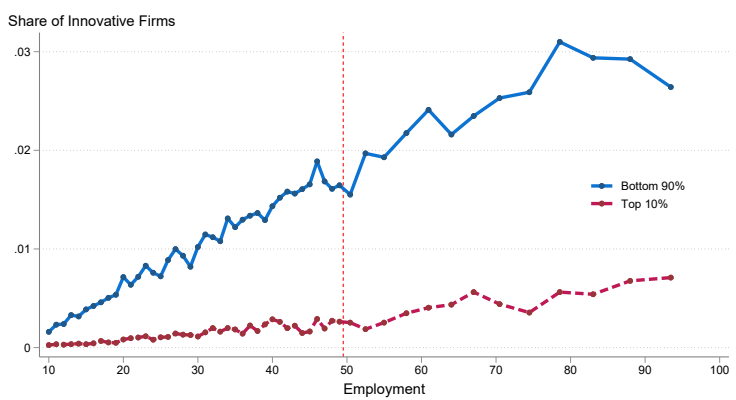

(c) Alternative C

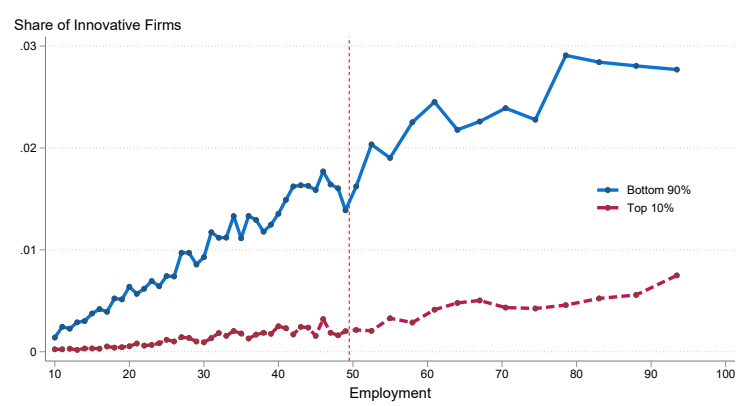

(b) Alternative B

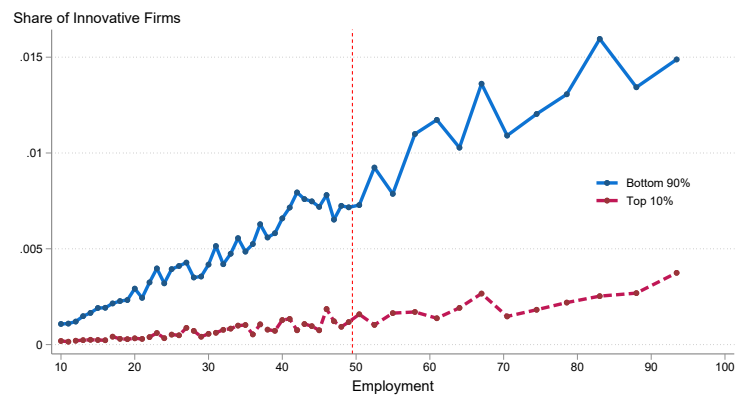

(d) Alternative D

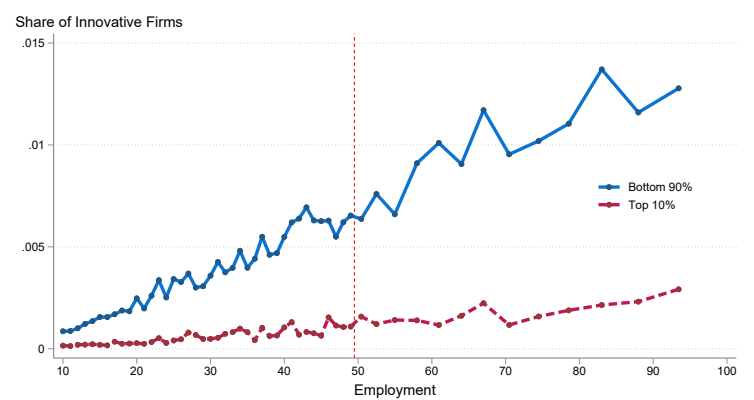

Notes: These Figures replicate 8 using different definitions of the what counts as an innovative firm, based on the timing of patents. Alternatives $\mathrm{A}, \mathrm{B}, \mathrm{C}$ and $\mathrm{D}$ define an innovative firm as a firm having filed a priority patent application between $t-2$ and $t+2$ $(\mathrm{A})$, at $t(\mathrm{~B})$, between $t-4$ and $t(\mathrm{C})$. Alternative $\mathrm{D}$ uses the logarithm of 1 plus the number of patent application at $t$. The solid line considers the bottom $90 \%$ most cited patent and the dashed line the top $10 \%$ most cited. 
Figure D4: Response to the Demand shock of patents of different quality

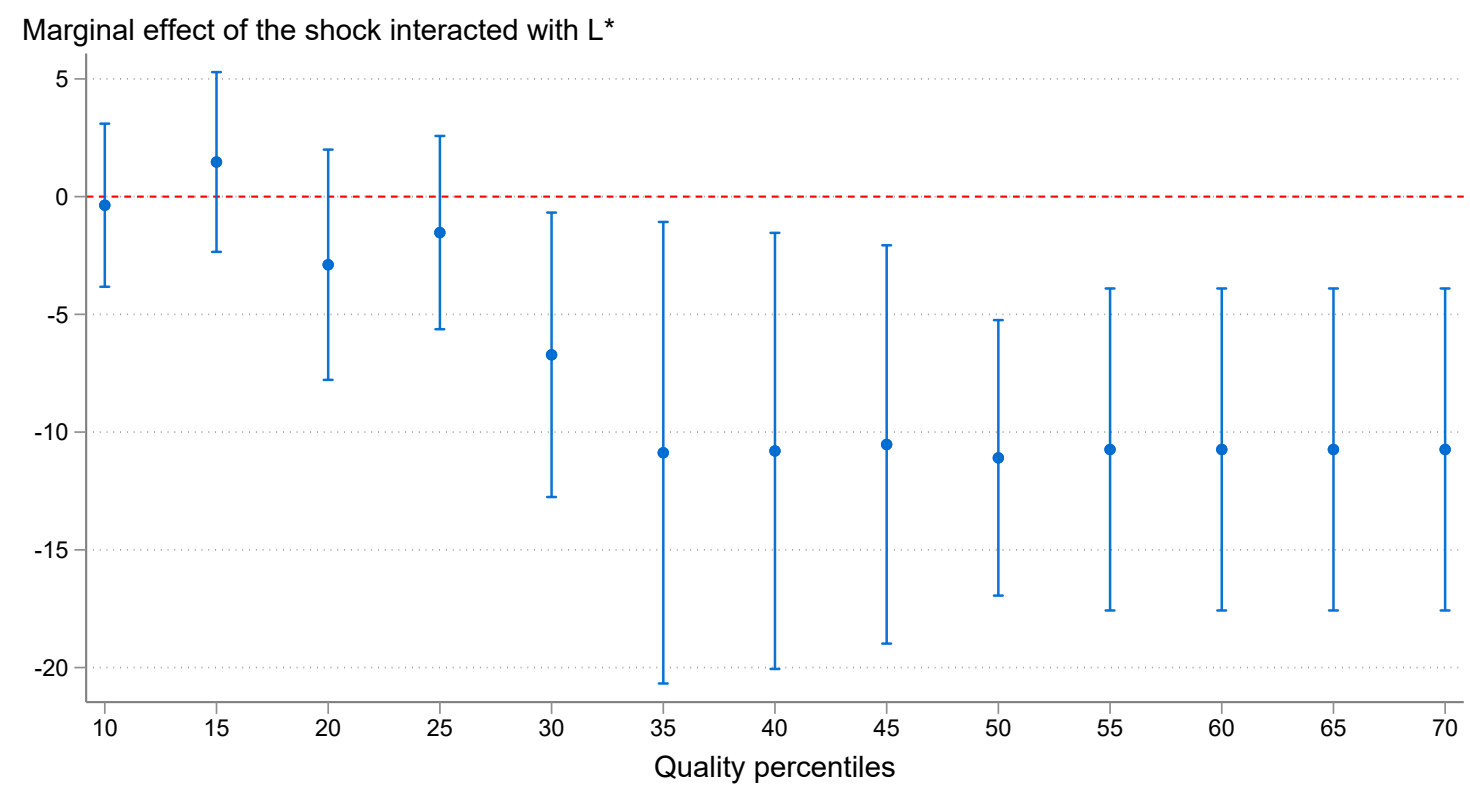

Notes: $95 \%$ confidence intervals around the estimated coefficient $\delta$ in equation (7). Each line corresponds to a separate estimation, where the dependent variable has been redefined by restricting to patents among the $\mathrm{x} \%$ more cited in the year, with $x$ equal to 10 , 15 etc... up to 70 . Note that the $65^{t h}$ percentile threshold correspond to 0 -citation patent and we include all patents for quality percentiles above 65 . The estimated model is the same as in column 5 of Table 2. 


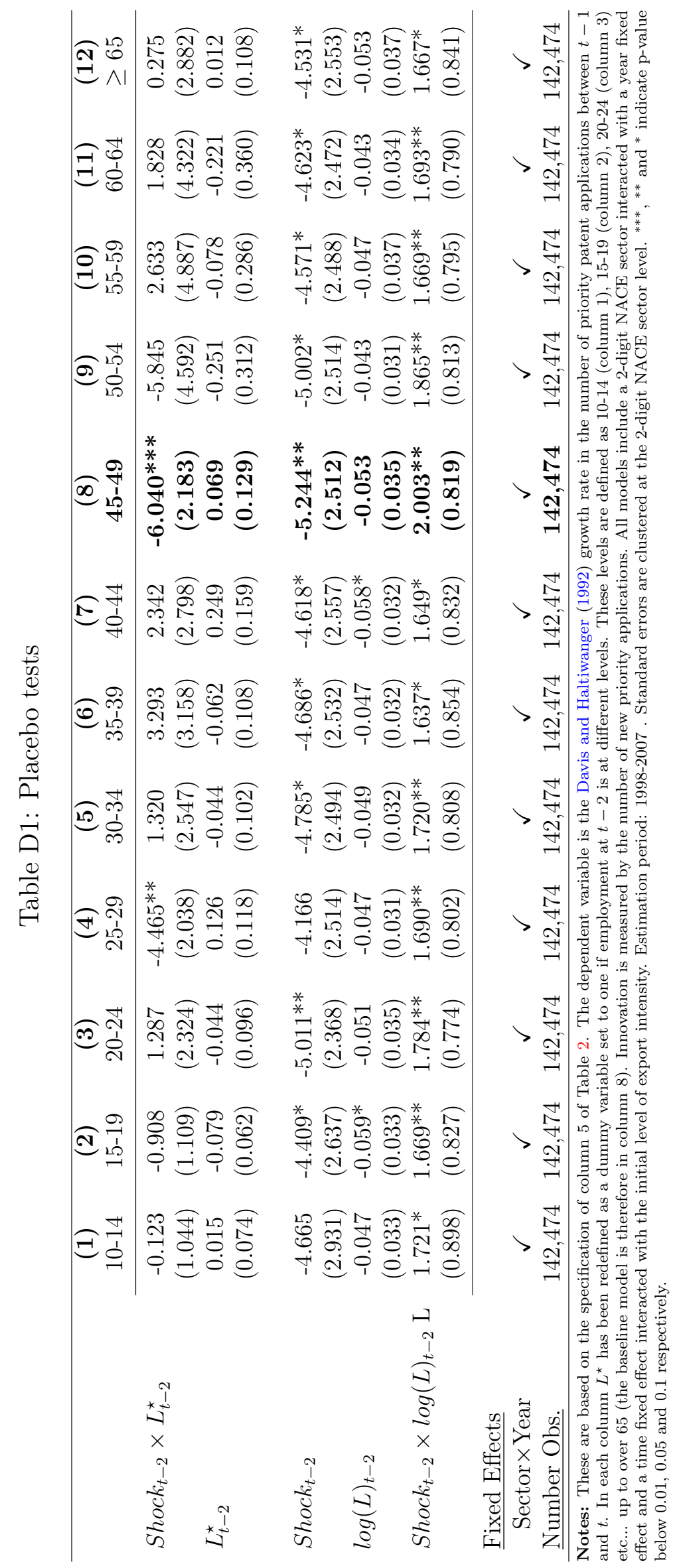

OA-32 


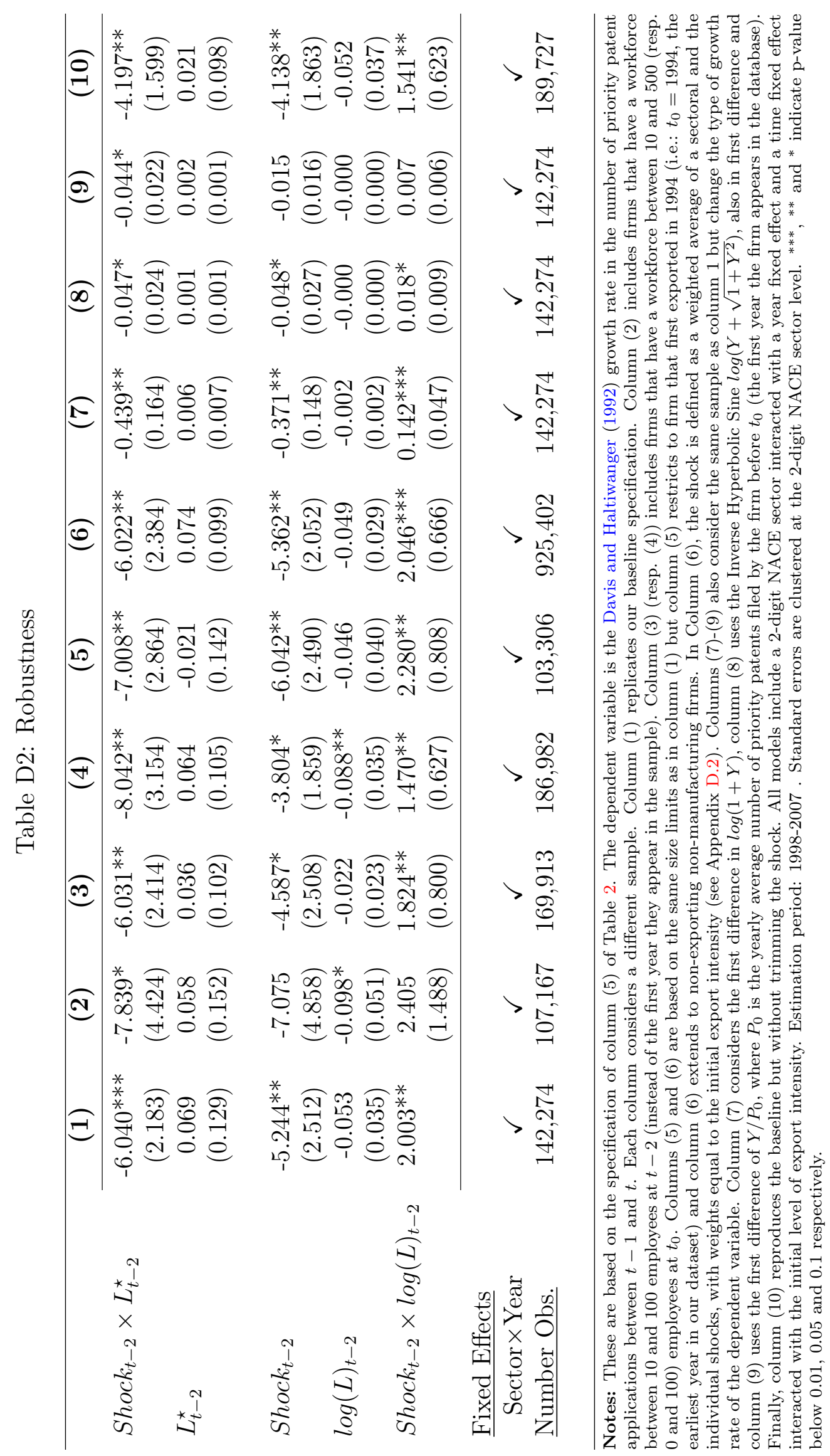

OA-33 


\section{D.4 Details (and robustness) of the estimates of the regulatory tax parameter and implications}

In this section we give more details regarding the calculation of the aggregate innovation losses and test robustness to our main exercise in Section 4.

\section{D.4.1 Static estimation of $\tau$}

Our theoretical model predicts a relationship between $Z$ and employment $l=n /(\gamma \omega)$. Specifically, equation (4) shows that:

$$
Z \propto l \text { if } l<(\bar{n}-1) /(\gamma \omega) \text { and } Z \propto l(1-\tau)^{\frac{1}{\eta-1}} \text { if } l \geq \bar{n} /(\gamma \omega)
$$

To map this into our data, we need to make an assumption on how $Z$ relates to the number of patents filed by a firm. Our baseline estimates assume that $Z \propto \log P$, where $P$ is the (smoothed) number of patent applications filed by the firm. We can therefore directly estimate $\tau$ from the innovation-size slopes for large firms vs. small firms.

In this subsection, we present some robustness tests around the baseline estimates. We report these in Table D3. Column (1) reports the baseline value and corresponding total innovation and welfare loss compared to an economy with $\tau=0 .{ }^{46}$ Column (2) does the same as column (1) but includes firms with up to 250 employees (instead of 150 in the baseline). It is

\footnotetext{
${ }^{46}$ To compute these loss, we have kept all other parameters the same. The only other parameters directly affected by changed in the slope estimates is $\beta / \zeta$. However, we know that this parameter plays little aggregate role.
} 
clear that restricting the upper threshold to 100 employees does not exaggerate the impact of the regulation (if anything, it underestimates it). Column (3) does the same as column (1) but includes an intercept, assuming that $Z=a \log P+b$ for some parameters $a$ and $b$. Columns (4) and (5) respectively assume that $Z$ is proportional to the number of patents or to the share of firms with at least one patent at this level of employment. Finally, columns (6) and (7) assume that the relationship between $Z$ and $P$ also depends on the sector and year. We thus perform an estimation without binning the data and include an additive sector and year fixed effect (column (6)), and a multiplicative sector-year fixed effect (column (7)).

Although the exact magnitude of the implicit tax varies across the table, it is always nontrivial and our baseline estimate is just below the midpoint of the range of estimates of $\tau$.

Table D3: Alternative estimation of $\tau$

\begin{tabular}{|c|c|c|c|c|c|c|c|}
\hline \multirow[b]{2}{*}{ Observations } & (1) & $(2)$ & (3) & (4) & $(5)$ & (6) & (7) \\
\hline & \multicolumn{5}{|c|}{ Employment binned } & \multicolumn{2}{|c|}{ Firm level } \\
\hline$\tau$ & $2.6 \%$ & $3.7 \%$ & $1.3 \%$ & $1.2 \%$ & $5.0 \%$ & $3.8 \%$ & $4.0 \%$ \\
\hline Total Innovation loss (\%) & 5.79 & 8.30 & 2.79 & 2.57 & 10.94 & 8.49 & 8.87 \\
\hline Welfare loss (\% of $\mathrm{C}$ equivalent) & 2.27 & 3.25 & 1.15 & 1.06 & 4.45 & 3.46 & 3.62 \\
\hline \multicolumn{8}{|c|}{ 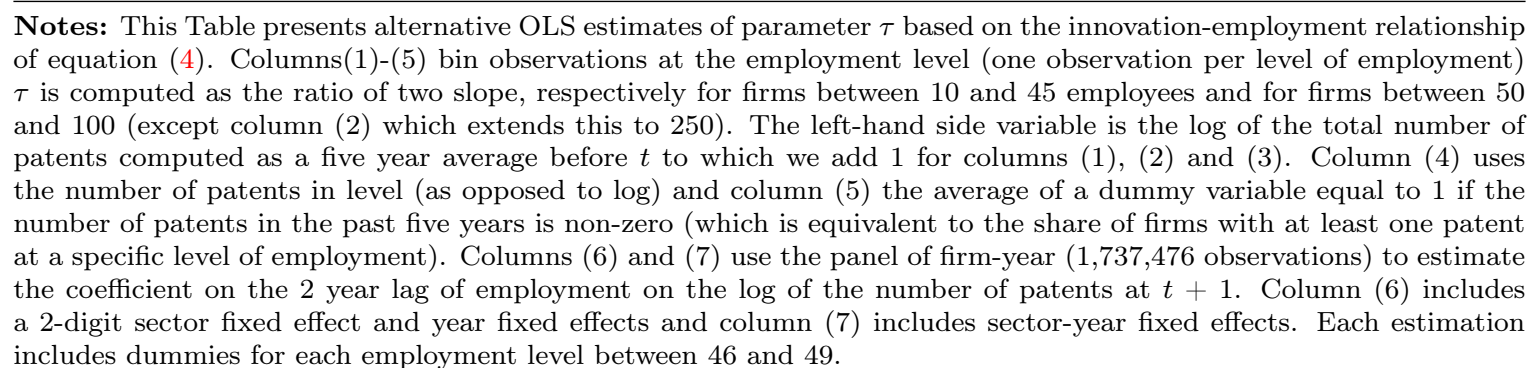 } \\
\hline
\end{tabular}

\section{D.4.2 Dynamic estimation of $\tau$}

We also estimate $\tau$ using a dynamic specification as presented in Section 4.2.3. The idea of the dynamic estimations is to use the response of total innovation $Z$ for a firm of size $n$ which receives a demand shock $\varepsilon$ (see Section 2.5):

$$
Z(n, \varepsilon)=\left(\frac{\beta \tilde{\pi}(n)}{\zeta \eta}\right)^{\frac{1}{\eta-1}} \omega \gamma l(n)(1+\varepsilon)^{\frac{1}{\eta-1}}
$$

where $l(n)=n /(\omega \gamma)$ is the level of employment absent a shock and $\tilde{\pi}(n)$ is equal to: 
Table D4: Sensitivity analysis for welfare

Robustness

Loss in total welfare

Baseline (full sample)

$2.27 \%$

1. $\gamma=1.2$

$0.82 \%$

2. $\gamma=1.50$

$7.31 \%$

3. $\eta=2$

$3.44 \%$

4. $\eta=1.3$

$1.00 \%$

5. $\omega=0.19$

$2.25 \%$

6. $\omega=0.25$

$2.29 \%$

7. $\beta / \zeta=1.40$

$1.49 \%$

8. $\beta / \zeta=1.90$

$2.73 \%$

9. $\beta=0.94$

$1.41 \%$

10. $\beta=0.98$

$4.85 \%$

11. $\tau$

Percentile $75^{\text {th }}(\tau=0.046)$

$4.11 \%$

Percentile $25^{\text {th }}(\tau=0.006)$

$0.50 \%$

Exporting manufacturing firms

12. Static estimation $(\tau=0.062)$

13. Using dynamic model $(\tau=0.060)$

Notes: baseline uses parameter values: $(\eta=1.5, \gamma=1.3, \tau=0.026, \beta / \zeta=1.66$ and $\omega=0.22$ ), see Table 3. In the robustness where $\gamma, \eta, \omega$ or $\beta / \zeta$ are changed, we keep $\tau$ as in the baseline. Results in line 11 report the $25^{t h}$ and $75^{t h}$ percentile for the loss of innovation in a sample computed from 100,000 independent draws of $\tau$ from two normal distribution. The corresponding value of $\tau$ and $\beta / \zeta$ are computed as an average for each percentile. Results in rows 12-13 show the result when restricting to exporting manufacturing firms and the corresponding estimation of $\tau$, either using the static baseline approach or the dynamic model described in Section 4.2.3. Loss in welfare is given in consumption equivalent and does not include initial quality (see section 4.3).

$$
\begin{array}{lr}
\pi & \text { if } n<\bar{n}-1 \\
\pi(1-\bar{n} \tau) & \text { if } n=\bar{n}-1 \\
\pi(1-\tau) & \text { if } n \geq \bar{n} .
\end{array}
$$

Hence, a shock of magnitude $\varepsilon$ implies a change in $Z$ such that:

$$
\Delta Z(n, \varepsilon) \equiv Z(n, \varepsilon)-Z(n, 0)=\left(\frac{\beta \tilde{\pi}(n)}{\zeta \eta}\right)^{\frac{1}{\eta-1}} \omega \gamma l(n)\left[(1+\varepsilon)^{\frac{1}{\eta-1}}-1\right],
$$

which yields:

$$
\frac{\partial^{2} \Delta Z}{\partial \varepsilon \partial l}=\left(\frac{\beta \tilde{\pi}(n)}{\zeta \eta}\right)^{\frac{1}{\eta-1}} \frac{\omega \gamma}{\eta-1}(1+\varepsilon)^{\frac{2-\eta}{\eta-1}}
$$


We will now use our empirical exercise to estimate this relationship.

Comparing large and small firms Our main exercise is to consider equation (12) which can be linked to the value of $\frac{\partial^{2} \Delta Z}{\partial \varepsilon \partial l}$ as explained in Section 4.2.3. Coefficients $c_{5}$ and $c_{4}$ are estimated by OLS using the exact same sample of firms as the one in column (5) of Table 2 (i.e. manufacturing exporting firms). The dependent variable, as in the baseline estimations, is the growth rate of the number of patents filed during the year, using the modified $\tilde{\Delta}$ operator (see Section 3.3). Observations with employment between 45 and 49 are removed from the sample (as we did with the static model as behavioral responses are different for these firms). The sample has 131,633 observations. Finally, the model includes sector by year fixed effects.

Once the estimated coefficients $\hat{c_{5}}$ and $\hat{c_{4}}$ are retrieved, we estimate equation (12) by taking the unweighted average of the shock $\epsilon$ and a value of $\eta$ set to 1.5. As our baseline, we chose to match $\epsilon$ to $\Delta S$. As an alternative, we have estimated the link between $\epsilon$ and $\Delta S$ by looking at the response of employment to a demand shock. In practice this does not impact the value of $\tau$. which is estimated to be about $6.0 \%$ if we exclude firms in the innovation valley (between 45 and 49 employees at t-2). Note that nothing substantial changes if we perform the exercises but include firms in the valley. In this case, the estimated value of $\tau$ is equal to $5.8 \%$.

Restricting the sample to a narrower size range In the previous analysis, we compared firms with an initial employment ranging between 10 and 100 employees, which is consistent with the approach taken in the rest of the paper. However, we can adopt a coarser selection criterion by examining firms with an employment level between 10 and 100 at $t-2$, and then further reducing the sample by comparing firms that fall within a narrower range of $x$ to $95-x$ employees at $t-2$ to estimate equation (12), where we vary $x$ over the range from 10 to 40 . In other words we consider size band windows from as wide as 10-85 employees to as narrow as 40-55 employees.

As we move $x$ from 10 to 40, we include fewer and fewer firms that are closer to the threshold from both sides (e.g. the 40-55 window compares firms of size 40 to 45 with those of size 50 to 55 employees). This procedure restrict the sample and decreases the precision of the estimates, but at the same time allows to compare firms that are more closely related. The resulting values of $\tau$ are presented in Figure D5. The values of $\tau$ are essentially estimated between $5 \%$ and $6 \%$ which is in line with what we found in our baseline dynamic estimation. As we increase $x$ above 30 , the sample becomes very small (i.e. 40 to 65 employees) which accounts for the greater volatility of the estimates. 
Figure D5: Estimating $\tau$ from dynamic responses: Robustness to narrowing the size window

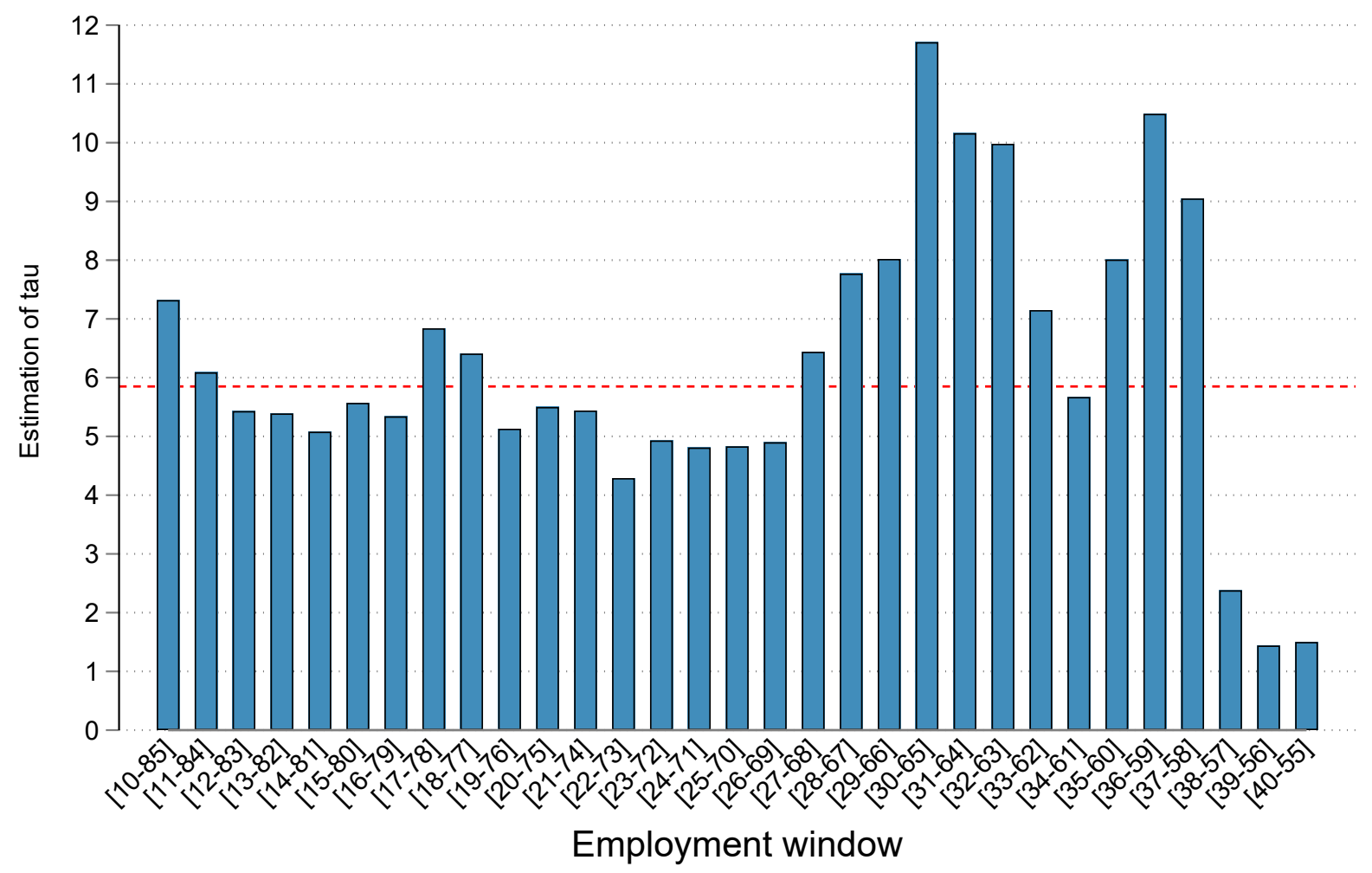

Notes: Estimation of $\tau$ from the dynamic evaluation presented in Section 4.2.3 and restricting to firms in the employment bracket displayed in the x-axis. Employment taken at at $t-2$ (see equation (12)). The horizontal line corresponds to the baseline $6 \%$. 
Using firms in the innovation valley As a third exercise, we propose an alternative dynamic estimation of $\tau$ which also uses the response of firms in the innovation valley to a demand shock, again using our estimates of $\frac{\partial^{2} \Delta Z}{\partial \varepsilon \partial l}$. Consider the following model:

$$
\begin{aligned}
\Delta Z(n, \varepsilon)_{i, t}= & c_{1} l_{i, t-2}+c_{2}\left[\mathbb{1}\left(l_{i, t-2}<V(\bar{l})\right) * l_{i, t-2}\right]+c_{3} \mathbb{1}\left(l_{i, t-2} \in V(\bar{l})\right) \\
& +c_{4}\left[\mathbb{1}\left(l_{i, t-2}<V(\bar{l})\right) * l_{i, t-2} * \Delta S_{i, t-2}\right]+c_{5}\left[\mathbb{1}\left(l_{i, t-2} \in V(\bar{l})\right) * l_{i, t-2} * \Delta S_{i, t-2}\right] \\
& +c_{6} \Delta S_{i, t-2}+\epsilon_{i, t} .
\end{aligned}
$$

where $V(\bar{l})$ denotes the innovation valley (firms between 45 and 49 employees) and $l_{i, t-2}<$ $V(\bar{l})$ indicates that employment is lower than 45. If we estimate this model for firms below 50 employees only, then the ratio of $c_{5}$ over $c_{4}$ is equal to:

$$
\frac{c_{5}}{c_{4}}=\frac{\mathbb{E}\left[(1+\varepsilon)^{\frac{2-\eta}{\eta-1}} \mid l \in V(\bar{l})\right](1-\tau \bar{n})^{\frac{1}{\eta-1}}}{\mathbb{E}\left[(1+\varepsilon)^{\frac{2-\eta}{\eta-1}} \mid l<V(\bar{l})\right]}
$$

Hence, with a value of $\bar{n}$ we can estimate $\tau$ from these equations using the same strategy as in Section 4.2.3. We use a value of $\bar{n}$ of 14 which corresponds to the baseline calibrations.

Implementing this method leads us to an estimate of $\tau$ equal to $5.7 \%$, very similar to our baseline dynamic approach. 


\section{D.5 Measuring different types of innovation}

Our baseline approach simply uses patent counts. In the extensions of C.2, we take several approaches to examining the different types of innovation. In order to measure how "radical" a patent is, we use two alternative methods: citations and text-based measures of novelty. Then we also consider measures of how "labor saving" the patent is by looking at measures of automation and process innovation.

Citations. The first method uses the now classical approach of considering future citations. For every patent in a technology class by year of application cell, we calculate all the citations to that patent by all granted patents that were filed in 2016 or earlier. Since the last year we use in our analysis sample is 2007, this gives us a minimum of 10 future years of citation information. We then calculate which quantile of the citations distribution a given patent lies in. A patent which was in the top decile of citations, for example, would be counted as radical for the purposes of column (1) of Table 5.

We validated the use of this measure by presenting employment growth regressions. We regressed the change in the firm's $\log$ (employment) on a distributed lag of patent counts with sector by time dummies. Table D 5 shows a representative example where we use patents from $t-1$ to $t-3$. To deal with zeros we add one to the patents before taking logs. Column (1) counts only "radical" patents in the top $10 \%$ of the technology-class-year cohort citation distribution and column (2) has incremental patents in the bottom $90 \%$. The coefficients of all patents are positive and individually and jointly significant, indicating that patenting is associated with faster firm growth as we would expect. And consistent with our priors, the coefficients on the radical patents are much larger than incremental patents. Summing the coefficients to show the long-run effects in the base of the column we see that the radical patents have about 2.5 $(=0.1402 / 0.0565)$ times the impact on employment growth compared to incremental patents. The base of the columns shows that in the long-run a doubling of incremental patents increases employment growth by $5.7 \%$ compared to $15 \%$ for radical patents.

More ambitiously, we can use these estimates to perform a back of the envelope calculation to see how much lower the loss of growth would be if we took into account that the regulation only affects incremental innovation. For example, using the approach of Table D5 radical innovations (the top $10 \%$ of the citations distribution) have 2.5 times the effect of incremental patents, so an innovation index should give a weight of $5 / 7$ to radical innovation and $2 / 7$ to incremental innovation (instead of implicitly equal weights using the patent count). If the overall fall in patenting is $5.8 \%$ as estimated in Table 4 and this comes entirely from incremental innovation, we need to scale down the growth effect by $18 / 23$ reflecting the lower impact of incremental 
Table D5: Regression results for different levels of the novelty of innovation

\begin{tabular}{lcc}
\hline & Top 10\% & Bottom 90\% \\
\cline { 2 - 3 } $\log \left(P_{f, t-1}\right)$ & $0.0598^{* * *}$ & $0.0187^{* * *}$ \\
& $(0.01524)$ & $(0.00536)$ \\
$\log \left(P_{f, t-2}\right)$ & $0.0466^{* * *}$ & $0.0223^{* * *}$ \\
$\log \left(P_{f, t-3}\right)$ & $(0.01472)$ & $(0.00556)$ \\
& $0.0338^{*}$ & $0.0154^{*}$ \\
Sum of coefficients & $(0.01742)$ & $(0.00762)$ \\
\cline { 2 - 3 } & $0.1402^{* * *}$ & $0.0565^{* * *}$ \\
Obs & $(0.0210)$ & $(0.0110)$ \\
\cline { 2 - 3 }$R^{2}$ & 196,284 & 196,284 \\
\hline
\end{tabular}

Notes: The dependent variable is the change in the firm's $\log ($ employment $)$. The left hand side is $\ln (1+$ patent count $)$ between $t-1$ and $t-3$. Column (1) restricting to the top $10 \%$ most highly cited patents in a technology-class year and column (2) has the other $90 \%$. Both models include a 2-digit NACE sector interacted with year fixed effects. Standard errors are clustered at the firm level. ${ }^{* * *},{ }^{* *}$ and ${ }^{*}$ indicate p-value below $0.01,0.05$ and 0.1 respectively.

innovation. This would imply a fall of $4.5 \%$ in growth (compared to the unregulated economy) compared to $5.8 \%$ in our baseline estimates. So the extension to different types of innovation does reduce the magnitude of the loss, but not by an enormous amount. Different assumptions will obviously change these exact magnitudes, but are unlikely (in our view) to overturn our main findings.

Google Patent Embedding. Our second, alternative measure of radical innovation involves a text-based analysis of novelty which is more involved and draws on some recent work by Google. In 2019, Google Patent released an embedding representation of each publication available in their public dataset (hereafter, "GP embedding"). As detailed in Srebrovic (2019), embeddings are a set of techniques in natural language processing that map a text to a vector of real numbers. By leveraging methods such as neural networks, this mapping allow to significantly reduce the dimensionality of a text input.

The GP embedding is a vector of 64 dimensions that have been constructed in order to predict a patent's CPC (Cooperative Patent Code) from its text (including all metadata, abstract and body of the patent description). Each element of the vector is a continuous variable ranging between -1 and +1 . It therefore summarize the text content of a vector in a simple algebraic representation which has the advantage of allowing to calculate the distance between two patents by taking the dot product between the two corresponding embeddings.

Formally, for each patent $p$, we let $\mathcal{E}(\mathbf{p})$ denote its embedding representation. We then 
define the distance between a patent $p$ and a patent $q$ as:

$$
d(p, q)=\mathcal{E}(\mathbf{p}) \cdot \mathcal{E}(\mathbf{q})
$$

Measure of novelty using text. Using this distance measure, we can construct a novelty measure to capture radical innovation. The concept of novelty of a patent captures the extent to which a patent is significantly different from previous innovations in the same field. Typical measures of novelty look at the diversity of technological classes in the set of citing patents, or in the set of cited patents. These measures, sometimes called "originality" are limited by the fact that the average patent does not receive many citations.

Recently, the innovation literature has devoted much attention to using the text content of patent documents to refine some existing measures. For example, Kelly et al. (2018) shows how using the description of the innovation included in a patent publication can be used to build measures of similarity and novelty.

Here, we adapt their methodology. More precisely, we define novelty for each patent as the distance between its embedding and a reference point. This reference point is computed by calculating the unweighted average of all USPTO patents filed in the past 5 years and within the same technological class (we use 3-digit CPC classification, that is around 130 different categories). Formally, we define novelty $N O V(p)$ for each patent $p$ as:

$$
N O V(p)=\mathcal{E}(\mathbf{p}) \frac{1}{N(k, t)} \sum_{q \in \mathcal{P}(k, t)} \mathcal{E}(\mathbf{q})=\frac{1}{N(k, t)} \sum_{q \in \mathcal{P}(k, t)} d(p, q)
$$

where $k$ is the technological class of patent $p,{ }^{47} \mathcal{P}(k, t)$ is the set of USPTO patent filed between $t-5$ and $t-1$ and belonging to technological class $k$ and $N(p, t)$ is its cardinal.

The static cross-section relationship between size and innovation when restricting attention to very novel patents (top 10\%) and other patents respectively are shown in Figure 6(a). This graph is analogous to Figure 8. Likewise, results from regressions similar to that performed in Table 5 but using thresholds based on the value of novelty, are shown in Table D6.

Automation. Patents that protect automation technologies have been the subject of a large body of work recently (see e.g. Dechezlepretre et al., 2020; Webb, 2019; Mann and Püttmann, 2018 for reviews). These papers typically use at the description (or abstract) of the patents to

\footnotetext{
$\overline{47}$ In the case where a patent has more than one CPC code, we consider patents from all the CPC codes in which case $k$ represents the set of technological classes. In other words, we use a weighted average.
} 
identify the occurrence of words that are usually associated with labor-saving technologies.

To build our automation measure, we use the work of Mann and Püttmann (2018) who look at the wording of USPTO patents and build a classifier to distinguish between automation and non-automation technologies. To apply their work to our set of patents, we once again leverage the GP embedding. Specifically, we regress the binary variable from Mann and Püttmann (2018) (1 if patent is classified as automation and 0 otherwise) on each of the 64 coordinates of the patent's embedding. We then use the estimated coefficients to predict the probability of being an automation patent for every patent owned by a French firm. Formally, we define our score of automation $A(p)$ for each patent $p$ as:

$$
A(p)=\sum_{i=1}^{64} \hat{\beta}_{i} \mathcal{E}(p)_{i}
$$

where $\hat{\beta}_{i}$ is the estimated coefficients from a model restricted to USPTO patents:

$$
Y_{q}=\sum_{i=1}^{64} \beta_{i} \mathcal{E}(q)_{i}+\nu_{t}+\varepsilon_{q}
$$

for a patent $q$ published during year $t$. In this model, $Y_{q}$ is equal to 1 if the patent has been classified as an automation patent and $\varepsilon$ is an error term.

The underlying idea is that a linear combination of the embedding coordinates capture the feature included in the text that predict that a patent protects a labor-saving technology.

We show the cross-section relationship between size and innovation result in Figure 6(b) and the dynamic regression in Table D7.

As an alternative to the automation measure, we also used a measure of the extent to which a patent protects a process innovation (as opposed to a product innovation) using the classification of Arora et al. (2020). This uses the percentages of product or process related words in either the claims or the description of the patent publication document. It is likely the process innovations are more labor saving than product innovations, so the impact of regulation such fall more heavily on the product innovations. As with Mann and Püttmann (2018), this measure is only computed on USPTO patents, we leverage GP again, using the same methodology as the one described above to predict a corresponding value for our set of patents owned by French firms. We obtain broadly similar results. For example, splitting patents at the median level of "process", there are only signficant negative effects of the threshold on below median levels of process innovation, i.e. for product innovation. 
Table D6: Regression results for different levels of the novelty of innovation

\begin{tabular}{|c|c|c|c|c|c|c|}
\hline Novelty & $\begin{array}{l}\text { Top } 10 \% \\
\text { (1) }\end{array}$ & $\begin{array}{l}\text { Top } 15 \% \\
\text { (2) }\end{array}$ & $\begin{array}{c}\text { Top 25\% } \\
\text { (3) }\end{array}$ & $\begin{array}{c}\text { Bottom } 75 \% \\
\text { (4) }\end{array}$ & $\begin{array}{c}\text { Bottom } 85 \% \\
\text { (5) }\end{array}$ & $\begin{array}{c}\text { Bottom } 90 \% \\
(\mathbf{6})\end{array}$ \\
\hline Shock $_{t-2} \times L_{t-2}^{\star}$ & $\begin{array}{l}-1.140 \\
(0.818)\end{array}$ & $\begin{array}{l}-1.273 \\
(1.053)\end{array}$ & $\begin{array}{l}-1.676^{*} \\
(0.907)\end{array}$ & $\begin{array}{c}-5.117^{* *} \\
(2.113)\end{array}$ & $\begin{array}{c}-5.570^{* * *} \\
(1.832)\end{array}$ & $\begin{array}{c}-5.621^{* *} \\
(2.018)\end{array}$ \\
\hline$L_{t-2}^{\star}$ & $\begin{array}{l}0.061^{*} \\
(0.031)\end{array}$ & $\begin{array}{c}0.071 \\
(0.055)\end{array}$ & $\begin{array}{c}0.094 \\
(0.103)\end{array}$ & $\begin{array}{c}0.055 \\
(0.113)\end{array}$ & $\begin{array}{c}0.036 \\
(0.096)\end{array}$ & $\begin{array}{c}0.053 \\
(0.100)\end{array}$ \\
\hline Shock $_{t-2}$ & $\begin{array}{l}-2.850 \\
(1.724)\end{array}$ & $\begin{array}{l}-3.957^{*} \\
(1.975)\end{array}$ & $\begin{array}{c}-4.489^{* *} \\
(1.823)\end{array}$ & $\begin{array}{l}-2.125 \\
(2.038)\end{array}$ & $\begin{array}{l}-2.317 \\
(2.180)\end{array}$ & $\begin{array}{l}-3.496 \\
(2.279)\end{array}$ \\
\hline $\log (L)_{t-2}$ & $\begin{array}{l}0.000 \\
(0.015)\end{array}$ & $\begin{array}{c}0.001 \\
(0.020)\end{array}$ & $\begin{array}{l}-0.027 \\
(0.026)\end{array}$ & $\begin{array}{l}-0.027 \\
(0.032)\end{array}$ & $\begin{array}{l}-0.051 \\
(0.034)\end{array}$ & $\begin{array}{l}-0.053 \\
(0.034)\end{array}$ \\
\hline $\operatorname{Shock}_{t-2} \times \log (L)_{t-2}$ & $\begin{array}{l}0.991^{*} \\
(0.553)\end{array}$ & $\begin{array}{l}1.401^{* *} \\
(0.655)\end{array}$ & $\begin{array}{l}1.560^{* *} \\
(0.598)\end{array}$ & $\begin{array}{c}0.948 \\
(0.676)\end{array}$ & $\begin{array}{l}1.015 \\
(0.719)\end{array}$ & $\begin{array}{l}1.381^{*} \\
(0.745)\end{array}$ \\
\hline $\begin{array}{l}\frac{\text { Fixed Effects }}{\text { Sector } \times \text { Year }} \\
\text { Number Obs. }\end{array}$ & $\begin{array}{c}\checkmark \\
142,474\end{array}$ & $\begin{array}{c}\checkmark \\
142,474\end{array}$ & $\begin{array}{c}\checkmark \\
142,474\end{array}$ & $\begin{array}{c}\checkmark \\
142,474\end{array}$ & $\begin{array}{c}\checkmark \\
142,474\end{array}$ & $\begin{array}{c}\checkmark \\
142,474\end{array}$ \\
\hline
\end{tabular}

Table D7: Regression results for different levels of the automation

\begin{tabular}{|c|c|c|c|c|c|c|}
\hline Auomation & $\begin{array}{l}\text { Top } 10 \% \\
\text { (1) }\end{array}$ & $\begin{array}{l}\text { Top } 15 \% \\
\text { (2) }\end{array}$ & $\begin{array}{l}\text { Top } 25 \% \\
\text { (3) }\end{array}$ & $\begin{array}{c}\text { Bottom } 75 \% \\
\text { (4) }\end{array}$ & $\begin{array}{c}\text { Bottom } 85 \% \\
\text { (5) }\end{array}$ & $\begin{array}{c}\text { Bottom } 90 \% \\
(\mathbf{6})\end{array}$ \\
\hline$S h o c k_{t-2} \times L_{t-2}^{\star}$ & $\begin{array}{c}0.043 \\
(0.394)\end{array}$ & $\begin{array}{l}-0.349 \\
(0.416)\end{array}$ & $\begin{array}{l}1.004 \\
(0.737)\end{array}$ & $\begin{array}{c}-5.974^{* *} \\
(2.815)\end{array}$ & $\begin{array}{c}-5.587^{* *} \\
(2.639)\end{array}$ & $\begin{array}{c}-6.024^{* *} \\
(2.440)\end{array}$ \\
\hline$L_{t-2}^{\star}$ & $\begin{array}{c}0.045 \\
(0.032)\end{array}$ & $\begin{array}{c}0.013 \\
(0.039)\end{array}$ & $\begin{array}{l}-0.005 \\
(0.062)\end{array}$ & $\begin{array}{c}0.045 \\
(0.115)\end{array}$ & $\begin{array}{c}0.051 \\
(0.110)\end{array}$ & $\begin{array}{c}0.046 \\
(0.109)\end{array}$ \\
\hline$S h o c k_{t-2}$ & $\begin{array}{l}-0.008 \\
(0.701)\end{array}$ & $\begin{array}{c}-1.333^{* *} \\
(0.637)\end{array}$ & $\begin{array}{l}-0.005 \\
(1.373)\end{array}$ & $\begin{array}{l}-4.517^{*} \\
(2.224)\end{array}$ & $\begin{array}{l}-4.432^{*} \\
(2.163)\end{array}$ & $\begin{array}{c}-5.258^{* *} \\
(2.071)\end{array}$ \\
\hline $\log (L)_{t-2}$ & $\begin{array}{c}0.005 \\
(0.004)\end{array}$ & $\begin{array}{l}0.013^{*} \\
(0.007)\end{array}$ & $\begin{array}{c}0.013 \\
(0.011)\end{array}$ & $\begin{array}{l}-0.059 \\
(0.039)\end{array}$ & $\begin{array}{l}-0.058 \\
(0.040)\end{array}$ & $\begin{array}{l}-0.056 \\
(0.040)\end{array}$ \\
\hline Shock $_{t-2} \times \log (L)_{t-2}$ & $\begin{array}{l}-0.053 \\
(0.239)\end{array}$ & $\begin{array}{l}0.413^{*} \\
(0.200)\end{array}$ & $\begin{array}{c}0.082 \\
(0.453)\end{array}$ & $\begin{array}{l}1.696^{* *} \\
(0.749)\end{array}$ & $\begin{array}{l}1.748^{* *} \\
(0.732)\end{array}$ & $\begin{array}{c}2.052^{* * * *} \\
(0.677)\end{array}$ \\
\hline \multicolumn{7}{|l|}{ Fixed Effects } \\
\hline $\begin{array}{l}\text { Sector } \times \text { Year } \\
\text { Number Obs. }\end{array}$ & $\begin{array}{c}\checkmark \\
142,474\end{array}$ & $\begin{array}{c}\checkmark \\
142,474\end{array}$ & $\begin{array}{c}\checkmark \\
142,474\end{array}$ & $\begin{array}{c}\checkmark \\
142,474\end{array}$ & $\begin{array}{c}\checkmark \\
142,474\end{array}$ & $\begin{array}{c}\checkmark \\
142,474\end{array}$ \\
\hline
\end{tabular}


Figure D6: Innovative firms at each employment level - novelty and automation

(a) Novelty

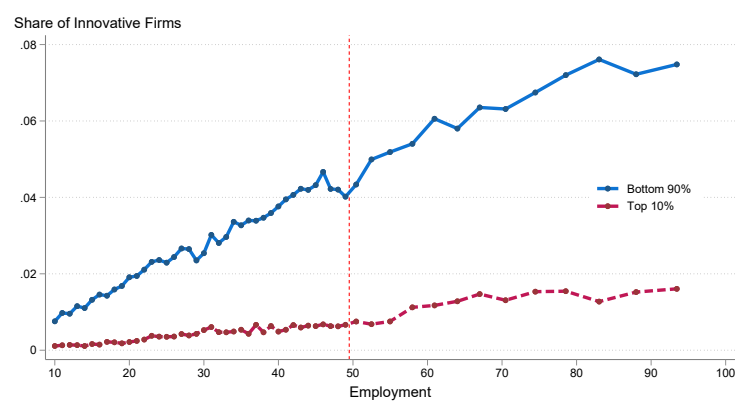

(b) Automation

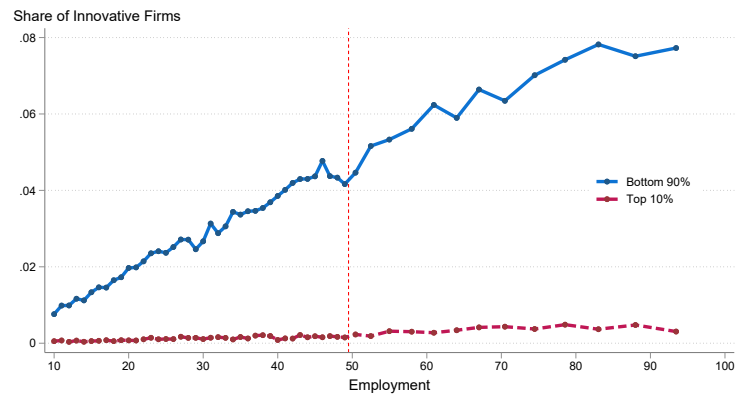

Notes: These Figures replicate Figure 8 but split patents between top $10 \%$ and bottom $90 \%$ according to their level of novelty (left panel) or their predicted level of automation (right panel). 
CENTRE FOR ECONOMIC PERFORMANCE

Recent Discussion Papers

\begin{tabular}{|c|c|c|}
\hline 1743 & $\begin{array}{l}\text { Christian A.L. Hilber } \\
\text { Andreas Mense }\end{array}$ & $\begin{array}{l}\text { Why have house prices risen so much more } \\
\text { than rents in superstar cities? }\end{array}$ \\
\hline 1742 & $\begin{array}{l}\text { Swati Dhingra } \\
\text { Rebecca Freeman } \\
\text { Hanwei Huang }\end{array}$ & $\begin{array}{l}\text { The impacts of non-tariff barriers on trade and } \\
\text { welfare }\end{array}$ \\
\hline 1741 & $\begin{array}{l}\text { Josh De Lyon } \\
\text { João Paulo Pessoa }\end{array}$ & $\begin{array}{l}\text { Worker and firm responses to trade shocks: } \\
\text { The UK-China case }\end{array}$ \\
\hline 1740 & $\begin{array}{l}\text { Carlo Altomonte } \\
\text { Domenico Favoino } \\
\text { Monica Morlacco } \\
\text { Tommaso Sonno }\end{array}$ & $\begin{array}{l}\text { Markups, intangible capital and } \\
\text { heterogeneous financial frictions }\end{array}$ \\
\hline 1739 & $\begin{array}{l}\text { Chad Bown } \\
\text { Paola Conconi } \\
\text { Aksel Erbahar } \\
\text { Lorenzo Trimarchi }\end{array}$ & Trade protection along supply chains \\
\hline 1738 & $\begin{array}{l}\text { Christian Krekel } \\
\text { Julia Rechlitz } \\
\text { Johannes Rode } \\
\text { Alexander Zerrahn }\end{array}$ & $\begin{array}{l}\text { Quantifying the externalities of renewable } \\
\text { energy plants using wellbeing data: The case } \\
\text { of biogas }\end{array}$ \\
\hline 1737 & $\begin{array}{l}\text { Nick Jacob } \\
\text { Giordano Mion }\end{array}$ & The UK's great demand and supply recession \\
\hline 1736 & $\begin{array}{l}\text { Gabriel M. Ahlfeldt } \\
\text { Fabian Bald } \\
\text { Duncan Roth } \\
\text { Tobias Seidel }\end{array}$ & Quality of life in a dynamic spatial model \\
\hline 1735 & Kilian Huber & $\begin{array}{l}\text { Are bigger banks better? Firm-level evidence } \\
\text { from Germany }\end{array}$ \\
\hline
\end{tabular}




\begin{tabular}{|c|c|c|}
\hline 1734 & $\begin{array}{l}\text { César Ducruet } \\
\text { Réka Juhász } \\
\text { Dávid Krisztián Nagy } \\
\text { Claudia Steinwender }\end{array}$ & All aboard: the effects of port development \\
\hline 1733 & $\begin{array}{l}\text { Jonathan Colmer } \\
\text { John Voorheis }\end{array}$ & $\begin{array}{l}\text { The grandkids aren't alright: the } \\
\text { intergenerational effects of prenatal pollution } \\
\text { exposure }\end{array}$ \\
\hline 1732 & $\begin{array}{l}\text { Kabir Dasgupta } \\
\text { André Diegmann } \\
\text { Tom Kirchmaier } \\
\text { Alexander Plum }\end{array}$ & $\begin{array}{l}\text { Heterogeneity in criminal behavior after child } \\
\text { birth: the role of ethnicity }\end{array}$ \\
\hline 1731 & $\begin{array}{l}\text { Andreas Diemer } \\
\text { Tanner Regan }\end{array}$ & $\begin{array}{l}\text { No inventor is an island: social connectedness } \\
\text { and the geography of knowledge flows in the } \\
\text { US }\end{array}$ \\
\hline 1730 & $\begin{array}{l}\text { Hanming Fang } \\
\text { Chunmian Ge } \\
\text { Hanwei Huang } \\
\text { Hongbin Li }\end{array}$ & $\begin{array}{l}\text { Pandemics, global supply chains, and local } \\
\text { labor demand: evidence from } 100 \text { million } \\
\text { posted jobs in China }\end{array}$ \\
\hline 1729 & $\begin{array}{l}\text { Ria Ivandić } \\
\text { Tom Kirchmaier } \\
\text { Ben Linton }\end{array}$ & $\begin{array}{l}\text { Changing patterns of domestic abuse during } \\
\text { COVID-19 lockdown }\end{array}$ \\
\hline 1728 & $\begin{array}{l}\text { Jonathan Colmer } \\
\text { Ralf Martin } \\
\text { Mirabelle Muûls } \\
\text { Ulrich J. Wagner }\end{array}$ & $\begin{array}{l}\text { Does pricing carbon mitigate climate change? } \\
\text { Firm-level evidence from the European Union } \\
\text { emissions trading scheme }\end{array}$ \\
\hline 1727 & $\begin{array}{l}\text { Tony Beatton } \\
\text { Michael P. Kidd } \\
\text { Matteo Sandi }\end{array}$ & School indiscipline and crime \\
\hline 1726 & $\begin{array}{l}\text { Maximilian v. Ehrlich } \\
\text { Henry G. Overman }\end{array}$ & $\begin{array}{l}\text { Place-based policies and spatial disparities } \\
\text { across European cities }\end{array}$ \\
\hline
\end{tabular}

The Centre for Economic Performance Publications Unit

Tel: +44 (0)2079557673 Email info@cep.lse.ac.uk

Website: http://cep.lse.ac.uk Twitter: @CEP_LSE 